\title{
II. Die Reaktion im Handeln des Mediziners
}

\section{Zur Person Karl Bonhoeffers}

„Bonhoeffer, seinem ganzen Wesen nach scharfsinnig und kritisch, dem Philosophischen gegenüber aber vorsichtig und bescheiden, blieb in den Grenzen der em-

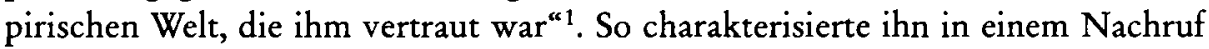
der Kollege und Studienfreund Robert Gaupp. Bonhoeffer rechnete sich auch selbst zu den dezidiert klinisch und naturwissenschaftlich orientierten Vertretern seines Fachs. Obwohl er es einmal positiv vermerkte, daß die Interessen vieler seiner psychiatrischen Kollegen „den sogenannten Geisteswissenschaften “ näher stünden als den "praktisch zufassenden klinischen Fächern " ${ }^{2}$, obwohl er sich privat für Philosophie ${ }^{3}$ und Soziologie interessierte - besonders angeregt durch seinen Studienfreund Max Weber, den „einzig genialen Menschen, der mir je begegnet ist ${ }^{\star 4}$, , fanden diese Interessen keinen unmittelbaren Niederschlag im eigenen Werk. Seine überaus zahlreichen Veröffentlichungen tragen fast ausschließlich den Charakter disparater fachwissenschaftlicher Aufsätze und Monographien zu Einzelproblemen, entstanden in der bewußten Bescheidung, nie mehr als kleine Inseln der Erkenntnis in einem Meer psychiatrischen Unwissens schaffen zu können.

Bekannt wurde Bonhoeffer durch die erstmalige Beschreibung der symptomatischen Psychosen ${ }^{5}$, also jener psychischen Störungen, die manchmal als Begleiterscheinung akuter Infektionen oder Vergiftungen auftreten und im allgemeinen als "exogene" Krankheiten nicht zu den "endogenen" Krankheiten oder Erbkrankheiten gezählt wurden. Freilich hielt Bonhoeffer den „Versuch einer scharfen Trennung exogener und endogener psychischer Typen " für problematisch", denn er vermutete, daß bei der Krankheitsentstehung mehrere Faktoren zusammenwirkten und hoffte, die „endogenen“ Erkrankungen von den „exogenen“ her erklären zu können. Solange dies nicht möglich sei, habe es „rein praktisch [...] sein Gutes, wenn wir in diesen Erkrankungen nicht lediglich das Verhängnis einer ererbten Anlage erblicken und uns dadurch zu einer dauernden thera-

\footnotetext{
1 Gaupp, Bonhoeffer, S. 1.

2 Bonhoeffer, Nervenärztliche Erfahrungen, S. $6 \mathrm{f}$.

$3 \mathrm{Vgl}$. Bonhoeffer, Widerstand, S. 93, Karl an Dietrich Bonhoeffer, 11.7. 1943.

4 Mdl. Auskunft Walter Bonhoeffer, 3.5. 1989.

5 Vgl. Bonhoeffer, Frage der Klassifikation; ders., Symptomatische Psychosen; ders., Frage der exogenen Psychosen; ders., Psychosen im Gefolge. Dazu bes. Neumärker, Bonhoeffer und Konzept; Dunn, Bonhoeffer; Propping, Genetic disorders; Hoff/Berner, Bedeutung.

$6 \mathrm{Vgl}$. Bonhoeffer, Frage der Klassifikation, S.2260.
} 
peutischen Resignation in äthiologischer Hinsicht verurteilt sehen würden ${ }^{7}$." Bonhoeffers Interesse für organisch verursachte Krankheitsbilder kommt auch in seiner Beschäftigung mit Alkoholpsychosen zum Ausdruck. Ein Schwerpunkt bei der Diagnose von Hirntumoren - vor der Entwicklung von geeigneten Röntgengeräten eine diagnostisch komplizierte Angelegenheit ${ }^{8}$ - und eine größere Anzahl neurologischer Themen verstärkten die Tendenz Bonhoeffers, in der Nachfolge seines Lehrers Carl Wernicke ${ }^{9}$ eher organisch nachweisbare Probleme zu behandeln, als über ungeklärte Erscheinungen zu spekulieren ${ }^{10}$. Damit vertrat er wissenschaftlich insgesamt einen "traditionellen Standpunkt" ${ }^{\text {"11. }}$.

Bonhoeffer steht in dem Ruf, die Psychoanalyse heftig bekämpft zu haben ${ }^{12}$. Tatsächlich verhielt er sich aber eher abwartend und gestand der Psychoanalyse im Gespräch durchaus eine gewisse Berechtigung zu. So berichtete Karl Abraham, dessen Habilitationspläne Bonhoeffer förderte, seinem Lehrer und Freund Freud nach Wien: „B. ist kein Freund der Psychoanalyse, aber auch kein prinzipieller Gegner, vor allem kein unfairer. Er gestand mir offen, seine Gegengründe seien gefühlsmäßig, ,durchaus unwissenschaftlich`! Er erkenne vieles an “13. Ähnlich äußerte sich Ludwig Binswanger: „Bonhoeffer steht der Analyse jedenfalls nicht feindlich gegenüber und anerkennt zum mindesten die Berechtigung und Notwendigkeit einer solchen Forschungsrichtung, was ja bei einem preußischen Ordinarius schon viel ist " ${ }^{\text {"14 }}$. Bonhoeffer selbst hat freilich nur den einen Satz veröffentlicht, wonach es „ein Verdienst der Freudschen Psychoanalyse gewesen [ist], daß auch außerhalb der orthodoxen Psychoanalyse in der Psychiatrie therapeutische Ansätze sich zu zeigen begannen “15. Damit ist keine begeisterte $\mathrm{Zu}$ -

${ }^{7}$ Ders., Psychosen im Gefolge, S. 127

${ }^{8}$ Das Ergebnis würdigte Sauerbruch in der Festschrift zu Bonhoeffers 70. Geburtstag; vgl. ders., Stand.

9 Vgl. Kleist, Wernicke; Bonhoeffer, Stellung Wernickes.

10 Vgl. hirnorganische Arbeiten weiterer Wernicke-Schüler, etwa Kleist, Kriegsverletzungen; Liepmann, Krankheitsbild der Apraxie.

11 So Horney nach Rubins, Karen Horney, S. 55. Horney promovierte 1913 bei Bonhoeffer - für eine Frau noch ungewöhnlich.

12 So vor allem Jones, Freud II, S.279, beruhend auf einer sehr unzureichenden Auswertung des Briefwechsels zwischen Freud und Abraham. Vgl. aber auch Gaupp, Bonhoeffer, S.1; Bethge, Bonhoeffer, S. 44 f.; Neumärker, Bonhoeffer, S. 76.

${ }^{13}$ Freud/Abraham, Briefwechsel, S.289, Abraham an Freud, 10.6. 1920. Zu den Habilitationsplänen vgl. ebenda, S. 129, Abraham an Freud, 1.12. 1912: "Ich wußte, daß B. eine durchaus konziliante Natur ist, sich auch von allen Ausfällen gegen uns ferngehalten hat. Er zeigte sich mir persönlich durchaus entgegenkommend, machte mich auf alle Hindernisse [gemeint war der „Antisemitismus der Fakultät “; 16.12. 1917, S.250] aufmerksam und obwohl er mir - in sehr ehrlicher Weise - keinerlei Versprechungen machte, so verhielt er sich doch auch nicht prinzipiell ablehnend."

${ }^{14}$ Freud/Binswanger, Briefwechsel, S. 90, Binswanger an Freud, 4.3. 1912. Vgl. auch UAT 443/3, Nachlaß Binswanger, Korrespondenz Bonhoeffer, Binswanger an Bonhoeffer, 14.5. 1912: „Ich habe mich sehr gefreut von Ihnen zu hören, dass Sie im Prinzip der analytischen Vertiefung unserer Wissenschaft sympathisch gegenüberstehen und nicht in die allgemeine Verdammung einstimmen, wie ich das zu constatieren schon in Breslau Gelegenheit hatte."

15 Bonhoeffer, Nervenärztliche Erfahrungen, S.7. Grell, Bonhoeffer, S.211, schließt aus diesem Satz völlig unzutreffend: „Therapieansätzen begegnete er mit Mißtrauen. Dies galt besonders für die Psychoanalyse." 
stimmung angezeigt, wohl aber eine Würdigung der therapeutischen Erfolge, wie sie 1941 (drei Jahre nach Freuds Vertreibung aus „Großdeutschland“) sonst kaum zu hören war.

Bemerkenswerte Zurückhaltung übte Bonhoeffer gegenüber allen rigorosen therapeutischen Methoden. Während die Oberste Heeresleitung im Ersten Weltkrieg empfahl, „Kriegszitterer“ und „Psychopathen“ mit der sogenannten "Kauffmannschen Methode“ durch Stromstöße wieder frontfähig zu machen, trat Bonhoeffer dafür ein, sie großzügig krank zu schreiben und nicht erneut an die Front zu schicken ${ }^{16}$ - bis die Kriegszensur weitere diesbezügliche Veröffentlichungen verbot ${ }^{17}$. Die 1917 entwickelte Malariatherapie bei progressiver Paralyse (Syphilis im Spätstadium wurde bekämpft durch Infektion des Patienten mit Malaria) führte Bonhoeffer erst 1924 ein, hielt sie zwar im Grenzfall durch den tödlichen Ausgang der Krankheit für gerechtfertigt, warnte aber angesichts einer Heilungsquote von nur $25 \%$ vor übertriebenen Erwartungen ${ }^{18}$. Experimente mit Humaninsulin als Schizophrenie-Therapie verbot Bonhoeffer 1930 seinem Mitarbeiter Manfred Sakel, der daraufhin die Klinik verließ und sein Verfahren in Wien erprobte ${ }^{19}$. Ungeachtet der internationalen Anerkennung dieser "Insulin-Schock-Therapie“ spottete Bonhoeffer, dies erinnere ihn „an die Methoden einer früheren aktiven therapeutischen Zeit, der Zeit vor 120 Jahren, als Horn, der erste Vertreter der Psychiatrie hier in Berlin, seine Kranken mit Serien von Eiswasserduschen und mit der Drehung auf der Rotationsscheibe behandelte und auch gute Erfolge sah" ${ }^{20}$. Auch gegenüber der seinerzeit viel gerühmten, heute freilich wegen Persönlichkeitsänderungen unter Kritik geratenen Lobotomie (Leukotomie), einer operativen Durchtrennung von Faserverbindungen des Stirnhirns, zur Schizophrenie-Bekämpfung (Nobelpreis 1949) äußerte Bonhoeffer „ausgesprochenes Mißtrauen“21: „Ich bin kein Freund von diesem wilden Arbeiten in Hirnregionen, die man noch lange nicht ausreichend kennt" ${ }^{22}$. - "Im ganzen habe ich den Eindruck, es lebt alles in Übertreibungen, und unsere Aufgabe wäre wohl im wesentlichen in der Rich-

${ }^{16}$ Bonhoeffer, Psychiatrisches zum Krieg, S. 447. Völlig falsch berichtet Klee, „Euthanasie“, S. 363, Bonhoeffer habe zu denen gehört, die im Ersten Weltkrieg versucht hätten, gewaltsam „die ,Kriegsneurotiker' an die Front zurückzubringen“, und im Zweiten Weltkrieg das "KZ als , therapeutische Einrichtung '“ entdeckten. Als Beleg gibt er ohne Seitenangabe Siemen, Grauen, an, wo $z w a r$ der Name Bonhoeffer erwähnt wird, aber nicht im Zusammenhang mit Stromstoßtherapie oder Konzentrationslagern als Stätten der Therapie.

17 Darauf machte Bonhoeffer später selbst aufmerksam; vgl. ders., Bedeutung der Kriegserfahrungen, S. 9, 29.

${ }_{18}$ Vgl. Bonhoeffer/Joßmann, Ergebnisse.

19 Vgl. Schwarz, Lebensbild, S. 81. Schwarz sah darin freilich einen Fehler Bonhoeffers.

${ }^{20}$ Bonhoeffer, Rückblick über 45 Jahre, S.560. Diesen herben Vergleich dehnte Bonhoeffer auch auf die Elektrokrampftherapie aus; vgl. ders., Nervenärztliche Erfahrungen, S. 46, 73.

${ }^{21}$ Focke, Begegnung Seidemann, S. 138, Bonhoeffer an Seidemann, 2.7. 1947. Bonhoeffer hatte Seidemann als erster Psychiaterin in Deutschland die Habilitation angeboten, aber der "Arierparagraph" machte das Vorhaben zunichte.

22 Ebenda, S. 140, Bonhoeffer an Seidemann, 12.10. 1947. 
tung einer weisen Mäßigung gelegen, die [...] eine mittlere Linie des Fortschritts herbeiführte ${ }^{23}$.

Dies sind nur Beispiele für eine insgesamt vorsichtige und restriktive Einstellung bei der Erprobung gefährlicher Therapieformen. Sie erscheint auch dann ethisch bemerkenswert, wenn man den heute allgemein kritisierten Rigorismus jener damals international üblichen therapeutischen Methoden nicht direkt in Zusammenhang mit der "Euthanasie“-Aktion bringt ${ }^{24}$. Bonhoeffer machte mit seiner Zurückhaltung deutlich, daß die Psychiatrie keine Heilung um jeden Preis anstreben, sondern sich bei der Auswahl der Mittel beschränken sollte. Diese Selbstbescheidung erfordert nach Bonhoeffer das ehrliche Eingeständnis begrenzter therapeutischer Möglichkeiten des eigenen Faches. Bonhoeffer erwartete daher von dem Psychiater ein "größeres Maß an geduldiger Ausdauer ${ }^{\text {“25 }}$ als von Vertretern anderer medizinischer Disziplinen wie etwa der Chirurgie.

Dabei legte Bonhoeffer bei der Erprobung neuer Therapien auch Wert auf die Einhaltung gewisser formaler Standards. Als Mitglied des Reichsgesundheitsrates war er 1928 an der Erstellung von „Reichsrichtlinien zur Forschung am Menschen" beteiligt ${ }^{26}$. Demnach sollte die Erprobung neuer Therapieformen nur zulässig sein - bei sorgfältiger Risikoabwägung - an geschäftsfähigen Menschen, die über eventuelle Risiken aufzuklären waren, schriftlich ihre Einwilligung zu erteilen hatten und sich von ihrer Zustimmung keine finanziellen Vorteile erhoffen durften. Zwar hat Bonhoeffer sich während der Debatte nicht zu Wort gemeldet, aber die Richtlinien wurden einstimmig, also auch mit seiner Stimme, verabschiedet ${ }^{27}$.

Als Klinikchef wird Bonhoeffer als „angenehm im Umgang“, obwohl „ziemlich reserviert und ruhig" geschildert, ein Charakterzug, der verstärkt worden sei durch die Ehrfurcht, die das Personal ihm entgegenbrachte ${ }^{28}$. Man redete ihn mit "Herr Geheimrat" und in dritter Person an, ein patriarchalischer Umgangston, der schon in den dreißiger Jahren "nicht mehr allgemein gebräuchlich“ war $^{29}$. Trotzdem machte Bonhoeffer seinen Mitarbeiterinnen und Mitarbeitern wenig Vorschriften und ließ alles „an einem ganz lockeren Zügel“ gehen. „Er herrschte durch sein Gesicht, seine leise und doch sehr einschmeichelnde Redeweise bei einem Gespräch." Wurde er bei Notfällen gerufen, kam er auch nachts oder sonntags ohne die geringste Miene des Vorwurfes oder des Ärgers. Bei Vorlesungen überzeugte er nicht durch Brillanz, sondern durch gute Vorbereitung und sachbezogenen und informativen Vortrag. Seine extrem kritische Haltung gegenüber allen Theorien, besonders den eigenen, machte unteren Semestern das

\footnotetext{
23 Ebenda, S. 158, Bonhoeffer an Seidemann, 29.9. 1948.

24 So Schmuhl, Rassenhygiene, S.261-290.

25 Bonhoeffer, Nervenärztliche Erfahrungen, S.17.

26 Endgültige Fassung als Rundschreiben RMdI, 28.2. 1931; abgedruckt in Sass, Medizin, S. 362 ff.

27 GeStaM, Rep 76-Va Sect. I Abt. X, No. 43 III, Protokoll des Reichsgesundheitsrates, 14.3. 1930.

28 So Horney nach Rubins, Karen Horney, S.55.

29 Mdl. Auskunft Prof. Dr. Ernst Kluge, 17.7. 1989.
} 
Verständnis schwer, ließ Vorlesungen aber für die höheren Semester und eine erstaunliche Zahl niedergelassener Ärzte zum Genuß werden ${ }^{30}$.

Politisch vertrat Bonhoeffer „liberale Ansichten“ ${ }^{31}$, sprach allerdings selten über Politik, besonders nicht in der Öffentlichkeit. In seinen Lebenserinnerungen widmete er einer persönlichen Begegnung mit Theodor Mommsen in Max Webers Elternhaus einen langen Abschnitt; er scheint durch den Weber-Kreis, den er bewunderte, geprägt worden zu sein. Bonhoeffer läßt außerdem erkennen, daß ihm die politische Meinung seines Vaters, den an der schwäbischen Demokratie ihre „laxe oder ablehnende Stellungnahme zur Kirche“ abstieß, weniger behagte als die seiner Mutter, einer von 1848 beeindruckten Demokratin, die noch dazu 1880 begann, „in der damals lebhaft erörterten Frauenfrage sich prak-

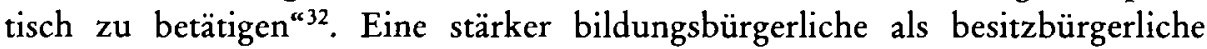
Orientierung zeigt Bonhoeffers Distanzierung von „Großindustriellen und Finanzmagnaten “33. Ungewöhnlich, auch in bildungsbürgerlichen Kreisen, war eine ausgesprochen heftige Abneigung gegen das Militär und militärischen Gehorsam, der er im Rückblick auf den eigenen Militärdienst im Jahre 1886 Ausdruck verlieh ${ }^{34}$.

Als Arzt und Wissenschaftler ging Bonhoeffers hauptsächliche Erwartung an die Politik wohl dahin, daß er „ohne wesentliche Behinderung durch politische Instanzen" Wissenschaft betreiben könne. Er sah von dieser Warte aus die Revolution von 1918 nicht als ein Hindernis, die „Machtergreifung“ von 1933 aber als eine Katastrophe an. Allerdings ist seine Ablehnung der Nationalsozialisten zunächst nicht im Wissenschaftsinteresse, sondern humanitär begründet: Die strikte Ablehnung entstand, nachdem fünf Nationalsozialisten einen Kommunisten in seiner eigenen Wohnung zu Tode geprügelt hatten und Hitler in einem öffentlichen Telegramm diese Tat gutgeheißen hatte ${ }^{35}$. Ernst Kluge, von 1934 bis 1938 Bonhoeffers Vorlesungsassistent, erinnert sich an einige abschätzige Bemerkungen über Nationalsozialisten und die drohende Kriegsgefahr, aber auch daran, daß Bonhoeffer einem Gespräch über Umsturzpläne auswich. Tatsächlich hatte Bonhoeffer seit Herbst 1938 von diesen Planungen, die seine Söhne und Schwie-

30 Vgl. PAGJ, Interview Dr. Lucie Rüsken, 30.1. 1961, S. 13, 17, 49.

31 So Horney nach Rubins, Karen Horney, S. 55.

32 Bonhoeffer, Lebenserinnerungen, S. 13, 19. Dieses mütterliche Erbe mag Bonhoeffer bewogen haben, 1932 gemeinsam mit zwei Kollegen die Ehrenpromotion von Alice von Salomon, der langjährigen Vorsitzenden des Bundes deutscher Frauen, mit dem Argument zu betreiben, man anerkenne, nwelche hervorragenden Seiten Frau Salomon nach der sozialen Seite der Frauenbewegung aufzuweisen hat und daß man ihr als der Ersten in Deutschland entscheidende und wirkungsvolle Organisationen dankt“; HUB, Med. Fak. 42, Bl. 94, Fakultätsratsprotokoll, 24.2. 1932.

33 Vgl. Bethge, Bonhoeffer, S.202, Karl an Dietrich Bonhoeffer, 20.3. 1931. Ähnlich Focke, Begegnung Seidemann, S. 160, Bonhoeffer an Seidemann, 28.11. 1948.

$34 \mathrm{Vgl}$. Bonhoeffer, Lebenserinnerungen, S.30f. Diese Einstellung hat ihn aber nicht gehindert, 1914 einen der Kriegsaufrufe zu unterzeichnen; vgl. Windt, Rad, S. 18.

${ }^{35}$ Ebenda, S.99f. Diese Schilderung ist zwar eineinhalb Jahrzehnte später entstanden, klingt aber aufgrund mehrerer vergleichbarer Briefe seiner Frau und Kinder glaubwürdig; vgl. Bethge, Bonhoeffer, S.256f. 
gersöhne betrieben, nur allzu gut Kenntnis und hatte sich, da einige Verschwörer in bezug auf einen direkten Mord an Hitler Bedenken trugen, sogar dazu bereit erklärt, diesen durch ein Psychiatergremium für unzurechnungsfähig erklären zu lassen ${ }^{36}$. Nach den Maßstäben des NS-Regimes hatte er sich damit des Hoch- und Landesverrates schuldig gemacht. Freilich ist er nach außen hin nicht aktiv geworden.

In religiöser Hinsicht neigte Bonhoeffer zu einem kirchlich distanzierten, nicht kirchenfeindlichen Protestantismus, der im allgemeinen zu spröde war, um nach außen in Erscheinung zu treten. Aus seiner Jugendzeit berichtete er, froh gewesen zu sein, vom Vater außerhalb der Konfirmandenzeit nicht zum sonntäglichen Kirchgang gezwungen worden zu sein ${ }^{37}$. Vom Kirchenkampf abgesehen ist dies die einzige Erwähnung kirchlichen Lebens in seinen Lebenserinnerungen. Dennoch charakterisiert ihn seine Schülerin Karen Horney als „ziemlich religi-

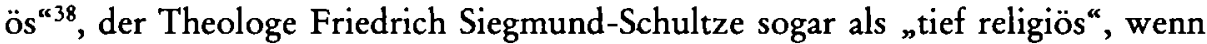
auch „nicht für eine bestimmte theologische Richtung interessiert ${ }^{\text {«39. Auf das }}$ Theologie-Studium seines Sohnes Dietrich reagierte Karl Bonhoeffer skeptisch, aber tolerant. Im Kirchenkampf nahm er diese Skepsis wieder zurück: „Als Du Dich seinerzeit für die Theologie entschlossen hast, dachte ich manchmal im Stillen, daß ein stilles, unbewegtes Pastorendasein, wie ich es von meinen schwäbischen Onkeln kannte und wie es Mörike schildert, eigentlich doch fast zu schade für Dich wäre. Darin habe ich ja, was das Unbewegte anlangt, mich gröblich getäuscht. Daß eine solche Krise auch auf dem Gebiete des Kirchlichen noch möglich würde, schien mir aus meiner naturwissenschaftlichen Erziehung heraus eigentlich ausgeschlossen "40. In Konsequenz dieser Einsicht hat Karl Bonhoeffer seinen Sohn im Kirchenkampf in jeder Hinsicht unterstützt, stellte beispielsweise im September 1933 Wagen und Chauffeur zur Verfügung, damit dieser, durch den Arztwagen des Preußischen Staates vor Durchsuchungen der Gestapo geschützt, während der Wittenberger „Nationalsynode“ Flugblätter gegen den „Arierparagraphen“ an die Bäume nageln konnte ${ }^{41}$. Doch ist er darüber kein regelmäßiger Kirchgänger geworden.

In der Diskussion um Zwangssterilisation und „Euthanasie“ hat Karl Bonhoeffer keine religiösen Argumente geltend gemacht. Auch finden sich in seinen Veröffentlichungen keine programmatischen Äußerungen, die etwa ethische "Grundsätze“ deutlich werden ließen. Wir müssen uns vielmehr im folgenden ganz und gar an Bonhoeffers Handlungsweisen orientieren, um die Grundlinien seiner Überzeugung herauszuarbeiten. Bonhoeffers Tätigkeit als Interessenvertreter der Psychiatrie in der Weimarer Republik, seine Position in der Phase der

\footnotetext{
36 Vgl. Hoffmann, Widerstand, S. 122.

37 Vgl. Bonhoeffer, Lebenserinnerungen, S. 13.

38 Nach Rubins, Karen Horney, S. 55.

39 EZA 626/I, 21.11, Nachlaß Siegmund-Schultze, Lebenserinnerungen, S. 103.

${ }^{40}$ DBW 13, S.90, Karl an Dietrich Bonhoeffer, 2.2. 1934.

41 Bethge, Bonhoeffer, S. 373.
} 
"Gleichschaltung" von Wissenschafts- und Klinikbetrieb ${ }^{42}$, sein praktisches Engagement zugunsten der vom Sterilisationsgesetz Betroffenen erweisen ihn als medizinischen Praktiker, dessen Ethik sich im Vollzug formulierte. Nichtsdestoweniger lassen sich im Verlauf dieser Untersuchung die Prinzipien seiner ethischen Entscheidungen herausarbeiten und abschließend darstellen.

\section{Vorsitzender des Deutschen Vereins für Psychiatrie (1918-1934)}

Im Jahre 1919 wurde Karl Bonhoeffer Erster Vorsitzender des Deutschen Vereins für Psychiatrie. Diesen Posten hatte er über fünfzehn Jahre inne und war damit verantwortlich für die jährlichen Vereinstagungen, den wichtigsten Treffpunkt deutscher psychiatrischer Wissenschaft und Fortbildung. Auch hatte er die Verhandlungen mit Reichsregierung, Parlament und Ministerialbürokratie zu führen.

Gleich nach seiner Wahl war Bonhoeffer mit einem sehr ernsten Problem konfrontiert: Während der alliierten Seeblockade 1917 waren in den Anstalten ungefähr 45000 Menschen verhungert ${ }^{43}$ oder durch den Hunger geschwächt der Spanischen Grippe erlegen, die weltweit mehr Tote forderte als der Erste Welt$\mathrm{krieg}^{44}$. Die furchtbaren Folgen der Lebensmittelknappheit forderten in Deutschland das Leben von rund 800000 Zivilisten $^{45}$. In der Verzweiflung über diese Situation kam die Diskussion auf, ob man sich in Kriegszeiten die Ernährung von Anstaltsinsassen, denen offiziell die gleiche Lebensmittelration (tausend Kilokalorien täglich) zustand ${ }^{46}$, leisten könne. Auf diese Debatte nahm Bonhoeffer in einem Votum Bezug, das die Last der Situation und den damit verbundenen Konflikt zur Sprache brachte, sich aber auch einer eindeutigen Stellungnahme nicht enthielt: Die "Gefahr" liege in einer bedrohlichen „Wandlung des Humanitätsbegriffes": „Ich meine nur das, daß wir unter den schweren Erlebnissen des Krieges das einzelne Menschenleben anders zu bewerten genötigt wurden als vordem, und daß wir in den Hungerjahren des Krieges uns damit abfinden mußten, zuzusehen, daß unsere Kranken in den Anstalten an Unterernährung dahinstarben, und dies fast gutzuheißen in dem Gedanken, daß durch diese Opfer vielleicht

${ }^{42} \mathrm{Vgl}$. auch Gerrens, Karl-Bonhoeffer-Gutachten.

43 Siemen, Grauen vorprogrammiert, S.32.

44 Braudel, Sozialgeschichte I, S.87.

45 Erdmann, Erster Weltkrieg, S. 187.

46 Siemen, Grauen vorprogrammiert, S.31, der das Sterben der psychisch Kranken als "lautlose Vernichtung lebensunwerten Lebens “ bezeichnet, „zum Nutzen der übergeordneten Interessen der Herrschenden ". Doch verhielten sich die staatlichen Behörden durchaus wohlwollend den Anstalten gegenüber; vgl. angesichts etwa 900-1000 Betheler Hungeropfer Bodelschwingh, Saat, S.74. Die im Vergleich höheren Sterblichkeitsziffern von Anstaltsinsassen lassen sich vollständig dadurch erklären, daß der Rest der Bevölkerung sich illegal Lebensmittel beschaffen konnte (Hamstern); vgl. dazu - das harte Urteil relativierend - Siemen, Menschen, S.31. Demgegenüber war die Lebensmittelversorgung 1939/40, als die „Euthanasie “-Aktion beschlossen wurde, vergleichsweise gut; es handelte sich um einen gezielten und bewußten Mord von Anstaltsinsassen. Diese unterschiedlichen Ausgangsbedingungen sollten im Vergleich nicht nivelliert werden. 
Gesunden das Leben erhalten bleiben könnte. In der Betonung dieses Rechts der Gesunden auf Selbsterhaltung, wie sie eine Zeit der Not mit sich bringt, liegt die Gefahr der Überspannung, die Gefahr, daß der Gedanke der opfermütigen Unterordnung der Gesunden unter die Bedürfnisse der Hilflosen und Kranken, wie er der wahren Krankenpflege zugrunde liegt, gegenüber den Lebensansprüchen der Gesunden an lebendiger Kraft verliert ${ }^{447}$.

Dieses Votum Bonhoeffers von 1918 war jedoch nur ein Vorspiel zur ersten großen politischen Auseinandersetzung über die Rechte von psychisch Kranken, im Zusammenhang mit einem Entwurf des Preußischen Ministeriums für Volkswohlfahrt über ein „Irrenfürsorgegesetz“. Dieser Entwurf sah zweierlei vor: a) sollten Zwangseinweisungen nur nach einem Amtsgerichtsentscheid für zulässig erklärt werden, b) sollten Einweisungen in öffentliche psychiatrische Anstalten nur bei "gemeingefährlichen" Kranken möglich sein. Einerseits wollte man damit Zwangseinweisungen von einem Gerichtsentscheid abhängig machen und damit eine Regelung schaffen, die zwar durch Art. 114 der Weimarer Verfassung (Freiheit der Person) nicht $\mathrm{zwingend}$ vorgeschrieben $\mathrm{war}^{48}$, die aber von der Logik einer freiheitlichen Verfassung her nahelag. Andererseits sollte der freiwillige Anstaltsaufenthalt, der von Krankenkassen oder Armenbehörden hätte finanziert werden müssen, auf "gemeingefährliche" Personen beschränkt und damit Geld gespart werden.

Bonhoeffer protestierte am 24.Januar 1924 in einem Gutachten gegen diesen Entwurf. Das Verfahren einer regelmäßigen Anrufung des Amtsgerichtes bei jeder Einweisung würde die Aufnahme auf Wunsch erschweren. Bonhoeffer empfahl, den Gesetzesentwurf zu streichen oder das preußische Gesetz dem badi-

47 AZP 76 (1920/21), S. 32, Bericht über Bonhoeffers Ansprache. - Aus diesen Sätzen hat man auch Bonhoeffers Befürwortung des gewandelten Humanitätsbegriffs herauslesen wollen, allerdings mit ganz willkürlicher Zitation. Damm/Emmerich, Irrenanstalt Dalldorf-Wittenau, S. 33, zitieren Bonhoeffer nach Siemen, Menschen, S.31f., wie folgt: „Karl Bonhoeffer fand [!] angesichts des Todes dieser Kranken und angesichts der Unterernährung, daß ,der Gedanke der opfermütigen Unterordnung der Gesunden unter die Bedürfnisse der Hilflosen und Kranken [. . . gegenüber den Lebensansprüchen der Gesunden an Kraft verliert'. Der mit solchen Argumenten verbrämte massenhafte Hungertod ihrer Patienten diente den Psychiatern im Zweiten Weltkrieg als Rechtfertigung, um die dann sehr viel gezielteren Patientenmorde zu legitimieren." Wirsing zitiert Bonhoeffer nach Damm/Emmerich, vgl. dies, Abschaffung, Frankfurter Allgemeine Zeitung, 24.9. 1988, S. 24, folgendermaßen: „Er [Bonhoeffer] stellte damals in der ,Allgemeinen Zeitschrift für Psychiatrie` die Überlegung an, ob ,der Gedanke der opfermütigen Unterordnung der Gesunden

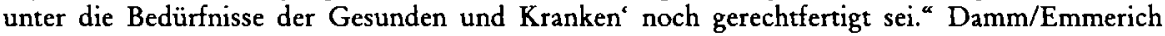
korrigierten nach Protest ihr fehlerhaftes Zitat für die zweite Auflage, erklärten gleichwohl: „An unserer Bewertung ändert das nichts" ${ }^{\prime}$, in: Totgeschwiegen ${ }^{2}$, S. 243.

${ }^{48}$ Die Rechtslage war insofern verwickelt, als eine Generalklausel des Preußischen Allgemeinen Landrechtes von 1783 ( $\$ 10$ II 17), welche von Vollmachten der Polizei sprach, seit dem Kaiserreich (gemäß unterschiedlicher Provinzialbestimmungen und Anstaltsreglements) auch auf Zwangseinweisungen angewandt worden war; vgl. Joachim/Korn, Deutsches Ärzterecht II, S. 618-641; Rittershaus, Irrengesetzgebung, S. 32-43. Andererseits stand das jüngere Recht auf Unverletzlichkeit der Person nach Art. 114 der Weimarer Verfassung unter Gesetzesvorbehalt. Hingegen wurde die Generalklausel des Allgemeinen Landrechts als Gesetz im Sinne der Verfassung angesehen; vgl. Anschütz, Verfassung, S. 480. 
schen Gesetz anzugleichen ${ }^{49}$ oder zumindest die Universitäts-Nervenkliniken aus dem Gesetz auszunehmen - damit jedenfalls hier eine Behandlung auf Wunsch stattfinden könne. Der Vorstand und die Justizkommission des Deutschen Vereins für Psychiatrie urteilten gleichfalls und verstärkten damit Bonhoeffers Votum: „Jeder Kranke, auch der Geisteskranke, sollte das Recht haben, nach seinem Ermessen ein Krankenhaus aufzusuchen [...] Auch der Ausdruck ,gemeingefährlich' muß aus einem zeitgemäßen Irrengesetz ausgemerzt werden. Geisteskrankheit bedeutet keinen Makel; jeder kann das Unglück haben, geisteskrank zu werden. Es ist aber eine vornehme, vielleicht die vornehmste Aufgabe dieses Irrenschutzgesetzes, auch zu seinem Teile dazu beizutragen, daß diese Ansicht dem Volke eingeprägt wird“ ${ }^{50}$.

Das Ministerium erarbeitete aufgrund des Protestes eine Neufassung, derzufolge zwar eine regelmäßige Anrufung des Gerichts bei freiwilligen Aufnahmen nicht nötig war, aber auf Kosten der Allgemeinheit nur noch ausgesuchte (billigere!) Anstalten zugelassen werden sollten. Dagegen protestierte Bonhoeffer in einem Schreiben an den preußischen Minister für Volkswohlfahrt, das er durch Unterschriften sämtlicher Direktoren der preußischer Universitätskliniken stützte: „Ein Irrenfürsorgesetz in dem geplanten Sinne würde zu einer scharfen Trennung sämtlicher Geisteskranker von allen Kranken anderer Art führen... Es unterliegt keinem Zweifel, daß jede Komplizierung der Aufnahmebedingungen geeignet ist, das unheilvolle Vorurteil des Publikums, unter dem die psychisch Kranken so lange zu leiden hatten und dem die freien Aufnahmen der Klinik in so günstiger Weise entgegengewirkt haben, wieder aufleben zu lassen" 51 .

Danach wurde auch der zweite Entwurf zurückgezogen ${ }^{52}$. Statt dessen präsentierten das Ministerium für Volkswohlfahrt und das Preußische Innenministerium am 15. Februar 1932 gemeinsam einen Erlaß (!), welcher die Zwangseinweisung neu regelte ${ }^{53}$. Demnach sollte die Polizei nach dem Attest eines beamteten Arztes, der kein Psychiater sein mußte, über die Zwangseinweisung „gemeingefährlicher" Geisteskranker verfügen. Zwangseingewiesenen blieb der Rechtsweg vor dem Verwaltungsgericht. Der Verein für Psychiatrie nahm, unter Bonhoeffers Einfluß, auch zu diesem Erlaß wieder kritisch Stellung. Man forderte die Rücknahme, weil Polizei und Verwaltungsgerichte die "Gemeingefährlichkeit" psychisch Kranker gemeinhin überschätzten und weil die Anstalten in die Lage

\footnotetext{
${ }^{49}$ Hier bedurften freiwillige Einweisungen nur eines ärztlichen Aufnahmegutachtens; Zwangseinweisungen waren durch das Bezirksamt aufgrund amtsärztlicher psychiatrischer Gutachten möglich und konnten vor dem Verwaltungsgericht angefochten werden; vgl. Fischer, Badisches Irrenfürsorgegesetz.

${ }^{50}$ GeStaM, Rep.76-VA Sect.I Tit.X No.85, Bl. 97-102, Bonhoeffers Gutachten, 24.1. 1924, mit dem Votum des Deutschen Vereins für Psychiatrie als Anhang.

${ }^{51}$ Ebenda, Bl. 119, Bonhoeffer u. a. an PrEM, 2.10. 1925.

52 Ebenda, Bl. 125.

${ }^{53}$ Wiederum wurde die durch Art.114 der Weimarer Verfassung vorgeschriebene gesetzliche Regelung lediglich durch die Generalklausel des Preußischen Polizeiverfassungsgesetzes von 1931 abgedeckt.
} 
versetzt werden müßten, offene Therapieformen auch an vermeintlich gemeingefährlichen Personen zu erproben ${ }^{54}$. In mündlicher Verhandlung mit dem preußischen Innenministerium erreichte Bonhoeffer Ende 1932 die Zusage, daß die Angelegenheit unter Beratung durch den Deutschen Verein für Psychiatrie noch einmal grundsätzlich geregelt werde $e^{55}$.

Es spricht für die starke Position des Deutschen Vereins für Psychiatrie in der Weimarer Republik, daß er die Rücknahme zweier Gesetzesentwürfe und eines Erlasses erreichen konnte. Bonhoeffer war in diesen Auseinandersetzungen die federführende Persönlichkeit im Verein. Die Protestresolutionen tragen seine Handschrift; sie spiegeln die Grundeinstellung Bonhoeffers, daß die Psychiatrie als Teil der allgemeinen Pathologie anzusehen und die psychiatrische Klinik als ein Krankenhaus anzuerkennen sei. Daher sollen die Geisteskranken das gleiche Recht freier Arzt- und Therapiewahl besitzen. Die von Bonhoeffer implizit gutgeheißene Zwangseinweisung in die psychiatrische Klinik aufgrund eines amtsärztlichen Gutachtens, anfechtbar vor dem Verwaltungsgericht, entsprach dem von der Weimarer Verfassung gewährten Standard an Persönlichkeitsrechten; heute muß mit gutem Grund schon für die Zwangseinweisung ein Gerichtsbeschluß herbeigeführt werden.

Gegen Mittelkürzungen für die Psychiatrie aufgrund der angespannten Haushaltslage in der Weltwirtschaftskrise formulierte Bonhoeffer abermals eine Protestresolution, die der Deutsche Verein für Psychiatrie auf der Tagung am 24. und 25. April 1930 wiederum einstimmig verabschiedete ${ }^{56}$. Diese Situation wiederholte sich im Januar 1932, als der Preußische Staatsrat unter dem Vorsitz des Kölner Oberbürgermeisters Konrad Adenauer entschied, daß die „für die Pflege und Förderung der geistig und körperlich Minderwertigen aufzuwendenden Kosten auf dasjenige Maß herabgesenkt werden [können], das von einem verarmten Volke noch getragen werden kann ${ }^{457}$. Bonhoeffer klagte auf der Jahrestagung des Vereins: „Unser Fach ist heute, wo uns allerwärts die Gefahr des kulturellen Abbaus vor Augen geführt wird, vielleicht in besonderem Maße bedroht. Man hört und liest es, daß in einem Volk, das Mühe hat, seiner gesunden Bevölkerung das Leben zu fristen, kein Platz ist für Ausgaben, deren produktiver Charakter nicht klar liegt. Gerade von den Anstalten ist die unrichtige Meinung im Publikum verbreitet, daß es sich im wesentlichen um eine unproduktive Verwahrungstätigkeit handelt. [...] Streichung der Etatsmittel, Abbau der Ärztezahl, des Personals, $[\ldots]$ ist, um nur einiges zu nennen, das, was wir heute erleben. [...] Es ist immer wieder unsere Aufgabe, der Öffentlichkeit klar zu machen und durch un-

\footnotetext{
${ }^{54}$ Vgl. AZP 99 (1933), Bericht Bonhoeffer, S. 184.

${ }^{55}$ Vgl. AZP 101 (1934), Bericht Bonhoeffer, S.3. Aufgrund der "Machtergreifung“ ist es dazu nicht mehr gekommen.

${ }^{56} \mathrm{Vgl}$. AZP 93 (1930), S. 388.

57 Nach Kaiser/Nowak/Schwartz, Eugenik, S.64f. Gleichzeitig forderte der Staatsrat, „den anerkannten Lehren der Eugenik eine weitere Verbreitung zu verschaffen", und sah an dieser Stelle bemerkenswerterweise keine Finanzierungsprobleme.
} 
sere Tätigkeit zu zeigen, daß die Aufgaben und Leistungen der psychiatrischen Krankenhäuser produktiver Natur sind, und daß wir noch nicht auf einer Höhe stehen, auf der ohne Schaden abgebaut werden kann ${ }^{\text {“58 }}$.

Wie sich an dieser letzten Auseinandersetzung vor der "Machtergreifung“ zeigt, hat Bonhoeffer sein Plädoyer für eine medizinisch-verantwortliche Betreuung und Förderung der Geisteskranken konsequent durchgehalten. Diese Position ist zu würdigen, weil sie sich sowohl von ideologischen als auch von wirtschaftlichen Gegebenheiten unabhängig zu machen verstand. Man vergleiche damit etwa das Konzept einer "differenzierten Fürsorge“, das der Centralausschuß der Inneren Mission in den $30 \mathrm{er}$ Jahren entwickelte, wonach „erhebliche Aufwendungen" nur für solche Gruppen Fürsorgebedürftiger gemacht werden sollten, die "voraussichtlich ihre volle Leistungsfähigkeit wieder erlangen“, während für alle „übrigen“ die wohlfahrtspflegerischen Leistungen auf „menschenwürdige Versorgung und Bewahrung" begrenzt werden sollten ${ }^{59}$.

\section{Einsatz für die Unabhängigkeit der Wissenschaft in der Phase der "Gleichschaltung“}

\section{Der Verein für Psychiatrie}

In der Zeit zwischen März und Juni 1933 gingen die meisten medizinischen Vereine auf die "Gleichschaltung" ein - teils freiwillig, teils halb-freiwillig. Hier nur einige Beispiele: Die Jahresversammlung des Verbandes beamteter Psychiater, deren Vorstandsmitglieder schon vor 1933 "teils der Nationalsozialistischen Partei, teils dem Stahlhelm“ angehörten, beschloß schon im Frühjahr 1933 die Selbstauflösung. Man traf sich zwar noch einmal, jedoch nur um das Verbandsvermögen an den Münchner Psychiater Rüdin für erbbiologische Forschungen zu überweisen ${ }^{60}$. Der Vorstand der Gesellschaft Deutscher Nervenärzte war im Sommer 1933 zurückgetreten, nachdem das Vorstandsmitglied Kurt Goldstein aus Deutschland hatte fliehen müssen, aber nicht von seinem Posten zurücktrat. Die Allgemeine ärztliche Gesellschaft für Psychotherapie führte im Zuge der "Gleichschaltung" durch Göring im Juli 1933 den Arierparagraphen für Vorstandsmitglieder ein ${ }^{61}$. Selbst die Deutsche Gesellschaft für Psychoanalyse führte (mit Freuds Billigung) 1933 per Geheimbeschluß den Arierparagraphen für Vorstandsmitglieder ein, weil man sonst keine Überlebenschancen für die Psychoanalyse sah, und warf den als politischen Gegner der Nationalsozialisten vertriebenen Wilhelm Reich aus dem Vorstand ${ }^{62}$.

\footnotetext{
${ }^{58}$ Vgl. AZP 99 (1933), Bericht Bonhoeffer, S. 148.

${ }^{59}$ So in der Treysarer Resolution von 1931, in: Kaiser/Nowak/Schwartz, Eugenik, S. 106, 108.

60 Vgl. PNW 36 (1934), Bericht Bresler, S. 269-271.

${ }^{61}$ Vgl. Lockot, Erinnern, S. 173.

${ }^{62}$ Vgl. Nitschke, Freuds Ungeduld, Die Zeit vom 5.10. 1990, S. 46 f.
} 
Der Deutsche Verein für Psychiatrie ergriff diesbezüglich zunächst keine Initiative. Jedoch wurde der Stein von anderer Seite ins Rollen gebracht: Am 16.Juli 1933, zwei Tage nach dem noch geheimgehaltenen Kabinettsbeschluß über das Erbgesundheitsgesetz, wurde Ernst Rüdin vom Reichsinnenminister Frick zum Kommissar für die Deutsche Gesellschaft für Rassenbygiene ernannt. Rüdin entließ den bisherigen Vorstand (Fischer, Muckermann, Verschuer), ersetzte etwa die Hälfte aller Ortsgruppenleiter durch „zuverlässige Nationalsozialisten "63, übernahm dazu den Vorsitz des Verbands für psychische Hygiene, dessen Vorsitzender Sommer zum Rücktritt genötigt wurde, machte den Psychiater Hans Römer (Ilmenau) zu seinem Geschäftsführer und benannte den Verband um in Deutscher Verband für psychische Hygiene und Rassenhygiene ${ }^{64}$. Schon am Tag nach der Ernennung zum Reichskommissar denunzierte Rüdin Bonhoeffer bei seinem Kollegen Gütt vom Reichsinnenministerium: „Tatsache ist, daß der Deutsche Verein für Psychiatrie nicht den Hoffnungen entsprochen hat und ihnen auch heute nicht entspricht, die der neue Geist der Erbbiologie und Rassenhygiene auf ihn setzen muß. Das soll nun anders kommen"65.

Daraufhin erhielten Bonhoeffer (und Rüdin!) vom Reichsinnenministerium schriftlich den Befehl, daß der Deutsche Verein für Psychiatrie und die Deutsche Gesellschaft für Rassenhygiene eine „engere Verbindung“ eingehen sollten. Gleichzeitig schrieb der Vorsitzende der Allgemeinen ärztlichen Gesellschaft für Psychotherapie Kretschmer (Marburg) an Bonhoeffer „vertraulich“, er befürchte ein Verbot der Psychotherapie, es bestünden in der Gesellschaft scharfe „Gegensätze der Weltanschauung" - gemeint waren politische Gegensätze - und er sei zurückgetreten ${ }^{66}$.

Bonhoeffer hatte 1932 gegenüber dem Vorstandmitglied Eichelberg (Hedemünden) den Plan geäußert, er wolle sich mit Erreichen des 65. Lebensjahres (1933) emeritieren lassen, vom Vereinsvorsitz zurücktreten und einem Jüngeren Platz machen. Er wurde aber nun bestürmt, „unter keinen Umständen“ das Amt niederzulegen, um dem Verein über die „schwierigen Zeiten“ hinwegzuhelfen ${ }^{67}$. Diesen „taktischen Gründen "68 wollte Bonhoeffer sich nicht verschließen und suchte beide Probleme - die Fusionsauflagen des Innenministeriums und das drohende Verbot des Psychotherapeutenverbandes - auf einmal zu lösen, indem er Rüdin und Kretschmer am 29.7. 1933 zu einer Vorstandssitzung des Deutschen Vereins für Psychiatrie in die Charité bat. Dabei beantragte er, die Ge-

\footnotetext{
${ }^{63}$ So in schöner Offenheit Bohn, Gesellschaft, S. 464.

${ }^{64}$ Vgl. den Bericht in: Zeitschrift für Psychische Hygiene 7 (1934), S. 119-124. Dort auch die lakonische Notiz: „Im Verlauf des Jahres 1933 schieden die nichtarischen Mitglieder aus dem Verband aus."

${ }^{65}$ Rüdin an Gütt, 17.7. 1933, zit. nach Weber, Rüdin, S. 225.

${ }^{66} \mathrm{HUB}, \mathrm{NL}$ KB 10, Kretschmer an Bonhoeffer, 12.4. 1933. Anfang 1933 wurde an einem später nicht verabschiedeten Gesetzesentwurf gearbeitet, nach dem die Psychotherapie als ,jüdischer Gelderwerb an erblich Minderwertigen" verboten werden sollte; vgl. Lockot, Erinnern, S. 112.

${ }^{67}$ HUB, NL KB 10, Eichelberg an Bonhoeffer, 4.9. 1933.

${ }^{68}$ Ebenda, Bonhoeffer an Ilberg (Schriftführer des Vereins), 4.12. 1933.
} 
sellschaft für Rassenhygiene, den Verband für psychische Hygiene und die Allgemeine ärztliche Gesellschaft für Psychotherapie nach einem später von der Mitgliederversammlung zu verabschiedenden Verfahren unter dem Dach des Deutschen Vereins für Psychiatrie zu vereinigen, indem man Rüdin für die Rassenhygiene und Kretschmer für die Psychotherapie in den Vorstand des Deutschen Vereins für Psychiatrie kooptiere ${ }^{69}$. Der Vorstand, Kretschmer und Rüdin akzeptierten diesen Vorschlag. Damit erfüllte Bonhoeffer formal die Fusionsauflagen des Innenministeriums, doch konnte Rüdin im Vorstand jederzeit überstimmt werden. Die Zuwahl Kretschmers verstärkte eine Mehrheit gegen Rüdin und bot außerdem dem Psychotherapeutenverband die Möglichkeit einer Fortexistenz innerhalb des Psychiaterverbandes.

Rüdin scheint erst im nachhinein bemerkt zu haben, wie ungünstig diese Regelung für ihn war. Er beantragte daher wenig später, auch den Verband für psychische Hygiene und Rassenhygiene einzuschließen und Römer für den Vorstand zu kooptieren ${ }^{70}$. Zwar gab es Römer gegenüber, der als "Adlatus Rüdins“ angesehen wurde, im Vorstand Widerstände, doch das Fazit lautete schließlich, daß es „unter den gegebenen Umständen kaum zu umgehen sein dürfte, dem Antrag Rüdins zuzustimmen "71. Die Mehrheit der Vorstandsmitglieder, Bonhoeffer eingeschlossen, votierte schließlich widerwillig dafür, ihn hinzuzuwählen.

Nun forderte Rüdin, noch im Wintersemester 1933/34 eine Vorstandssitzung einzuberufen, da das Reichsinnenministerium „auf eine baldige Bereinigung des Verhältnisses zwischen Psychiatrie und Rassenhygiene" dränge ${ }^{72}$. Doch Bonhoeffer ließ sich bis zum 12. Mai $1934 \mathrm{Zeit}^{73}$ und führte zur Begründung aus, eine Vorstandssitzung sei so lange überflüssig, wie Eichelberg nicht einen ersten Entwurf der Satzungsänderung präsentiert habe. Eichelberg freilich hatte in vollem Einvernehmen mit Bonhoeffer die Sache „absichtlich“ ruhen lassen und präsentierte erst nach mehrmaligen Ermahnungen - „Herr Römer läßt aber nicht nach" ${ }^{44}$ - einen Satzungsentwurf, wonach der Verband für psychische Hygiene

${ }^{69}$ Ebenda, Protokoll der Vorstandssitzung, 29.7. 1933. Gegenüber zuverlässigen Vorstandsmitgliedern räumte Bonhoeffer freimütig ein, daß die Kooptierungsbestimmung in der Vereinssatzung sich ursprünglich wohl auf die Nachwahl ausscheidender Vorstandsmitglieder und nicht deren Vermehrung bezogen hatte; vgl. ebenda, Ilberg an Bonhoeffer, 30.5. 1934: „Wenn ich Sie recht verstanden habe, soll zunächst abgewartet werden, ob das Amtsgericht Berlin-Mitte es moniert, daß wir über die Vermehrung des Vorstandes im Juli 1933 und die Vereinigung mit den zwei anderen Verbänden noch nichts berichteten." Demnach riskierte man den Einspruch des Amtsgerichtes. Soweit ist es aber nie gekommen.

70 Wer in der Person Römers und im Verband für psychische Hygiene eine sozialpsychiatrische Alternative zum Deutschen Verein für Psychiatrie sieht, so trotz aller Kritik am Verband Siemen, Menschen, S. 47-51, 89-94, unterschätzt, daß die vom Verband geforderte freie psychiatrische Fürsorge außerhalb der Anstalten vor allem dem Diktat leerer Kassen nachzugeben bereit war und daß sich hier mit Rüdin, Luxenburger, Göring und Cimbal die wichtigsten Eugeniker und späteren Vertreter der ${ }_{n} N e u e n$ Deutschen Seelenheilkunde“ gesammelt hatten; vgl. Lockot, Erinnern.

${ }^{71}$ HUB, NL KB 10, Ilberg an Bonhoeffer, 4.9. 1933.

72 Ebenda, Rüdin an Bonhoeffer, o. D. [ca. Weihnachten 1933].

${ }_{73}$ Ebenda, Einladung gez. Ilberg, 25.2. 1934.

${ }^{74}$ Ebenda, Eichelberg an Bonhoeffer, 23.3. 1934. 
und Rassenhygiene dem Deutschen Verein für Psychiatrie als eine Abteilung angegliedert würde, Beschlüsse dieses Verbandes seien nur mit Zustimmung des Vorstandes des Deutschen Vereins für Psychiatrie gültig ${ }^{75}$.

In Vorbereitung für die Mitgliederversammlung des Vereins im Mai schrieb Bonhoeffer an ausgewählte Kollegen, er würde sich außerordentlich freuen, gerade sie dieses Jahr bei der Mitgliederversammlung des Vereins begrüßen zu dür$\mathrm{fen}^{76}$, offenbar in der Absicht, Gesinnungsgenossen für den Fall einer Kampfabstimmung zu sammeln. Am 24./25. Mai 1934 erschienen so viele Mitglieder, selbst aus Polen, Holland und der Schweiz, daß man von dem für die Tagung vorgesehenen Hörsaal der psychiatrischen Klinik in Münster in das immer noch überfüllte Audimax umziehen mußte ${ }^{77}$. Bei der Eröffnungsansprache für die erste Versammlung nach Verabschiedung des Erbgesundheitsgesetzes erklärte Bonhoeffer, er begrüße die auf „Initiative der Reichsregierung“ erfolgte vorläufige Fusion mit dem Verband für psychische Hygiene und Rassenbygiene, mit der zum Ausdruck komme, daß Psychiatrie und Rassenhygiene in Zukunft enger zusammenarbeiteten, sehe es aber nicht als seine Aufgabe an, auf die ,inhaltliche Seite" des "eugenischen Problems" einzugehen. Nur warne er davor, daß die Psychiatrie, die fast ein Jahrhundert zu "kämpfen“ gehabt hätte, „um den Geisteskranken aus ihrer Verfehmung heraus ihre natürliche Stellung in der Pathologie zu erringen“, das Erlangte wieder preisgebe. Er protestiere gegen „die Überschwemmung mit unerfreulichen, z.T. widerlichen psychopathologischen Problemen, wie wir sie in der Literatur und auf der Bühne in den letzten Jahrzehnten erlebt haben" und wie sie von "offizieller Seite" gefördert würde. Zu befürchten sei eine „unerwünschte und beabsichtigte Rückwirkung, die der Kampf für die Erbgesundheit der kommenden Generationen für unser Fach mit sich bringt. Es besteht die Gefahr, daß im Publikum, begünstigt durch eine drastische Bildpropaganda, die immer wieder darauf hinweist, daß die Anstaltsinsassen einen wirtschaftlich kostspieligen und erbhygienisch gefährlichen Ballast bilden, sich so etwas wie eine Diskreditierung des Berufes entwickelt, der sich zu einem wesentlichen Teil mit der ärztlichen Betreuung dieser Individuen zu befassen hat" ${ }^{\text {"78 }}$.

Damit hatte Bonhoeffer zwar keine direkte „Kritik am Sterilisationsgesetz “79 geübt, aber indirekt vor den Rückwirkungen des Gesetzes auf die Psychiatrie, mehr auf die Psychiater als die psychisch Kranken, gewarnt. Auch formulierte er sein Anliegen vorsichtig; dennoch konnte in dieser angespannten Situation für aufmerksam Zuhörende kein Zweifel daran bestehen, wer mit der kritisierten „offiziellen Seite“ gemeint war. Bonhoeffers Votum war die einzige diesbezüglich kritische Stellungnahme, die auf der Tagung abgegeben wurde. Sein Vor-

\footnotetext{
75 Ebenda, Eichelberg an Bonhoeffer, 28.3. 1934.

76 Ebenda, Bonhoeffer an "Sehr geehrter Herr College“, o.D.

77 Vgl. den Bericht, PNW 36 (1934), S. $269 \mathrm{ff}$.

78 Vgl. AZP 102 (1934), Bericht Ilberg, S. 389-392.

79 So aber Güse/Schmacke, Psychiatrie II, S. 401.
} 
schlag, erst einmal keine neue Satzung zu verabschieden, setzte sich ohne längere Diskussion durch. Kritik übte lediglich der Wuppertaler Psychotherapeut Matthias Heinrich Göring, der "mit oberster Genehmigung " ${ }^{\text {80 }}$ die Leitung des deutschen Psychotherapeutenverbandes übernommen hatte und sich, bezugnehmend auf Bonhoeffers Eröffnungsansprache zu Wort meldete: „So begrüße ich denn als Reichsleiter der jungen deutschen Psychotherapeutischen Gesellschaft den 92jährigen Verein, der, wie wir auch gestern abend gesehen haben, krampfhaft an seinen alten, ehrwürdigen Traditionen festhält, in aller Ehrfurcht mit der Bitte um gütiges Verstehen und um freundliche Unterstützung; ich grüße Sie mit dem neuen deutschen Gruß einer jungen vorwärtsstürmenden Bewegung: Heil Hitler! ${ }^{\text {81 }}$

Am 9.Juli 1934 forderte das Innenministerium Bonhoeffer auf, sofort eine Satzung zu erstellen, derzufolge Vorstandsbeschlüsse und Satzungsänderungen nur mit Billigung des Innenministeriums gültig sein sollten, der Vorsitzende vom Innenministerium ernannt, alle anderen Vorstandsmitglieder jederzeit vom Innenministerium entlassen werden könnten. Gefordert wurde außerdem die „Verschmelzung" des Deutschen Vereins für Psychiatrie mit der Gesellschaft deutscher Nervenärzte, dem Neurologenverband: „Bei den gemeinsamen Aufgaben, die die beiden Gesellschaften z.B. auf dem Gebiete der Erbkrankheiten zu lösen haben, erscheint mir eine einheitliche Führung erforderlich ${ }^{\alpha 2}$. Bei einer Rücksprache im Innenministerium wiederholte man Bonhoeffer gegenüber nur die bereits schriftlich vorgetragenen Forderungen ${ }^{83}$. Dagegen konnte Bumke, der kommissarische Vorsitzende der neurologischen Gesellschaft, Bonhoeffer von einem Gespräch mit Rüdin berichten, „daß die Anregung zur Verschmelzung oder zur einheitlichen Führung der beiden Gesellschaften von ihm [Rüdin] ausgegangen ist “84 und daß Rüdin ihn aufgefordert habe, eine außerordentliche Mitgliederversammlung der Gesellschaft deutscher Nervenärzte einzuberufen. Bei dieser Gelegenheit habe Rüdin ihm außerdem eröffnet, daß er, Rüdin, vom Innenministerium für den Vorsitz im Deutschen Verein für Psychiatrie vorgesehen sei ${ }^{85}$.

Mitte September 1934 fuhr Bonhoeffer zu persönlichen Verhandlungen mit Rüdin nach München, in deren Verlauf es, einem Brief Bumkes an Bonhoeffer zufolge, aber zu einer „Drohung“ Rüdins gekommen sein muß, für den Fall daß Bonhoeffer sich weiterhin verweigere ${ }^{86}$. Bumke selbst hatte mittlerweile

${ }^{80}$ So Eichelberg in bezug auf ein Gespräch mit Kretschmer; vgl. HUB, NL KB 10, Eichelberg an Bonhoeffer, 28.3. 1934. Matthias Heinrich Göring war ein Vetter Hermann Görings.

${ }^{81}$ Vgl. AZP 102 (1934), Bericht Ilberg, S.427.

${ }^{82}$ HUB, NL KB 10, RMdI an Bonhoeffer, 9.7. 1934.

${ }^{83}$ Ebenda, Bonhoeffer an Bumke, 19.7. 1934.

84 Ebenda, Bumke an Bonhoeffer, 27.7. 1934.

${ }^{85}$ Ebenda, Bumke an Bonhoeffer, 13.9. 1934

${ }^{86}$ Ebenda, Bumke an Bonhoeffer, 21.9. 1934. „Ich gestehe, daß ich Rüdins Taktik nicht verstehe. Wenn er sich doch bei Ihnen ansagen wollte, so hätte er mir die doppelte Peinlichkeit der Aussprache hier und meines Briefes an Sie ersparen können [. . .] Selbstverständlich will Herr Rüdin auch die Gesellschaft deutscher Nervenärzte gleichschalten. Daß ihr auch Internisten angehören, hat 
nachgegeben, weil er sich „außerstande“ sah, „Kräfte für diesen Kleinkrieg zu vergeuden ${ }^{\text {c87}}$, und schließlich eine außerordentliche Mitgliederversammlung der neurologischen Gesellschaft einberufen hatte, bei der die „Gleichschaltung“ weisungsgemäß vollzogen wurde ${ }^{88}$. Bonhoeffer blieb hart, bis das Innenministerium am 24. September 1934 schriftlich seinen Rücktritt forderte ${ }^{89}$. Darauf erklärte Eichelberg solidarisch, er lege Wert darauf, „daß der ganze Vorstand zurücktritt und nicht nur einzelne Personen"90, woraufhin Ende September 1934 (fast) alle Vorstandsmitglieder des Deutschen Vereins für Psychiatrie zurücktraten.

Damit war für Rüdin die Bahn frei. Er berief alle bisherigen Mitglieder des Deutschen Vereins für Psychiatrie und der Gesellschaft Deutscher Nervenärzte zu einer außerordentlichen Mitgliederversammlung der neugegründeten Gesellschaft deutscher Neurologen und Psychiater und ließ dort eine Satzung beschließen, die es als Vereinsziel benannte: „... im nationalsozialistischen Staate die Nerven- und Seelenheilkunde in wissenschaftlicher und praktischer Hinsicht zu fördern und dadurch an der Gesundhaltung und Aufartung des deutschen Volkes mitzuhelfen "91. Bonhoeffer und die anderen ehemaligen Vorstandsmitglieder (ausgenommen Rüdin und Nitsche) waren nicht erschienen ${ }^{92}$ und taten auf diese Weise ihren Protest in stiller Form kund.

Auch der in Berliner Arbeiterbezirken tätige Verein für jugendliche Psychopathen, den Bonhoeffer gemeinsam mit dem Theologen Friedrich SiegmundSchultze gegründet hatte ${ }^{93}$, konnte dem neuen Regime nicht gelegen sein, hatte sich der Vorstand doch noch 1932 gegen die Sterilisation Jugendlicher ausgesprochen. 1933 strich das Reichsinnenministerium dem Verein die finanzielle Unterstützung, da das Vereinsziel, „durch eine intensive Heilbehandlung“ eine Besserung des nach Ansicht des Ministerium „anlagemäßig bedingten Zustandes“ herbeizuführen, „abwegig“ erscheine. Eine „so weitgehende Fürsorge für jugendliche Psychopathen“ sei mit dem „Grundgedanken der nationalsozialistischen Gesundheitspolitik" nicht vereinbar ${ }^{94}$. Nachdem Bonhoeffer sich für das Rechnungsjahr 1933 noch aus dem preußischen Innenministerium diejenigen Mittel

er erst durch mich erfahren. Er besteht auf der Wahl von Herrn Jacoby-Magdeburg zum ersten Vorsitzenden, der aber ihm offenbar unterstellt werden soll.“

${ }^{87}$ Ebenda, Bumke an Bonhoeffer, 21.9. 1934.

${ }^{88}$ Ebenda, Eichelberg an Bonhoeffer, 3.10. 1934: „Herr Rüdin war zu der Sitzung eingeladen, war aber nicht erschienen. Sowohl Herr Bumke wie Herr Förster [Neurologe aus Breslau] hielten die Sache wohl für zu belanglos, um irgendwie zu kämpfen. Es ist das vielleicht auch der richtige Standpunkt. Wie so häufig in der jetzigen Zeit, waren fast alle Mitglieder mit dem gefaßten Beschluß nicht einverstanden, aber sie faßten ihn, weil sie nichts Besseres wußten.“

${ }^{89}$ Ebenda, RMdI an Bonhoeffer und Bumke (Abschrift), 24.9. 1934.

${ }^{90}$ Ebenda, Eichelberg an Bonhoeffer, 3.10. 1934.

$91 \$ 2$ der Satzung zit. nach Ehrhardt, 130 Jahre, S. 109-114. Vgl. auch Rüdin/Nitsche, Bericht.

92 Siehe die Anwesenheitsliste, in: Ebenda.

${ }^{93}$ Vgl. EZA, 626/I, 21.11, Nachlaß Siegmund-Schultze, Lebenserinnerungen, S. 103.

94 Vgl. BAP, 49.01 REM 1355, Bl. 372, gez. Gütt an Verein für jugendliche Psychopathen e.V., 6.1. 1935. 
besorgen konnte, die das Reichsinnenministerium ihm verweigerte ${ }^{95}$, setzte er für 1934 durch, daß sie aus dem Etat der Charité und damit indirekt aus dem des Kultusministeriums bestritten wurden ${ }^{96}$. Daraufhin löste Rüdin auch diesen Verein im Auftrag des Innenministeriums zugunsten seiner neuen Gesellschaft deutscher Neurologen und Psychiater auf ${ }^{77}$.

\section{Psychiatrische Zeitschriften}

Die "Gleichschaltung" der Vereine zog die Reglementierung psychiatrischer Zeitschriften nach sich. Bonhoeffer verteidigte die vom Schriftführer des Deutschen Vereins für Psychiatrie, Geheimrat Ilberg, herausgegebene Allgemeine Zeitscbrift für Psychiatrie gegenüber Ansprüchen Römers und Rüdins ${ }^{98}$, übergab sie auf Ilbergs Wunsch hin in die Hände von Carl Schneider (Chefarzt von Bethel) und Hermann Paul Nitsche (Leiter der Anstalt Sonnenstein b. Pirna) ${ }^{99}$. Nitsche, Ilbergs Nachfolger, scheint bereits ein doppeltes Spiel getrieben zu haben, denn er war seit Juni an „streng vertraulichen“ Vorgesprächen mit Rüdin und Gütt im Reichsinnenministerium beteiligt, in denen die "Gleichschaltung" des Deutschen Vereins für Psychiatrie vorbesprochen wurde ${ }^{100}$, und nachdem sich Rüdin im Deutschen Verein für Psychiatrie durchgesetzt hatte, erhielt Römer die Zeitschrift 1938 doch $^{101}$. Auch für das Centralblatt für Neurologie und Psychiatrie wollte Ilberg eine Preisgabe an Rüdin und Römer vermeiden. Bonhoeffer übernahm die Herausgabe, wobei er die eigentliche Redaktionsarbeit seinem ehemaligem Mitarbeiter Jürg Zutt überließ, der mangels Parteimitgliedschaft keinen Lehrstuhl erhalten hatte und eine Berliner Privatklinik leitete.

Vom Verein unabhängig und im Besitz des Verlegers war die Monatsschrift für Psychiatrie und Neurologie, deren Herausgabe Bonhoeffer seit 1912 innehatte. Er hielt das Blatt von nationalsozialistischen und eugenischen Tendenzen weitgehend frei; entsprechend wurde die Zeitschrift (neben einigen wenigen anderen) 1936 vom Verbot der Einfuhr deutschen medizinischen Schrifttums in die Tschechoslowakei ausgenommen ${ }^{102} .1937$ mußte Bonhoeffers jüdischer Verleger Karger nach Basel fliehen ${ }^{103}$, aber Bonhoeffer erklärte sich „selbstverständ-

${ }^{95}$ HUB, NL KB 5, Charité-Direktion an Bonhoeffer, 24.3. 1934, darin Abschrift des PrEM an Charitédirektion, 19.3. 1934; BAP, 49.01 REM 1355, Bl. 371, Bonhoeffer an Gütt, 2.3. 1935.

${ }^{96}$ Vgl. BAP, 49.01 REM 1355, Bl. 387, Bonhoeffer an Verwaltungsdirektor der Charité, 18.7. 35.

97 Vgl. Weber, Rüdin, S. 206.

${ }^{98}$ Vgl. HUB, NL KB 10, Ilberg an Bonhoeffer, 30.5. 1934, Ilberg an Römer, 23.11. 1933 (Durchschlag für Bonhoeffer).

${ }^{99}$ Ebenda, Bonhoeffer an Nitsche und Schneider, 13.12. 1933, Ilberg an Bonhoeffer, 22.12. 1933, Bonhoeffer an Rüdin, 27.12. 1933.

100 Vgl. Weber, Rüdin, S.225.

101 Vgl. Geleitwort, in: AZP 107 (1938), S.1f.

102 Vgl. HUB, NL KB 8, Buchstabe K, Karger an Bonhoeffer, 7.4. 1936.

${ }^{103}$ Ebenda, Karger an Bonhoeffer, 10.4. 1937. Karger schildert hier, wie schwer es war, Lizenz, Wohn- und Arbeitsgenehmigung zu erhalten. 
lich “104 bereit, die Zusammenarbeit fortzusetzen. Am 12.Januar 1938 erklärte das Kultusministerium in einem Geheimerlaß: „Nach einer Mitteilung des Präsidenten der Reichsschrifttumskammer ist der Verlag Karger in Basel ein jüdisches Unternehmen und der Vorsitzende dieses Unternehmens ein bekannter Deutschenhetzer. Eine Mitarbeit deutscher Wissenschaftler bei dem genannten Verlag ist daher unerwünscht. Dieser Erlaß wird nicht [.. . ] veröffentlicht “ ${ }^{105}$. Bonhoeffer beschwerte sich beim Ministerium: Es handele sich um einen angesehenen medizinischen Verlag, von deutschfeindlichen Äußerungen Kargers sei ihm nichts bekannt, er bäte um Überprüfung des Erlasses und werde bis zu einer definitiven Antwort die Zusammenarbeit fortsetzen ${ }^{106}$. Das Kultusministerium antwortete: „Der Erlaß [...] besteht zu Recht und ist bis zu der zu erwartenden grundsätzlichen Regelung der Frage der Mitarbeit deutscher Wissenschaftler an jüdischen Verlagen und des damit zusammenhängenden Fragenkomplexes zu befolgen" ${ }^{107}$. Zum 1.Januar 1939 wurden alle „jüdischen“ Verlage in Deutschland verboten und die Mitarbeit deutscher "Arier" in ausländischen „jüdischen“ Verlagen unter Strafe gestellt ${ }^{108}$. Erst jetzt entschloß Bonhoeffer sich, das Blatt dem Schweizer Psychiater Klaesi zu übergeben. Dieser dankte ihm in der ersten Nummer des Jahres 1939 öffentlich für die bisherige Arbeit, schrieb, daß Bonhoeffers Rücktritt zum "größten Leidwesen“ aller Beteiligten geschehen „mußte", und erklärte, er werde sich bemühen, die Zeitschrift im bekannten Stil fortzuführen, damit sich „auch in Zukunft, wer die Monatsschrift liest, ihrer Erstherausgeber und ihres Ersterscheinungsortes erinnert ${ }^{109}$.

\section{Personalpolitik}

Die „Gleichschaltung", auf die die Wissenschaft reagieren mußte, betraf auch Bonhoeffers Klinik und seine Universitätstätigkeit. Den Vorschlag des Dekans, die gesamte medizinische Fakultät möge kollektiv dem NS-Lehrerbund beitreten, wehrte Bonhoeffer gemeinsam mit einigen Kollegen $a b^{110}$, aber einige nicht viele - seiner Mitarbeiter traten ein. Schwerwiegendere Auswirkungen hatte die NS-Personalpolitik für die Charité. Die zahlreichen Entlassungen von Bonhoeffers unmittelbaren Mitarbeiterinnen und Mitarbeitern gegen seinen Wil-

104 Ebenda, Bonhoeffer an Karger, 14.4. 1937.

${ }^{105}$ HUB, Med. Fak. 1480, Bl. 79, REM an Rektor der Universität „vertraulich“, 12.1. 1938.

${ }^{106}$ Ebenda, Bl. 80, Dekan an REM, 13.5. 1938, mit Bezug auf nicht erhaltenes Schreiben Bonhoeffers.

${ }^{107}$ Ebenda, Bl. 81, Rektor an Dekan, o. D., darin REM an Rektor.

${ }^{108}$ Vgl. Karger an den Verf., 9.10. 1989; vgl. auch Droste, Geschichts-Kalendarium 2/I, S. 495.

${ }^{109}$ Klaesi, Geleitwort.

${ }^{110}$ Bonhoeffer, Lebenserinnerungen, S.100. Das Ergebnis der längeren Diskussion wird auch im Fakultätsprotokoll vom 27.10. 1933 festgehalten: „Der Beitritt zum NS-Lehrerbund Reichsfachschaft Hochschullehrer und Wissenschaftler wird den einzelnen Mitgliedern der Fakultät frei gestellt“; vgl. HUB, Med.Fak. 42, Bl. 212. Bonhoeffer wurde nie Mitglied einer NS-Organisation; vgl. BDC, Akte Bonhoeffer. 
len und oft gegen seinen Protest waren einschneidend. Die folgende Aufzählung beansprucht keine Vollständigkeit, macht aber das Ausmaß des Terrors deutlich: Entlassen wurden aufgrund der Rassegesetze der stellvertretende Chefarzt Paul Joßmann, die Oberärzte Franz Kramer und Erwin Strauß, die Assistenzärzte/innen Lothar Kalinowski, Herta Seidemann, Ernst Sternberg und Hanns Schwarz; aus politischen Gründen wurden entlassen oder flohen die Assistenzärzte/innen Hans Pollnow, Martin Grotjahn, Fredy Quadfasel, Edith Vowinkel und zwei Berliner Honorarprofessoren, die sich bei Bonhoeffer habilitiert hatten: Karl Birnbaum wurde aufgrund der Rassengesetze entlassen, Kurt Goldstein aus politischen und rassischen Gründen verfolgt.

Bonhoeffer hat für die meisten von ihnen Sondergenehmigungen für die Fortbeschäftigung beantragt und erstaunlich oft auch genehmigt bekommen ${ }^{111}$. Sie haben sich 1949 in einer von einundzwanzig Emigranten zusammengestellten Festschrift zum achtzigsten Geburtstag bei ihm bedankt ${ }^{112}$. Ihr Schicksal sowie das Schicksal jüdischer Doktorandinnen und Doktoranden ${ }^{113}$ ist nicht unser The$\mathrm{ma}$, denn die nationalsozialistischen Verfolgungsmaßnahmen richteten sich gegen sämtliche jüdische oder politisch mißliebige Ärztinnen und Ärzte, unabhängig davon, ob sie wie Birnbaum ${ }^{114}$ für oder wie Goldstein und Kallmann ${ }^{115}$ gegen eugenische Zwangsmaßnahmen eintraten. Aber das Regime drängte auch darauf, daß die auf diese Weise „frei“ gewordenen Stellen mit linientreuen Eugenikern und Nationalsozialisten besetzt wurden. Zur Illustration der Position Bonhoeffers in solchen Auseinandersetzungen seien die Fälle Hefter und De Crinis herausgegriffen.

Der achtundzwanzigjährige Volontärarzt Ernst Hefter, den Bonhoeffer seiner Tochter gegenüber „der Hitlerjunge" ${ }^{\text {"116 }}$ nannte, schrieb 1933 einen nach Einschätzung des Reichspropagandaministeriums „ausgezeichneten“ Aufsatz über die Ziele nationalsozialistischer „Erb- und Rassenpflege“ für eine Tageszeitung.

111 Charakteristisch ist die folgende Beschwerde Bonhoeffers: „Die Feststellung, daß die Anstellung des Dr. Sternberg durch die nichtarische Großmutter seiner Frau ein Hindernis erfahren soll, hat mich peinlich überrascht, weil mir dadurch wieder ein erfahrener Mitarbeiter genommen werden soll“; BAP, 49.01 REM 1355, Bl. 381, Verwaltungschef der Charité an REM, 8.7. 1935, darin Begründung Bonhoeffers; sowie HUB, NK 8, Buchstabe S; BAP, 49.01 REM 1355, Bl. 382, 5.8. 1935. Zu Joßmann vgl. HUB, NK 2 (o. Bl.); HUB, NK 3, Bl. 90, Gildemeister an Bonhoeffer, 1.9. 1933; ebenda, Bl. 92, Bonhoeffer an Gildemeister, 19.9. 1933; HUB, NK 8 Buchstabe J, Bonhoeffer an "Sehr geehrter Herr Ministerialrat", 14.9. 1933. Zu Kramer vgl. Schottlaender, Verfolgte Wissenschaft, S. 91 f., Bonhoeffer an Achelis, 29.11. 1933; HUB, NK 8 Buchstabe K, Bonhoeffer an "Seine Exzellenz den Herrn Minister"; BAP, 49.01 REM 1355, Bl. 367, Bonhoeffer an PrEM, 15.5. 1935. Zu Schwarz vgl. ders., Leben, bes. S. 155, 195 f., 200f., 207, 286.

112 Vgl. MPN 117 (1949)

${ }^{113}$ Die letzte jüdische Doktorandin Karl Bonhoeffers, Milly Goldschmidt, wurde auf Antrag Bonhoeffers mit Sondergenehmigung am 10.5. 1937, einen Monat nach dem völligen Promotionsverbot für Juden im Fach Medizin, promoviert; vgl. den Briefwechsel HUB, Med. Fak. 1480, Bl. 188-192.

114 Vgl. Ivo/Hagemann, Karl Birnbaum; Liedtke, Karl Birnbaum.

115 Siehe S. 43 und S. 47.

116 Vgl. PAGJ, Interview Christine von Dohnanyi (1961), S.7. 
Über diesen Aufsatz muß es zu einem Streit mit Bonhoeffer gekommen sein, den wir nur aus Hefters Denunziation bei Staatsrat Conti kennen, der seinerseits das Reichspropagandaministerium in Kenntnis setzte. Gemäß Schreiben des Reichspropagandaministeriums an das Reichsinnenministerium hatte Bonhoeffer von Hefter die Entscheidung gefordert, er müsse sich entscheiden, „entweder Politiker oder Psychiater zu werden“, und ihm „versteckt gedroht“, daß sein Fortkommen an der Klinik „durch weitere, ähnliche öffentliche Betätigung in Frage gestellt“ sei. Man befand im Reichspropagandaministerium, „angesichts des bestehenden Streites zwischen Ärzten und Universitätsdozenten " müßten derartige Versuche, den „Zielen des nationalsozialistischen Staates entgegenzuwirken“, im „Keime erstickt“ werden, und forderte das Reichserziehungsministerium auf, ein Rundschreiben an alle Universitätsnervenkliniken zu veranlassen, wonach es Chefärzten untersagt werden sollte, die Propagandatätigkeit ihrer Assistenzärzte für „Erb- und Rassenpflege“ zu unterbinden ${ }^{117}$.

Als Hefter nach einem zwischenzeitlichen Forschungsaufenthalt in den USA seine Stelle als Voluntärassistent bei Bonhoeffer wieder aufnehmen wollte, lehnte dieser ab und setzte sich gegenüber dem NS-Dozentenbund durch ${ }^{118}$, der im Antwortschreiben darauf hinwies, man werde Bonhoeffers Nachfolger auf die besonderen Fähigkeiten dieses begabten Volontärarztes aufmerksam machen. Die Karriere Hefters verlief dann tatsächlich recht steil: 1936 wurde Hefter wissenschaftlicher Mitarbeiter im Berliner Hauptgesundheitsamt, 1938 Oberarzt an den Wittenauer Heilanstalten, 1942 dirigierender Arzt und verantwortlich für die Durchführung der „Euthanasie“-Aktion ${ }^{119}$.

Anders als Hefter konnte De Crinis an der Charité reüssieren, er wurde schließlich Bonhoeffers Nachfolger, jedoch erst nach längeren Auseinandersetzungen, die die Machtkämpfe des Dritten Reiches widerspiegeln, wobei Bonhoeffer zufolge das Erziehungsministerium auf der Seite der NSDAP, das Innenministerium auf seiten der SS stand ${ }^{120}$. Nach dem Zeugnis seiner Tochter blieb Bonhoeffer die letzten Dienstjahre (ab 1933) nur noch deshalb im Amt, um einen nationalsozialistischen Nachfolger zu verhindern ${ }^{121}$.

Das Berufungsverfahren für einen Nachfolger Bonhoeffers begann mit Berufungsvorschlägen sämtlicher Ordinarien des Deutschen Reiches. Bonhoeffer selbst schlug am 21.Januar 1938 seinen langjährigen Mitarbeiter Creutzfeld vor,

117 BAP, 15.01 RMdI 26227, Bl. 252, RMVP gez. Thomalla an RMdI, 23.2. 1934; ebenda, Bl. 272, RMVP gez. Haegert an REM, 14.4. 1934.

118 BAP, 49.01 REM 1355, Bl. 378, Verwaltungsdirektor der Charité an REM, 19.7. 1935, darin Begründung Bonhoeffers. Bonhoeffer hatte sich folgendermaßen über Hefters Forschungsprojekt geäußert: „Ob seine [Hefters] Absicht, die Wirkungen der Rassemischung auf den menschlichen Konstitutionstypus zu bearbeiten, innerhalb eines Jahres in wissenschaftlicher Weise sich wird durchführen lassen, ist mir zweifelhaft"; vgl. HUB, NK 8, Buchstabe H, Bonhoeffer an Verwaltungsdirektor der Charité, 29.6. 1935.

119 Krüger, Kinderfachabteilung, S. 156, 173.

$120 \mathrm{Mdl}$. Auskunft Prof. Dr. Ernst Kluge, 17.7. 1989.

121 Vgl. PAGJ, Interview Christine von Dohnanyi (1961). 
dessen Verdienste bei der Entdeckung der Creutzfeld-Jakob-Krankheit würdigend und dessen politischen Standpunkt - Creutzfeld war kein Nationalsozialist - aus naheliegenden Gründen verschweigend. Rüdin empfahl Kurt Pohlisch: „Ich kann mir nichts Besseres für die Berliner Regierung und Fakultät denken, als daß Sie diesen Mann für sich gewinnen, damit er auch dort [...] der neuen, für das Dritte Reich und die Reichshauptstadt so ungeheuer wichtigen Forschungs- und Lehrrichtung [.. .] zum Durchbruch verhelfe [...] er betreibt Erbbiologie am Krankenbett“122. Das Innenministerium und ein einziger Ordinarius, nämlich Carl Schneider, empfahlen das SS- und SD-Mitglied Maximilian de Crinis mit dem Argument, de Crinis habe "die weltanschaulichen Erkenntnisse des Nationalsozialismus in der Psychiatrie wissenschaftlich sich auswirken lassen “123. Die Fakultät setzte keinen der drei Genannten, sondern August Bostroem, Eduard Gamper und Ferdinand Kehrer auf die Berufungsliste und sah von de Crinis ab, weil er nicht die Gewähr biete, „den Belastungen der hiesigen Klinik gewachsen zu sein" ${ }^{\text {124. }}$.

Nun drängten NS-Dozentenbund und Reichsinnenministerium, die Berufungsliste im nachhinein zugunsten von de Crinis zu ändern, weil dessen vom Innenminister als „ausgezeichnet" beurteilte "Gerichtliche Psychiatrie ${ }^{\text {“125 }}$ von der Fakultät bisher nicht habe gewürdigt werden können. Die Fakultät bat Bonhoeffer um ein Gutachten über dieses Buch, dessen Urteil schlagkräftig und eindeutig ausfiel:

„Sehr verehrte Spectabilität!

Anliegend schicke ich Ihnen die von Herrn Minister bezeichnete gerichtliche Psychiatrie von de Crinis. Ich glaube nicht, daß de Crinis selbst diese Arbeit als eine ihn wissenschaftlich besonders qualifizierende bezeichnen würde. Es handelt sich um eine offenbar auftragsgemäß geschriebene Abhandlung, für die wahrscheinlich nur ein bestimmter Raum zur Verfügung stand. Das Buch hält sich ganz an der Oberfläche. Ich glaube kaum, daß Sie darin einen Anlaß finden werden, das bisherige Votum abzuändern. Das Buch [...] will ich nicht behalten!"126

Bestärkt durch diese Stellungnahme, änderte die Fakultät ihre Berufungsliste nicht. Dennoch wurde de Crinis zum 1. November 1938 vom Ministerium berufen. Mit Bonhoeffer verließen auch eine Reihe von Ober- und Assistenzärzten die Klinik, da sie es für „wenig erstrebenswert“ hielten, „unter einem SS-Mann

122 Nach Neumärker, Bonhoeffer, S. $175 \mathrm{f}$.

123 HUB, Bonhoeffer Personalakte, Bl. 378, Schneider an Dekan, 29.11. 1937.

124 Nach Neumärker, Bonhoeffer, S. 176. Der Assistenzärtin Lucie Brosowski zufolge hätte de Crinis es unter normalen Umständen mit etwas Glück zum Chefarzt einer kleinen Klinik bringen können, war aber mit der Leitung einer Universitätsklinik überfordert. So habe de Crinis sich grundlegende Tätigkeiten wie die Lumbal-Punktion von seiner Assistenzärztin beibringen lassen müssen; vgl. PAGJ, Interview, 30.1. 1961, S.39.

$125 \mathrm{Vgl}$. De Crinis, Gerichtliche Psychiatrie.

${ }^{126}$ HUB, Personalakte Bonhoeffer, Bl. 378, Bonhoeffer an Dekan, 25.5. 1938; vgl. auch Neumärker, Bonhoeffer, S. 176f. 
$\mathrm{zu}$ arbeiten " 127 , wurden von de Crinis durch SS-Leute ersetzt, so daß von Anfang 1933 bis Ende 1938 sämtliche Oberarzt- und die meisten Assistenzarztstellen mindestens ein-, wenn nicht mehrmals neu besetzt worden waren. Dies kostete die Klinik ihren Rang als eine der ersten deutschen, wenn nicht europäischen psychiatrischen Kliniken ${ }^{128}$.

Bonhoeffer war damit trotz erheblicher Bemühungen auf der ganzen Linie gescheitert. Sein Verein wurde "gleichgeschaltet" und, wenn auch eineinhalb Jahre später als andere psychiatrische Vereine, in den Dienst der „Erb- und Rassenpflege" gestellt. Die wichtigsten Zeitschriften wurden ihm genommen. Die jüdischen Assistenzärzte wurden entlassen, wenn auch zwei Jahre später, als das Gesetz es gebot. Die Klinik wurde von einem SS-Obersturmbannführer übernommen.

\section{Stellungnahmen zur Zwangssterilisation vor 1933}

Im folgenden werden die Stellungnahmen Bonhoeffers zur Frage der Zwangssterilisation wiedergegeben, die im Kontext der schwierigen und emotionalisierten Diskussion dieses Themas in der Weimarer Zeit ${ }^{129}$ sein betont sachliches, „neutrales“ und differenziertes Votum erkennen lassen. Bonhoeffer hat für eugenische Fragen kein besonderes eigenes Interesse aufgebracht, hat seine Mitarbeiterinnen und Mitarbeiter vor 1933 nicht darüber arbeiten lassen ${ }^{130}$ und ist gemeinsam mit der Berliner Fakultät für die Abschaffung des sozial- bzw. rassenhygienischen Lehrstuhls eingetreten ${ }^{131}$. Seine Stellungnahmen zur Zwangssterilisation

${ }^{127}$ Mdl. Auskunft Prof. Dr. Ernst Kluge, 17.7. 1989. Kluge ging mit dem Oberarzt Betzendahl nach Kiel. Ferner verließ der Oberarzt Jürg Zutt die Klinik.

${ }^{128}$ Bonhoeffer hat diesen Verlust selbst am schärfsten beobachtet. „Nachdem schon die Nazizeit und der Krieg uns eingeengt hat, werden wir weiter rückständig bleiben, wenn keine Aussprache unter den Fachleuten möglich ist. Das ist schmerzlich"; Focke, Begegnung Seidemann, S.137, Bonhoeffer an Seidemann, 10.7. 1947.

129 Die Rechtslage war nicht geklärt: Zum Tatbestand der Körperverletzung nach $\$ 224$ des deutschen Strafgesetzbuches von 1871 gehörten "Angriffe" auf eine fremde Person, die den Verlust der „Zeugungsfähigkeit" zur Folge haben. Die „Einwilligung" des Verletzten spielte bei Körperverletzungsdelikten keine Rolle (allerdings dachte man 1871 an „Mutproben“ oder Duelle). Die ersten Sterilisationen provozierten einen juristischen Interpretationsstreit, inwiefern die Sterilisation nach persönlicher Einwilligung als Körperverletzung nach $\$ 224$ strafbar oder als Operation nach den gültigen Einwilligungsregeln straffrei sei; vgl. die Übersicht bei Müller, Sterilisation, S. 53 f., dessen Ergebnis, Sterilisation auf Wunsch falle unter $\$ 224$, insofern unrealistisch ist, als Sterilisation auf Wunsch weit verbreitet war und vor 1933 nie verfolgt wurde.

${ }^{130}$ Vgl. die Bibliographien von Albrecht, Creutzfeld, Joßmann, Kramer, Pohlisch, Roggenbau, Schulte, Thiele und Zutt, in: BAP, 49.01 REM 1355, 1366. Von diesen hat überhaupt nur Pohlisch Vererbungsfragen ausführlich behandelt, aber $Z$ wangssterilisationen keineswegs im Sinne seiner späteren Arbeiten gefordert.

${ }^{131}$ Nach dem Tod des ersten Lehrstuhlinhaber (Grotjahn) erklärte die Fakultät einstimmig mit Bonhoeffers Stimme, daß "nicht nur [ . . . Kandidaten fehlen“, sondern ein Ordinariat für Sozialhygiene „überflüssig“ sei und durch einen Lehrauftrag für medizinische Statistik ersetzt werden solle, "weil dies allein als wissenschaftlich wohl fundierte Basis sozialhygienischer Forschung der Fakultät erscheint ${ }^{\text {", }}$, und verzichtete auf Benennung eines Kandidaten; vgl. HUB, Med. Fak. 42, Bl. 80, Fakultätsratsprotokoll, 19.1. 1932. Nachdem Chajes 1932 ernannt, 1933 als Sozialdemokrat je- 
waren jeweils nur Reaktionen auf Sterilisationsforderungen von anderer Seite. Sie erscheinen maßvoll und sind doch zugleich gegenüber der Zwangssterilisation entschieden kritisch.

Gleichzeitig sind sie - aus heutiger Sicht - an einer Stelle sehr angreifbar, nämlich im Sprachgebrauch. Begriffe wie „Rasse“, „Rassenverbesserung“, „minderwertig“ gehören auch zu seiner Terminologie (wie solche Begriffe als scheinbar neutrale termini technici - die aus heutiger Sicht doch sehr wohl anthropologische Konnotationen beinhalten - von den meisten Zeitgenossen unterschiedlichster politischer Provenienz als selbstverständlich verwendet wurden). Bereits Darwins vieldiskutiertes Hauptwerk „Über die Entstehung der Arten durch natürliche Zuchtwahl oder die Erhaltung der begünstigten Rassen im Kampfe um's Dasein" enthält mißdeutbare Begriffe, die jedoch der allgemein üblichen Wissenschaftssprache angehörten ${ }^{132}$. So bleibt die Frage offen, was einem kritischen Wissenschaftler an terminologischer Behutsamkeit abzufordern gewesen wäre - Bonhoeffer bleibt hier ganz und gar zeitgenössisch konform. Dagegen sind seine Voten inhaltlich bemerkenswert:

Im Jahre 1918 wurde Bonhoeffer aufgefordert, eine Stellungnahme zur Zulässigkeit des Schwangerschaftsabbruches abzugeben. Er erklärte, sie sei de lege lata nur bei Gefahr für das Leben oder die Gesundheit der Schwangeren zulässig, und nahm gegenüber der Forderung, den eugenisch indizierten Schwangerschaftsabbruch und die eugenisch indizierte Sterilisation durch Gesetzesänderung ebenfalls für zulässig zu erklären, ablehnend Stellung: „Hierzu ist zu sagen, daß unsere Kenntnisse über Vererbungsverhältnisse, über die degenerativen und regenerativen Faktoren uns bis jetzt für den Einzelfall nichts sicher Verwertbares geben. Es fehlt noch an Untersuchungen über den Lebensgang der Descendenten von Geisteskranken durch Generationen hindurch. Im ganzen besteht wohl eine zu pessimistische Betrachtungsweise. [...] Nach dem Stand unseres Wissens wird man zumindest vorläufig sagen müssen, dass dem Arzte nicht nur das Recht, sondern auch die Befähigung abgeht, in diesen Vererbungsfragen Vorsehung zu spielen. Der Arzt wird gut tun, sich in Sachen der Rasseverbesserung auf das ihm zukommende Gebiet zu beschränken. Tatsächlich ist das, was ihm hier in eugenischer Hinsicht zu tun bleibt, viel sicherer und erfolgversprechender als Schwangerschaftsunterbrechung und Sterilisation. Das grosse Gebiet der Lues [Syphilis] und des Alkoholismus gibt uns reichlich Arbeit" ${ }^{\text {"133. }}$.

doch von den Nationalsozialisten entlassen worden war, und das sozialhygienische durch ein rassenhygienisches Ordinariat ersetzt und mit Lenz besetzt werden sollte, erklärte die Fakultät wiederum einstimmig, „daß eine außerordentliche Professur genügt", und empfahl dafür Verschuer, der damals noch als gemäßigt galt; vgl. ebenda, Bl. 208, Fakultätsratsprotokoll, 19.10. 1933. Das Reichserziehungsministerium ernannte Lenz zum Ordinarius.

132 Beispielsweise wurde der Begriff „Rasse“ in einem naturwissenschaftlichen Sinn vor 1933 auch im jüdischen Lexikon benutzt, vgl. Art "Rasse, jüdische“, Jüdisches Lexikon IV, II, S. 1243-1247, und es gab eine zionistische Rassenhygiene; vgl. die sorgfältig differenzierende Untersuchung von Doron, Rassenbewußtsein.

${ }^{133}$ Bonhoeffer, Indikationen, S. 15. 
Damit erteilte Bonhoeffer dem Gedanken der eugenisch indizierten Sterilisation ebenso wie dem des eugenisch indizierten Schwangerschaftsabbruches eine Absage. - Noch im selben Jahr unterzeichnete Bonhoeffer eine „EntschlieBung“, wonach eugenische Heiratsverbote für "Geisteskranke“, wie von der Deutschen Gesellschaft für Rassenbygiene gefordert, nicht angebracht wären ${ }^{134}$.

1923 beauftragte der "Ausschuß für Bevölkerungspolitik und Rassenhygiene“ des Preußischen Landesgesundheitsrats (dessen Mitglied er war) Bonhoeffer mit der Erstellung eines Gutachtens über einen Antrag des Zwickauer Medizinalrates Gerhard Boeters ${ }^{135}$. Der Antrag von Boeters war, in Form eines Gesetzentwurfs, an die Sächsische Staatsregierung gerichtet und forderte die Zwangssterilisation sämtlicher Blind- und Taubgeborenen, außerdem aller „Blödsinnigen“, Epileptiker, „Geisteskranken“, Sittlichkeitsverbrecher, aller Personen, „die zwei oder mehrere uneheliche Kinder geboren haben“, und aller „Verbrecher" ${ }^{136}$. Dieser Antrag war - trotz der willkürlichen Zusammenstellung der Zielgruppen - in der Diskussion um die Einführung der Zwangssterilisation in der Weimarer Republik ein wichtiges Votum ${ }^{137}$ und fand auch in der Tagespresse ein breites Echo.

Bonhoeffer hingegen griff den Boeterschen Gesetzentwurf scharf an, und zwar an seinen schwächsten Punkten: Es würden „eugenische, kriminalistische und ärztliche Indikationsstellungen“ vermengt. Der Begriff "Geisteskrankheit" müsse vom psychiatrischen Standpunkt aus differenziert werden, da eugenische Sterilisation sinnvollerweise nur für diejenigen Geisteskrankheiten diskutiert werden könne, „deren vererbbare Natur feststeht ${ }^{\text {"138 }}$. Boeters These, die USA hätten bereits die Sterilisation von Sittlichkeitsverbrechern eingeführt, sei falsch, da es sich um die Kastration handele und diese auch in Deutschland nach gültiger Rechtslage zulässig sei, „wenn der seltene Fall vorliegt, daß der Patient auf keine andere Weise als durch die Operation von dem ihn und die Allgemeinheit schädigenden Leiden befreit werden kann" und außerdem die betreffende Per-

${ }^{134}$ BAK, R 86/2372, Bl. 53-58, Entschließung der wissenschaftlichen Deputation für das Medizinalwesen vom 8.5. 1918, unterzeichnet von Bonhoeffer, Bumm, Rubner, Neufeld, Krohne, Bier, Lentz, Krauss, Lubarsch, Hildebrandt, Strassmann, Dietrich, Noel, Schjerning und Heffter.

135 Der Text dieses Gutachtens, den Bonhoeffer als Eingangsreferat für die Sitzung vortrug, ist in der Literatur um die Vorgeschichte der Zwangssterilisation oft übersehen worden, weil die Originalakten des Preußischen Landesgesundheitsrates nicht erhalten sind und man die Debatte nur nach den Handakten des Vertreters des Reichsgesundheitsamtes verfolgen kann, in denen Bonhoeffers Gutachten nicht vorhanden ist; vgl. Weingart/Kroll/Bayertz, Rasse, S. 291 ff.; Schmuhl, Rassenhygiene, S. 102; Thomann, Weg, S.140f. Bonhoeffer hat sein Gutachten aber selbst veröffentlicht; vgl. ders., Unfruchtbarmachung. Es wurde nur von der Karl Bonhoeffer-Forschung rezipiert, die es ihrerseits unterließ, das Gutachten auf die Ausschußdiskussion zu beziehen; vgl. Neumärker, Bonhoeffer; Seidel/Neumärker, Bonhoeffer; Grell, Bonhoeffer. Klee nimmt weder Gutachten noch Ausschußdiskussion zur Kenntnis; vgl. ders., „Euthanasie“, S. 81; ähnlich in ders., „Geldverschwendung an Schwachsinnige und Säufer", Die Zeit vom 25.4. 1986, S.41-45; vgl. dazu auch den Leserbrief von H.E. Tödt, in: Die Zeit, 16.5. 1986, S.23.

136 Abgedruckt in: Kaiser/Nowak/Schwartz, Eugenik, S. 95 f.

${ }^{137}$ So Kaiser/Nowak/Schwartz, Eugenik, S. XIX; ähnlich Weingart/Kroll/Bayertz, Rasse, S. 246-253.

${ }^{138}$ Im folgenden nach Bonhoeffer, Unfruchtbarmachung. 
son „einverstanden“ ist. Den Ausgangspunkt für Bonhoeffers Argumentation bildet das Persönlichkeitsrecht des Einzelnen:

„Ein so schwerer Eingriff des Staates in das Persönlichkeitsrecht des Individuums rechtfertigt sich nur, wenn das höhere Rechtsgut des Schutzes der Allgemeinheit ihn erforderlich macht, weil andere gangbare, zum gewollten Ziele führende Wege nicht zur Verfügung stehen.“

So setzt Bonhoeffer für den Normalfall die Gültigkeit des Persönlichkeitsrechtes voraus. Nur im Ausnahmefall hält er einen Eingriff in das Persönlichkeitsrecht aufgrund eines ordnungsgemäß vom Parlament verabschiedeten Gesetzes für zulässig - sicherlich ist dabei an die Rechtslage nach Art.114 der Weimarer Verfassung gedacht ${ }^{139}$. Darüber hinaus verlangt er, daß die Notwendigkeit eines solchen Eingriffes für den Schutz der Allgemeinheit in jedem Einzelfall zwingend nachgewiesen werde. Dabei ist es von heute aus betrachtet juristisch nicht unproblematisch, wenn er den Schutz der Allgemeinheit höher bewertet als den Schutz des einzelnen, läßt sich die Verletzung von Persönlichkeitsrechten doch nicht in der Weise aufrechnen, daß die Verletzung des Rechtes eines einzelnen leichter wiegen als die Verletzung der Rechte von vielen. Doch muß eine Interpretation schon Bonhoeffers Nebensatz zum Hauptsatz machen, um hier eine pauschale Unterordnung des Persönlichkeitsrechtes des einzelnen unter die Rechte der Allgemeinheit zu sehen ${ }^{140}$. Im Ergebnis nähert Bonhoeffer sich einer etwa aus dem Seuchenschutz bekannten Position an, wenn bei nachgewiesener Ansteckungsgefahr für die Allgemeinheit unter gewissen Umständen die Freizügigkeit eingeschränkt werden kann. Ähnlich will Bonhoeffer auch hier den Befürwortern der Zwangssterilisation die naturwissenschaftliche Beweislast zumuten und bewertet alle Unklarheiten der Vererbungswissenschaft als Argument gegen die Zwangssterilisation, wie sich in seinen folgenden Ausführungen gegen Boeters zeigt:

Die „Zunahme der Frequenz der Geisteskrankheiten“ werde zwar „vielfach behauptet", habe sich aber bisher statistisch nicht nachweisen lassen. Die Zunahme der Anstaltsaufnahmen in der Vorkriegszeit hänge ebenso wie die Abnahme seit 1918 von „wirtschaftlichen Gründen“ ab. Bei den einzelnen in Frage kommenden Krankheiten ergäben sich Probleme. Bei Schizophrenie sei der Erbgang "nicht vollständig geklärt“, aber „wahrscheinlich rezessiv“. Nach neueren Erhebungen seien auf 50 schizophrene Großeltern nur ein schizophrener Enkel gekommen, das sei eine "geringe Erkrankungswahrscheinlichkeit" und lasse die Sterilisation Schizophrener eugenisch irrelevant erscheinen. Bei manisch-depressiver Veranlagung sei die Wahrscheinlichkeit zwar größer, aber die Sterilisation komme

\footnotetext{
139 Siehe S. 47 Anm. 197.

${ }^{140}$ So resümieren Neumärker/Seidel, Bonhoeffer, S. 273: „Kein prinzipielles ethisches Urteil, keine ärztliche Interessenabwägung zugunsten der persönlichen Integrität und Würde der dem Arzt anbefohlenen Patienten veranlaßten Bonhoeffer im Jahre 1923 zu äußern, ihm scheine beim Stand der Dinge die zwangsweise Sterilisation, nicht geboten', sondern die Skepsis gegenüber der Effizienz eines solchen Vorhabens."
} 
„wegen ihrer großen Verbreitung und den fließenden Übergängen zur Norm“ nicht in Betracht. Außerdem fände sich hier ein „Einschlag von Künstlertum und geistig Hochwertigem“, der wünschenswert sei. Genuine Epilepsie sei „in ihrem Erbgang nicht geklärt“, angeborener Schwachsinn „mindestens“ zu einem Drittel nicht erblich. Die Betroffenen bekämen aber nach einer eigenen Untersuchung ${ }^{141}$ ohnehin meist keine Kinder. Die Mehrzahl der psychisch kranken Menschen lebe außerhalb von Anstalten, ihre Zwangssterilisation sei „unmöglich“.

Die eugenische Sterilisation auf Wunsch erklärt Bonhoeffer - de lege lata - für "zulässig und in gewissem Sinne geboten“, wenn man sie gegen Mißbrauch schütze. Als Beispiel für einen „Mißbrauch“ nennt er nicht die Sterilisation aus sozialen Gründen, sondern die von Armenbehörden durch Privatärzte durchgeführte Sterilisation junger Mädchen, „weil sie ihnen durch uneheliche Kinder lästig werden“. Diesen Mißbrauch solle man dadurch verhindern, daß nur staatlich zugelassene Stellen, und zwar durch Rechtsverordnung, berechtigt würden, eine Sterilisationsoperation durchzuführen.

Bonhoeffer faßte sein Gutachten in acht Leitsätzen zusammen ${ }^{142}$ :

„1. Die Vorschläge des Herrn Boeters sind nicht geeignet als Unterlagen für Maßnahmen der Gesetzgebung und Verwaltung zu dienen.

2. Die Praxis der in Amerika und in der Schweiz geübten operativen Unfruchtbarmachung zeigt neben den eugenischen vielfach von der Vererbungsfrage unabhängige medizinisch-therapeutische und kriminalpolitische Gesichtspunkte. Die gesammelten Erfahrungen ergeben die Ungefährlichkeit der Operation, bei sachgemäßer Ausführung das Ausbleiben schädlicher Folgewirkungen bei den Operierten.

3. Die eugenische Indikation muß ihr Anwendungsgebiet auf vererbbare Krankheiten und Defektzustände beschränken.

4. Die Berechtigkeit der Operation ist davon abhängig zu machen, daß der krankhafte Zustand des zu Operierenden auch mit erheblicher Wahrscheinlichkeit bei den Nachkommen zu erwarten ist.

${ }^{141} \mathrm{Vgl}$. Bonhoeffer, Kenntnis des großstädtischen Betteltums. Eine Analyse dieser Arbeit, die in zeitgeschichtlichem Kontext mit der soziologischen Strafrechtsschule v. Listzs (Individualprävention) steht, kann hier nicht geleistet werden. Grell, in: Totgeschwiegen², S. 239, meint, Bonhoeffer habe die sozialen Phänomene Bettelei und Diebstahl aufgrund einer medikalisierenden Betrachtungsweise pathologisiert. Wir interpretieren gegenläufig: Diejenigen Obdachlosen, die Bonhoeffer um 1900 als "schwachsinnig“ oder als Epileptiker ansah, würden auch nach heutigen medizinischen Maßstäben als geistig Behinderte oder Epileptiker gelten. Doch würden sie ihren Lebensunterhalt nicht durch Bettelei und Diebstahl verdienen müssen, und im Falle einer Straffälligkeit nicht mit Zuchthaus bestraft, sondern, wie von Bonhoeffer gefordert, wegen eingeschränkter $\mathrm{Zu}$ rechnungsfähigkeit in eine Anstalt eingewiesen werden. Unseres Erachtens bildet nicht der medikalisierende Blick auf das Soziale, sondern der soziale Umgang mit dem „Medizinischen“, mit Krankheit und Behinderungen, das eigentliche Problem. Derselbe Personenkreis, der um 1750 als "Dorftrottel“ mehr oder minder in die Dorfgemeinschaft integriert lebte, landete um 1900 als straffälliger Obdachloser im Zuchthaus, um 1960 als "Anstaltsinsasse“ in einer "Anstalt" und heutzutage vielleicht in einer "betreuten Wohngemeinschaft".

142 Diese werden hier erstmals ganz veröffentlicht; BAK, R 86 Reichsgesundheitsamt 2374, Bl. 35; vgl. bisher Thomann, Weg, S.140f. 
5. Eine einschneidende Wirkung auf die Beseitigung der in Betracht kommenden Krankheiten würde auch bei weiterer Ausdehnung des Anwendungsgebietes, etwa im Sinne der Boetersschen Vorschläge, nicht zu erwarten sein.

6. Einer $z$ wangsweisen Unfruchtbarmachung von staatswegen ist grundsätzlich zu widerraten.

7. Die Zulassung der Unfruchtbarmachung mit Zustimmung des zu Operierenden (im Falle der Geschäftsunfähigkeit unter Schaffung der erforderlichen Kautelen) ist bei dem Vorliegen der oben gegebenen Indikation zulässig und in manchen Fällen erstrebenswert.

8. Es empfiehlt sich, daß nur bestimmte, von staatswegen zu bezeichnende Organe zur eugenischen Indikationsstellung und Ausführung zugelassen werden."

Der Ausschuß (weitere Mitglieder waren Max Hirsch, die Professoren Gottstein, Goldschmidt, Grotjahn, Poll, Westenhöfer und Baur, sowie je ein Vertreter des Reichsgesundheitsamtes und des Preußischen Justizministeriums) folgte Bonhoeffers Antrag, keine Empfehlung zur Erarbeitung eines Sterilisationsgesetzes abzugeben. Aber einige Ausschußmitglieder meinten doch, daß Bonhoeffers Fassung der Leitsätze den „Negativismus“ gegenüber der Sterilisation „für die Zukunft mit allzu großer Sicherheit festlege", und schlugen daher einige Neuformulierungen vor, die von der Ausschußmehrheit gegen Bonhoeffers Stimme verabschiedet wurden. Satz 5 und 6 hießen nunmehr:

„5. Die bisherigen klinischen und Erbforschungserfahrungen ergeben bei den einzelnen psychischen Krankheiten und krankhaften Zuständen vorläufig [!] einen ganz geringen Umkreis von Krankheiten, die unter diesem Gesichtspunkt für die Unfruchtbarmachung in Betracht kommen.

6. Einer zwangsweisen Unfruchtbarmachung von staatswegen ist vorläufig [!] zu widerraten ${ }^{1143}$.

Bonhoeffer hat es in seinen Lebenserinnerungen als einen Erfolg angesehen, daß der Ausschuß keine Empfehlung zur Verabschiedung eines Sterilisationsgesetzes abgab ${ }^{144}$. Diese Einschätzung besteht zu Recht. Wohl aber haben etliche Ausschußmitglieder nur taktiert, was Bonhoeffer nicht übersehen hat: So hatte der Präsident des Reichsgesundheitsamtes Bumm kurz zuvor in einer handschriftlichen Aktennotiz "auch aus taktischen und innenpolitischen Gründen“ davor gewarnt, „in dieser Zeit großer Beunruhigung und außerordentlicher Reizbarkeit des deutschen Volkes" mit einer Gesetzesvorlage seitens der Reichsregierung hervorzutreten ${ }^{145}$. Und Ausschußmitglied Alfred Grotjahn trat anderen Ortes dafür ein, bis zur Einführung der $Z$ wangssterilisation noch einige Jahre abzuwarten ${ }^{146}$. Vor diesem Hintergrund muß die Änderung des einen kleinen Adverbs aus Satz 6 von "grundsätzlich" in "vorläufig" als eine nachhaltig schwerwiegende

\footnotetext{
143 BAK, R 86 Reichsgesundheitsamt 2374, Bl. 35.

144 Bonhoeffer, Lebenserinnerungen, S. 101.

145 Stellungnahme vom 15.10. 1923 nach Thomann, Weg, S.138.

146 Grotjahn, Hygiene, S.319. Zu Grotjahn vgl. Dieckhöfer/Kaspari, Tätigkeit; Kaspari, Eugeniker.
} 
Anpassung an den Kurs der Deutschen Gesellschaft für Rassenbygiene beurteilt werden. Diese hatte in $\$ 27$ ihrer 1922 aufgestellten Leitsätze erklärt, daß die Zeit für Zwangsmaßnahmen "noch nicht reif“ sei ${ }^{147}$. Einer der beiden Verfasser, Fritz Lenz (der zweite war Rüdin), begründete dies derart: „Durch Eintreten für zwangsmäßige Sterilisation schadet man nur der guten Sache“ ${ }^{148}$. Und: „Mit Rücksicht auf die noch fehlende biologische Einsicht unserer Regierungen und Volksvertretungen sowie der öffentlichen Meinung überhaupt, glaube ich aber der gesetzlichen Einführung der zwangsmäßigen Sterilisierung einstweilen widerraten zu müssen “149. Doch nicht in allen Stellungnahmen wurde so deutlich, $\mathrm{da} ß$ der vorläufige Widerspruch gegenüber $Z$ wangsmaßnahmen nur taktisch bedingt war. Bonhoeffer erinnerte sich noch Jahrzehnte später nur an das Ergebnis, daß nämlich führende Erbbiologen wie Rüdin und Luxenburger sich noch 1932 gegen Zwangssterilisationen ausgesprochen hatten ${ }^{150}$. Er rätselte sogar, ob Rüdin 1933 nicht von den Nationalsozialisten „umgestimmt“ oder „unter Druck gesetzt" worden sein könnte ${ }^{151}$. Diese Fehleinschätzung belegt, wie sehr er die taktische Argumentation, aber auch den Fanatismus seiner Kollegen unterschätzte.

Erneut wurde die Sterilisationsfrage 1932 vor dem Preußischen Landesgesundheitsrat verhandelt. Bonhoeffer war "durch eine Reise verhindert ${ }^{\text {“152, an }}$ der Sitzung teilzunehmen, äußerte sich aber schriftlich, indem er dem Vorsitzenden mit einem Sonderdruck der Klinischen Wochenschrift sein Gutachten von 1923 einsandte ${ }^{153}$. Bei dieser Sitzung war keine einhellige Meinung zu erreichen. Die meisten Teilnehmer sprachen sich weder ausdrücklich für noch ausdrücklich gegen Zwang aus. Die Breslauer Ärztin Clara Bender war die einzige,

147 Vgl. Leitsätze, in: Archiv für Rassen- und Gesellschaftsbiologie 14 (1922), S. 372-375.

148 Vgl. Lenz, Soziale Notwendigkeit, S. 439.

149 So Lenz, in: Baur/Fischer/Lenz, Grundriß II ${ }^{2}$, S. 278.

150 Bonhoeffer, Rückblick Sterilisationsgesetz, S.1. Bock, Zwangssterilisation, S.192 Anm. 27, behauptet demgegenüber, Bonhoeffers Erinnerung könne kein Gewicht zukommen, weil es sich nur um „privat" geäußerte Ansichten Rüdins und Luxemburgers gehandelt habe. Tatsächlich sind diese aber durchaus veröffentlicht; vgl. Rüdin, Ergebnisse; Luxenburger, Sterilisation. Luxenburger hat sich sogar noch im Juni 1933 in einer bereits dem Verlag zugeschickten Stellungnahme gegen Zwang ausgesprochen, was man im Reichsinnenministerium als Kritik am Erbgesundheitsgesetz las; vgl. BAP, 15.01 RMdI 26248, Bl. 395, Gütt an Rüdin, 1.10. 1933. Rüdin beruhigte das Ministerium, dieses Votum sei dadurch zu erklären, daß Luxenburger die Pläne zum Erbgesundheitsgesetz nicht gekannt habe. Selbstverständlich befürworte Luxenburger Zwangssterilisationen und sei bereit, die Druckfahnen zu ändern [!]; vgl. ebenda, Bl. 388, Rüdin an Gütt, 9.8. 1933.

151 Bonhoeffer, Lebenserinnerungen, S. 102.

152 Ostermann, Eugenik, S.241. Gleichwohl ist Bonhoeffer aufgrund einer Unaufmerksamkeit des Protokollanten als anwesend verzeichnet; vgl. Eugenik im Dienste, S.1. Ein solch kleiner FauxPas ist in der Literatur gleich zu weiteren Spekulationen ausgeufert: Die Notiz im Protokoll, der Ausschußvorsitzende habe aus dem Schweigen „einiger prominenter Fachleute" auf deren Zustimmung geschlossen, inspiriert Bock, Zwangssterilisation, S.65 Anm. 75, in ihrem Gefolge auch Grell, in: Totgeschwiegen ${ }^{2}$, S. 237, zu der Feststellung, der Vorsitzende habe vom Schweigen Bonhoeffers und einiger anderer prominenter Fachleute gesprochen. Tatsächlich erklärt sich Bonhoeffers Schweigen durch seine Abwesenheit.

153 Eugenik im Dienste, S. 100. Nach diesem Protokoll wird im folgenden zitiert. 
die zwar für eine gesetzliche Neuregelung der Sterilisation eintrat, aber diese im Entscheidungsprozeß allein von den Betroffenen, bei „breitestem Spielraum und Rechtsschutz" und unter Verzicht auf eine Indikationsfeststellung, bestimmt sehen wollte ${ }^{154}$. Offen für $Z$ wangssterilisationen plädierten der juristische Sachverständige Graf zu Dohna ${ }^{155}$, der sozialdemokratische Gesundheitspolitiker und Inhaber des Berliner Lehrstuhls für Sozialhygiene Benno Chajes ${ }^{156}$, der Vorsitzende des Preußischen Medizinalbeamtenvereins Bundt ${ }^{157}$ und die Nationalsozialisten Diel ${ }^{158}$ und Conti ${ }^{159}$. Beispielhaft für die „Mittelpositionen“ ist die des Juristen Kohlrausch: Er wollte die eugenische Sterilisation "vorläufig" mit der Erfordernis der Zustimmung des „zu Sterilisierenden“ verbunden wissen ${ }^{160}$. Ein Unterausschuß einigte sich auf einen Gesetzesentwurf, der Anstaltsleitern das Recht einräumte, einen Sterilisationsantrag zu stellen, aber die Zustimmung des Betroffenen, gegebenenfalls auch des gesetzlichen Vertreters, verlangte ${ }^{161}$. Die Sterilisation gegen den Willen eines Betroffenen wie auch die Sterilisation aus sozialen Gründen sollte verboten $\operatorname{sein}^{162}$. Der Indikationenkatalog zählt erbliche Geisteskrankheit, erbliche Geistesschwäche, erbliche Epilepsie, eine "sonstige“ Erbkrankheit und krankhaftes Erbgut als Sterilisationsgrund auf ${ }^{163}$.

Nachdem Bonhoeffer zurückgekehrt war, argumentierte er nicht mehr grundsätzlich gegen den Gesetzesentwurf, sondern beschränkte sich in einem Schreiben an den Präsidenten des Preußischen Landesgesundheitsrates auf Änderungsvorschläge: „In $\ 1$ halte ich die Einfügung der erblichen Sucht für nicht begründet. Eine erbliche Sucht gibt es nach meiner und außerordentlich vieler Kliniker

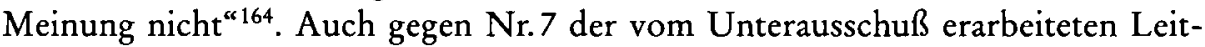
sätze, „Die Indikation zur Sterilisierung ist gegeben bei Schizophrenen,“ habe er Bedenken, da sie „zu radikal“ erscheine. Erblich sei höchstens eine Kerngruppe der Schizophrenie. Wenn dort behauptet werde, daß die „Zahl der seelischen Erkrankungen der Nachkommen Schizophrener" bei „etwa $50 \%$ " liege, sei das viel zu hoch angesetzt. Die Sterilisation von „Psychopathen“ ausdrücklich zu fordern, erscheine nicht angemessen, denn man solle sich "nicht dem Vorwurf aussetzen, daß man die Psychopathen überhaupt als etwas Auszurottendes betrach-

154 Ebenda S. 100.

155 Ebenda S. 63 .

156 Ebenda S. 88.

157 Ebenda S. 85.

158 Ebenda S. 93.

159 Ebenda S. 59.

160 Ebenda S. 51.

161 Ebenda S. 108.

162 Die „ständige Konferenz" der Inneren Mission wollte diesen Entwurf um eine Bestimmung verschärft wissen, wonach die Zustimmung von Pfleglingen bzw. Entmündigten durch die des Pflegers/Vormunds ersetzt werden könne; vgl. Kaiser, Sozialer Protestantismus, S. 339.

163 Ebenda S. 107.

164 Vgl. HUB, NK 37, Bonhoeffer an Präsidenten des Landesgesundheitsrates, 17.8. 1932. Der später gedruckte Gesetzesentwurf enthält den von Bonhoeffer kritisierten Indikationsgrund „erbliche Sucht“ tatsächlich nicht; vgl. Eugenik im Dienste. Hat Bonhoeffer hier Erfolg gehabt? 
tet". Dagegen machte Bonhoeffer den Vorschlag, das Gesetz so zu formulieren, daß im Falle der Rücknahme einer zuvor erteilten Einwilligung durch Geisteskranke während der Vorbereitungen zur Operation das weitere Vorgehen dem Ermessen des Arztes zu überlassen sei.

Auch wenn der Gesetzesentwurf breite Zustimmung bei den Parteien bis in die Sozialdemokratie hinein fand ${ }^{165}$, kam es in den Wirren des Jahres 1932 nicht mehr zu einer amtlichen Rezeption. Die einzige offizielle Würdigung des Entwurfes erfolgte bereits 1933 in der Begründung des Erbgesundheitsgesetzes. Dort wurde behauptet, daß bereits der Landesgesundheitsrat auf seiner Tagung am 2.Juli 1932 nach Anhörung von über hundert Sachverständigen die „Maßnahme der Sterilisierung zur Förderung der Erbgesundheit gebilligt" habe ${ }^{166}$. Die wichtigsten Unterschiede zwischen dem Gesetzesentwurf von 1932 und dem Erbgesundheitsgesetz - die neuartige Indikationsfestschreibung, die Meldepflicht von „Erbkrankheiten“ und die Zwangsmaßnahmen - wurden verschwiegen. Trotz der Unterschiede wird in der Forschung die Kontinuität zwischen dem Entwurf von 1932 und dem Erbgesundheitsgesetz stark betont ${ }^{167}$. Doch konnte sich der Entwurf noch als „a compromise among the postulate of the eugenicists, the exegencies of legal nature, and the ethical belief of the population" ausnehmen ${ }^{168}$ und etwa in Kraemers "Kritik der Eugenik vom Standpunkt des Betroffenen" gerade noch akzeptiert werden. Das Erbgesundheitsgesetz hingegen lag weit jenseits eines solchen Kompromisses.

Bonhoeffers durch die Zeitläufte überholten Einwände gegenüber dem Entwurf entsprachen inhaltlich in etwa denen Kraemers, der sich auch auf ihn berief ${ }^{169}$. Dennoch sind seine Äußerungen heute zu Recht der Kritik ausgesetzt, da er eine eindeutig ablehnende Haltung gegenüber der Eugenik habe vermissen lassen. In der vorliegenden Arbeit wurde versucht, Bonhoeffers Haltung in den jeweiligen Situationen bzw. zu den einzelnen Problemen detailliert darzulegen, doch sei noch einmal der Gesamteindruck wiedergegeben: Bonhoeffer betonte schon 1918 seine klare Ablehnung von eugenischem Schwangerschaftsabbruch, Sterilisation und Eheverboten, die er 1923 gegenüber dem Antrag von Boeters, der die Zwangssterilisation vorsah, bekräftigte. In juristischer Hinsicht argumentierte er mit dem unveräußerlichen Persönlichkeitsrecht jedes Einzelnen gegenüber dem Zugriff des Staates. Von daher kam der Naturwissenschaft, wollte sie eine Ausnahme rechtfertigen, eine schwere Beweislast zu. Bonhoeffers medizini-

165 Vgl. Fürth, Entvölkerung, Vorwärts vom 4.1. 1933, in: BAP, 15.01 RMdI 26227, Bl. 40. Dort auch die Einschätzung: „Sogar die zur Stunde sehr konservative Ärzteschaft hat sich für ein Gesetz zur Ordnung der Frage der Sterilisation ausgesprochen."

166 Zit. nach Ristow, Erbgesundheitsrecht, S.284.

${ }^{167} \mathrm{Vgl}$. Kaiser/Nowak/Schwartz, Eugenik, S. XIX; Weingart/Kroll/Bayertz, Rasse, S. $468 \mathrm{f}$.

${ }^{168}$ So nach der Flucht in die USA der bedeutendste deutsche Vererbungswissenschaftler Goldschmidt, Ivory Tower, S.231.

${ }^{169}$ Kraemer, Kritik, S. 24. Kraemer würdigte einen nicht mehr erhaltenen Rundfunkvortrag vom 24.1. 1933, in dem Bonhoeffer die Sterilisation von "Psychopathen" mit dem Argument ablehnte, diese seien der „Sauerteig der Gesellschaft“; ebenda, S. 35. 
sches Urteil nötigte ihn an dieser Stelle, "grundsätzliche“ (nicht nur „vorläufige") Zurückhaltung zu üben. Das rechtlich wie medizinisch verantwortungsbewußte Votum, das Bonhoeffer damit abgab, brachte ihn 1932 in eine Minderheitsposition. Er versuchte, von einer gesetzlichen Regelung abzuraten, bzw. das Ergebnis abzumildern. Seine strikte Ablehnung von Zwangsmaßnahmen weichte er nur an einer Stelle auf: die Rücknahme einer bereits erteilten Einwilligung wollte er dem Ermessen des Arztes überlassen, wobei er nicht berücksichtigte, daß Einwilligungen auch durch Überreden, indirekten oder direkten Druck von Eltern, Angehörigen oder Anstaltsleitern zustande kommen konnten.

\section{Einsatz für die Entschärfung des Gesetzes durch alternative Diagnostik}

„Das Gesetz vom 15. Juni 1933 ging über alle bis dahin gemachten Vorschläge und anderwärts bestehenden gesetzlichen Regelungen hinaus durch die Einführung des Zwanges. [...] Die Gefahr von Fehlurteilen durch unzulänglich ausgebildete Ärzte war groß, um so mehr die Zugehörigkeit zur Partei als die fachliche Qualifikation Berücksichtigung fand. Im eigenen Umkreis erfuhr ich dies, als einer meiner jungen, psychiatrisch noch unerfahrenen Volontäre meiner Klinik mitteilte, daß er auf Veranlassung des Ärzteführers Conti zum fachärztlichen Mitglied des Erbgesundheitsgerichts ernannt worden sei. Er war einsichtig genug, auf meine Veranlassung diese Stelle sofort wieder niederzulegen. Es kann wohl als sicher angenommen werden, daß sich vielen Orts keine ausgebildeten Psychiater fanden. An eine Rücknahme des Zwangsgesetzes war bei der Mentalität des Nationalsozialismus nicht zu denken. So blieb nur die Möglichkeit, zu hemmen und auf psychiatrischen Lehrgängen auf die besonderen diagnostischen Schwierigkeiten im Erbgesundheitsverfahren hinzuweisen. Während ich im Hinblick auf meine akademischen Aufgaben nach Möglichkeit mich der gerichtlichen psychiatrischen Tatigkeit entzogen hatte, schien es mir nun geboten, in dem Erbgesundheitsobergericht die Stelle des sachverständigen Psychiaters zu übernehmen, um Einfluß auf die Begutachtung der Gerichte zu übernehmen. Tatsächlich ist, wie mir von vielen Seiten bestätigt wurde, das Ergebnis gewesen, daß in Berlin und auch in den Provinzen die diagnostische Beurteilung vorsichtig gehandhabt wurde. Daß die Tätigkeit der Berliner Klinik auf dem Gebiete der erbbiologisch-psychiatrischen Lehrgänge und der entsprechenden Publikationen im Braunen Haus in München unangenehm empfunden wurde, ergab sich daraus, daß die Kurse nach zweijährigem Bestehen vom Innenministerium nicht mehr gestattet wurden ${ }^{\alpha 170}$.

${ }^{170}$ Bonhoeffer, Lebenserinnerungen, S. 102. 
So schilderte Bonhoeffer autobiographisch seine Erinnerungen an das Erbgesundheitsgesetz und dessen Konsequenzen. Im folgenden soll sein Bericht anhand der Quellen überprüft werden ${ }^{171}$.

Die Situation hatte sich gewandelt: Wenn Bonhoeffer vor 1933 durch gute Beziehungen zur Ministerialbürokratie seinen Einfluß hatte ausspielen können, so fehlten ihm nunmehr, nach der Entlassung der leitenden Beamten des Innenministeriums und ihrer Ersetzung durch altverdiente Nationalsozialisten, die Ansprechpartner, die für ein vertrauliches Gespräch geeignet gewesen wären. In einem Brief an einen Kollegen ließ Bonhoeffer durchblicken, daß ihm die Urheber des Gesetzes wegen ihrer mangelnden medizinischen Qualifikation suspekt waren: „Welche Gründe den Gesetzgeber bewogen haben, daß 10. Lebensjahr für die Operation anzusetzen, weiß ich auch nicht. Bei der Vorbereitung des Gesetzes sind Psychiater außer Rüdin nicht mehr dabei gewesen. Ich glaube, die Dinge sind im übrigen ausschließlich von den Herren des Reichsinnenministerium bearbeitet worden. $\mathrm{Ob}$ ein Gynäkologe zugezogen worden ist, ist mir zweifelhaft" ${ }^{\text {"172 }}$.

Einer der wenigen, zu dem noch ein Vertrauensverhältnis bestand, war der Präsident des Reichsgesundheitsamtes, Hans Reiter, der zuvor einmal die Hygiene-Professur in Berlin innegehabt hatte. Auf dessen Anfrage an Bonhoeffer, wie man die Zahl aller vom Gesetz betroffenen Geisteskranken erheben könnte ${ }^{173}$, antwortete dieser, eine genaue Erhebung sei angesichts der unpräzisen Ausführungsbestimmungen nicht möglich. Doch erlaube er sich bei der Gelegenheit, einige Vorschläge zur „Präzisierung“ zu machen: „Es bestehen doch allerhand Zweifel im einzelnen, z.B. ob bei 1), dem angeborenen Schwachsinn, wirklich alle Schwachsinnigen gemeint sind oder nur die Erbschwachsinnigen. [...] Bei 2) und insbesondere bei 3) Manisch-Depressivem, werden Erläuterungen erforderlich sein, über die bei diesen Stämmen nicht ganz selten vorkommenden geistig hochwertigen Stämme und inwieweit diese geschont werden müssen. Bei $3 \mathrm{c}$ ) wird es sich vielleicht empfehlen, in der Klammer ein ,auch 'einzufügen, so daß es lautet, ,auch wegen des höheren Lebensalters', damit ganz klar zum Ausdruck kommt, dass die Unfruchtbarmachung auch aus anderen Gründen unterbleiben kann" 174 .

Bonhoeffers Taktik ist deutlich: Er macht Reiter, der kurz zuvor Zwangssterilisationen noch abgelehnt hatte ${ }^{175}$, einen Vorschlag, wie dieser das Gesetz entschärfen könne. Sehr gewichtig ist dabei Bonhoeffers Vorschlag, die Ziffer $3 \mathrm{c}$ der Durchführungsbestimmung durch ein unscheinbares „auch“ zu ergänzen.

\footnotetext{
171 Es gehört zum methodisch legitimen Zweifel, Tatsachenberichten in Autobiographien aus der Zeit des Nationalsozialismus nicht ungeprüft Glauben zu schenken. Freilich darf dieser Zweifel auch nicht die Prüfung ersetzen; so bei Grell, Bonhoeffer.

172 HUB, NK 40, Bonhoeffer an „Sehr geehrter Herr College“, 19.6. 1934.

173 HUB, NK 37, Reiter an Bonhoeffer, 11.9. 1933.

174 Ebenda, Bonhoeffer an Reiter, 20.9. 1933.

175 Siehe S. 42f. Anm. 167.
} 
Die Kann-Bestimmung in $\$ 1$ des Gesetzes („Wer erbkrank ist, kann unfruchtbar gemacht werden"; Hervorhebung U.G.) soll nach Bonhoeffer in der Durchführungsbestimmung möglichst weit interpretiert werden (eine Sterilisation könne „auch wegen des höheren Lebensalters" - aber auch aus anderen Gründen - unterbleiben). Damit war eine Interpretation ermöglicht, wonach die Zwangssterilisation zwar nicht grundsätzlich ausgeschlossen war, aber Gutachter und Gerichte sie nach freiem Ermessen hätten ablehnen können ${ }^{176}$. - Ob Reiter Bonhoeffers Vorschlag akzeptierte, ist nicht bekannt; aber die am 5. Dezember 1933 veröffentlichten Ausführungsbestimmungen lassen von Bonhoeffers Anregungen nichts erkennen ${ }^{177}$.

\section{Vorträge und Aufsätze zur Diagnostik}

Über den Kommentar von Gütt/Rüdin/Ruttke, der Anfang 1934 die Indikation festschrieb, soll Karl Bonhoeffer sich mündlich verschiedentlich mokiert haben $^{178}$. Seine Möglichkeiten, sich öffentlich zu äußern, waren hingegen durch die Zensur stark eingeschränkt. Jederzeit konnte der Beauftragte des Führers für das medizinische Schrifttum Klare, in Personalunion auch stellvertretender Reichsärztefübrer, die Verfasser oder Herausgeber unerwünschter medizinischer Schriften zur Rechenschaft ziehen ${ }^{179}$. Darüber hinaus mußte ab November 1933 jede die „Erb-und Rassenpflege“ betreffende Schrift vor Drucklegung vom Aufklärungsamt für Bevölkerungspolitik und Rassenpflege, einer zum Stab des Stellvertreters des Führers gehörenden Institution, genehmigt werden. Bonhoeffer nutzte die verbleibenden Möglichkeiten zur Umgehung der Zensur, indem er in seinen wissenschaftlichen Beiträgen auf eugenische Fragen scheinbar nur beiläufig einging und indem er aus eigener Initiative Fortbildungskurse für Ärzte, Richter und Studenten abhielt, auf denen er seine Diagnostik der vom Sterilisationsgesetz betroffenen Krankheiten vorstellte. Bonhoeffers Intention war dabei, die Diagnosen inhaltlich und sprachlich. möglichst differenziert zu halten, um vor allem durch sachliches Unterscheidungsvermögen, aber auch durch terminologisches Geschick den Weg in die Sterilisation möglichst oft zu verhindern. Diese Kurse wurden als Tagungen der Berliner Gesellschaft für Neurologie und Psychiatrie organisiert, auf deren "Gleichschaltung" man mangels Interesse verzichtet hatte ${ }^{180}$. Zunächst tolerierte das Regime sogar die Drucklegung der Ta-

${ }^{176}$ Die Kann-Bestimmung in diesem Gesetz ist als solche schon verblüffend; vermutlich wurde sie aus dem Entwurf von 1932 entnommen, wo sie die "Erlaubnis“ zur Sterilisation bedeuten sollte. Zur weiteren Diskussion siehe S. $93 \mathrm{f}$.

177 RGBl 1933 I, S. 1021.

${ }_{178}$ Mdl. Auskunft Prof. Dr. Ernst Kluge, 17.7. 1989.

${ }^{179}$ Mit ihm verhandelte Bonhoeffer betreffend seiner Monatsschrift; vgl. HUB, NL KB 8, Buchstabe S, Bonhoeffer an Schniewand, 29.7. 1938.

180 Allerdings berichtet Bonhoeffer, daß auch hier „zwei meiner Nazi-Assistenten“ versucht hätten, ihn zur Niederlegung des Vorsitzes zu bewegen: „Ich lehnte dies ab, aus dem Gefühl der Verantwortung, den bisherigen wissenschaftlichen Betrieb dieser alten, angesehenen Gesellschaft solan- 
gungsprotokolle in der Allgemeinen Zeitschrift für Psychiatrie und griff nicht einmal ein, als Bonhoeffer die Vorträge auch noch separat erscheinen ließ ${ }^{181}$. Erst nach dem zweiten Kurs 1936 verbot die Zensurstelle weitere Kurse und Veröffentlichungen ${ }^{182}$. Immerhin war es Bonhoeffer gelungen, einige Gedanken zur Entschärfung des Gesetzes mittels alternativer Diagnostik an die Öffentlichkeit zu bringen.

a) Bonhoeffers erster in diesem Zusammenhang erschienener Aufsatz „Die Bedeutung der exogenen Faktoren bei der Schizophrenie“, dessen zeitgeschichtliche Bindung nicht verleugnet werden kann, wird bis heute wissenschaftlich diskutiert ${ }^{183}$. Bonhoeffer räumt darin ein, daß zwar ein Kernbereich der Schizophrenie (Katatonie, Paranoia, Hebephrenie) ein "von äußeren Erscheinungs- und Verlaufsformen weitgehend unabhängiges Erscheinungsbild" habe, dennoch seien "der Ursprung und der Umfang der Schizophrenien noch keineswegs geklärt". Anhand ausgesuchter Beispiele, bei denen Schizophrenie in engem zeitlichen Zusammenhang mit einer Kohlenmonoxid-Vergiftung oder einer Schwangerschaft aufgetreten war, postuliert er zu bedenken, daß auch exogene Faktoren bei der Schizophrenie-Entstehung eine Rolle spielen könnten. „Die Entscheidung, ob es symptomatische Schizophrenien, d.h. exogen verursachte Schizophrenien gibt, oder ob es sich immer um eine Auslösung einer an sich endogenen Schizophrenie handelt, bleibt [...] problematisch." Daher stellt er die "praktische Frage“, ob man in gewissen Fällen ausgesprochen exogener Auslösung schizophrener Attacken berechtigt sei, „den Anlagefaktor als so geringfügig zu betrachten, daß man ihn unter Umständen bei der Frage der Verhütung erbkranken Nachwuches außer acht lassen darf“"184. Die Resonanz auf diesen Aufsatz war gespalten: Ablehnung aus dem Münchner Kaiser-Wilhelm-Institut einerseits („Es gibt keine [... ] symptomatische Schizophrenie“) ${ }^{185}$, Zustimmung durch einen ehemaligen Bonhoeffer-Schüler in der von Bonhoeffer selbst herausgegebenen Monatsschrift anderseits ${ }^{186}$.

Bonhoeffer wiederholte seine These zwei Jahre später im zweiten Kurs: Bei Schizophrenie habe man es nicht "mit einem festen, unverrückbaren klinischen Gebilde zu tun", weshalb sorgfältig zu diagnostizieren sei. Nicht unter die Schizophrenie zu rechnen seien die von seinem Schüler Pohlisch 1925 beschriebenen „hyperkinetischen Motilitätspsychosen “187, die „puerperalen Schizophrenien“,

ge wie irgend möglich von den politischen Einflüssen fernzuhalten“; vgl. Bonhoeffer, Lebenserinnerungen, S. 101. Bonhoeffer wurde 1941 genötigt, den Vorsitz an de Crinis abzugeben; vgl. Jasper, De Crinis, S. 87.

181 Bonhoeffer (Hrsg.), Psychiatrische Aufgaben; ders. (Hrsg.), Erbkrankheiten.

182 Bonhoeffer identifizierte sie in seinen Lebenserinnerungen mit ihrem Sitz („Braunes Haus in München“); vgl. Lebenserinnerungen, S. 102.

${ }^{183}$ Zustimmend Propping, Genetic disorders; kritisch Huber, Gibt es?

${ }^{184}$ Bonhoeffer, Bedeutung, S. 200, 203.

185 Kurt Schneider, Diagnose, S. 1389.

${ }^{186} \mathrm{Vgl}$. Leonhard, Exogene Schizophrenien.

${ }^{187}$ Pohlisch, Hyperkinetischer Symptomenkomplex. 
zu denen sein Schüler Daseking vor „fünf Jahren“ eine längere Untersuchung angefertigt habe ${ }^{188}$, und die „Degenerationspsychosen“, die er selbst 1907 beschrieben habe ${ }^{189}$. Zu warnen sei außerdem vor einer „Frühdiagnose der Schizophrenie“, die vorschnell nach nur einem der „kurzdauernden sogenannten schizophrenen Schübe“ erstellt werde: „Es ist nicht angängig, jede hypochondrische Pubertätsphase und jede sensitive Reaktion mit Beziehungsideen, die reaktiv infantilistischen Bilder in der Pubertät, Affektkrisen, Verstimmungszustände von Psychopathen für schizophrene Attacken oder manisch-depressive Episoden zu erklären. An alle diese und andere episodische Störungen wird unter dem Einfluß des Kraepelinschen und vor allem des Bleulerschen Schizophreniebegriffes zu wenig gedacht ${ }^{\text {“190 }}$.

Mehrere Kollegen kritisierten diesen Vortrag, interessanterweise ohne Bonhoeffers Namen zu erwähnen (stand dessen exzellenter Ruf der Namensnennung im Wege?). So kritisierte Rüdin, daß ,immer noch versucht wird, das eine oder andere Krankheitsbild abzubröckeln, mit anderen Bezeichnungen zu versehen“191. Gruhle erklärte mit Verweis auf Gütt/Rüdin/Ruttke: „Die Kommentatoren wünschen zu verhindern, daß durch eine andersartig gewählte Bezeichnung der Diagnosen das Gesetz umgangen wird. Bei sicherer endogener Psychose hat sich der Arzt also zu entscheiden, ob er z. B. das sog. degenerative Irresein (das ist eine Psychose mit unbestimmten, atypischen Symptomen) der manisch depressiven Gemütsstörung oder der Schizophrenie zurechnen will. Auch die an einzelnen psychiatrischen Kliniken (mehr für den Hausgebrauch) verwendeten Bezeichnungen (wie Paranoia, Paraphrenie, episodische Dämmerzustände, hyperkinetische Psychosen, Motilitätspsychose, sensitiver Beziehungswahn, Randpsychosen usw.) gelten nicht für die Anwendung des Gesetzes. Derartige Diagnosen sind der Schizophrenie zuzuzählen " ${ }^{192}$. Dagegen erklärte das EOG Karlsruhe in einer Grundsatzerklärung unter Berufung auf „namhafte Autoritäten wie Bostroem, Bonhoeffer u. a.“, daß man bei einem „ersten Schub einer schizophrenen Erkrankung, die bei einem erblich nicht belasteten Menschen auftritt und de-

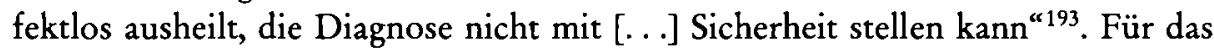
Innenministerium bildete dieser Vortrag nicht nur den Anlaß, Bonhoeffer die

${ }^{188}$ Bonhoeffers Schüler Kluge kam später in seiner von Creutzfeld betreuten Habilitation zu dem Ergebnis, daß der „exogene Faktor bei der Genese dieser Krankheitsbilder im Vordergrund“ stehe; vgl. Kluge, Entwicklung, S.280.

${ }^{189}$ Vgl. Bonhoeffer, Degenerationspsychosen, bes. S.3f., 10. Obwohl Bonhoeffer damit den Begriff "Degenerationspsychosen“ in Deutschland eingeführt hatte, behauptete er nicht die reine Erblichkeit, sondern siedelte die "Degenerationspsychosen" im Grenzbereich erblich-exogen an und hielt sie durch Therapie oder Änderung der Lebensumstände, bei Gefängnisinsassen z. B. durch Entlassung aus dem Gefängnis, für heilbar.

${ }^{190}$ Bonhoeffer, Rückwirkungen des Sterilisationsgesetzes. In ähnlicher Richtung argumentierte einer seiner Oberärzte in einer Reihe von Aufsätzen: Betzendahl, Degenerationsbegriff, S. 313; ders., Reproduktionszwang; ders., Paranoische Episode.

191 Vgl. Rüdin, Empirische Erbprognose, S. $19 \mathrm{f}$.

192 Vgl. Gruhle, Grundriß, S.159.

193 EOG Karlsruhe, 28.4. 1941, EA 9 (1941), S. 185. 
Veranstaltung weiterer Kurse zu verbieten, sondern es wurden auch „Richtlinien zur Schizophreniediagnose“ an alle Gesundheitsämter verschickt, in denen vor Bonhoeffers Diagnostik und der seines Frankfurter Kollegen Karl Kleist gewarnt wurde: „Vor längerer Zeit versuchten Schroeder und Kleist nach den Anschauungen Wernickes, unter symptomatologischen und verlaufsmäßigen Gesichtspunkten gewisse Sondergruppen aus dem Gebiete der Schizophrenie unter dem Namen der Degenerationspsychosen auszuscheiden. Diese Abtrennungen fanden seinerzeit nicht die allgemeine Anerkennung der Fachwelt, scheinen aber seit der Einführung der Unfruchtbarmachung wieder mehr hervorzutreten. Ferner hat Bonhoeffer die von Wernicke umschriebene sog. hyperkinetische Motilitätspsychose, die er von der Schizophrenie abtrennt, neuerdings [!] stärker betont. [...] Wenn von manchen Klinik- und Anstaltsleitern der Ausweg gesucht wird [...], nur wegen Fehlens einer nachgewiesenen erblichen Belastung von der Unfruchtbarmachung abzusehen, beeinträchtigen sie offensichtlich die einheitliche Durchführung des Sterilisationsverfahrens “194.

Ohne direkte Bezugnahme auf diese amtliche Kritik erklärte Bonhoeffer zwei Jahre später in einem Vortrag, er halte an seiner gelegentlich kritisierten Auffassung betreffs der hyperkinetischen Motilitätspsychosen fest und rate auch weiterhin dazu, hier „mit der Unfruchtbarmachung zurückhaltend zu sein. Es ist kein Zufall, daß die Publikationen aus meiner und der Kleistschen Klinik hervorgegangen sind. Denn in letzter Instanz ist der Vater der Aufstellung dieses Krankheitstypus Wernicke, der das hyperkinetische Krankheitsbild in klassischer Weise beschrieben hat" ${ }^{\star 195}$.

b) Zum „Manisch-Depressiven-Irresein“"196 erklärte Bonhoeffer, es sei „keine eng umschriebene Krankheit, die sich in allen ihren Äußerungsformen scharf von der Norm abhebt“. Ein dominanter Erbgang werde diskutiert, aber irgend etwas Exaktes über die genauen Erbbeziehungen sei „nicht bekannt“. „Die Frage des sterilisierenden Eingriffes wird hier zumeist mit einem urteilsfähigen Individuum zu diskutieren sein." Manisch-Depressive seien oft Künstler und besäßen wertvolles Erbgut. Deshalb wolle er „im allgemeinen sagen, daß dieser Personenkreis der Mehrzahl nach nicht in den Bereich der Auszumerzenden gehört“. Nach dem Hinweis, daß man nicht zögern solle, „die Fortpflanzung dieser Temperamentsart eher zu fördern als zu verhindern“, schloß er: „Kein Schematismus sondern sorgfältiges Prüfen des Einzelfalles.“

Den ersten Widerspruch erntete Bonhoeffer schon 1934 bei der letzten noch von ihm geleiteten Hauptversammlung des Deutschen Vereins für Psychiatrie, als ihm sein Münchner Kollege Bumke widersprach: „Nun hat Herr Kollege Bonhoeffer kürzlich darauf aufmerksam gemacht, daß es doch gar nicht selten bei der einfachen Manie oder Melancholie bliebe und daß Leute, die eine solche

194 Nach Kihn, in: Handbuch der Erbkrankheiten III, S. $321 \mathrm{f}$.

195 Bonhoeffer, Klinische Tagesfragen, S. $21 \mathrm{f}$.

196 Bonhoeffer, Manisch-Depressives-Irresein. 
Psychose durchgemacht hätten, häufig auch wertvolle Menschen und unter Umständen auch wertvolle Erblasser sein könnten. Ich stimme ihm vollkommen zu. Aber wir können leider bis heute jedenfalls die Fälle, bei denen es bei einer Manie oder Melancholie bleiben wird, von den periodischen und zirkulären Fällen nicht unterscheiden. Wir werden zum mindesten jeden Fall anzeigen und auch hier die Praxis der Erbgesundheitsgerichte abwarten müssen“" ${ }^{\text {"97. }}$.

Das EOG Frankfurt lehnte - beraten durch ein Gutachten Kleists, welches sich auf Bonhoeffers Aufsatz berief - die Sterilisation Manisch-Depressiver wegen „Hochwertigkeit" in einem Grundsatzurteil ab ${ }^{198}$, das bald als „Frankfurter Fehlurteil“ bekannt wurde ${ }^{199}$. Die Gegner dieses Urteils argumentierten: „Die Tätigkeit des Erbgesundheitsrichters wäre unglücklich, wenn er nicht fest an den endlichen Erfolg seiner Tätigkeit glaubte. In diesem Glauben muß er alles tun, um den Erfolg zu erringen, d.h. keine Ausnahme, gleichgültig aus welchem Grunde zulassen. Wie schwer andernfalls der Kreis der Ausnahmefälle zu begrenzen ist, zeigt die Rechtsprechung des ErbgesGer. Münster, die von der Unfruchtbarmachung schon absieht, wenn eine ,über dem Durchschnitt stehende

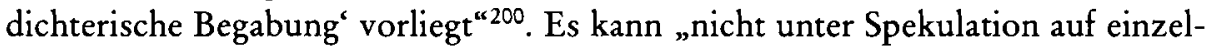
ne hochwertige Nachkommen vereinzelter hochwertiger Erbkranker eine weitgehende Verbiegung des Gesetzesgedankens im Sinne einer kompensatorischen Gesinnung allen Erbkranken gegenüber vorgenommen werden. Wer aus innerer Unentschiedenheit heraus zu der Ausgleichslehre kommt, zeigt, daß er über einen der unmerklichen Prüfsteine nationalsozialistischer Haltung, die auch heute noch überall warten, angestoßen zu werden, wieder einmal gestolpert ist“201.

Da Bonhoeffer, Kleist und das Frankfurter Gericht sich aber auf die Kann-Bestimmung aus $\$ 1$ des Erbgesundheitsgesetzes beriefen, konnte ihr Standpunkt juristisch nur dadurch erschüttert werden, daß man den Begriff „kann“ im Gesetzeswortlaut als "muß“ verstand. Diese Interpretation ergab, trotz eines gewissen Anhaltspunktes in der Ausführungsverordnung, einen so schweren Verstoß gegen die juristische Logik, daß sie nicht von allen Zeitgenossen nachvollzogen werden konnte ${ }^{202}$. Die Diskussion wurde schließlich so peinlich, daß Oberregie-

197 AZP 104 (1934), Bericht Ilberg, S. 427. Bumke, in den zwanziger Jahren Gegner der Zwangssterilisation, lief in den dreißiger Jahren zu ihren Befürwortern über und fordete im Krieg schließlich Verschärfungen des Erbgesundheitsgesetzes, vgl. Güse/Schmacke, Psychiatrie II, S. 356-364.

198 EOG Frankfurt, 17.12. 34, JW 64 (1935), S. 1876, zuvor schon: EG Frankfurt, 7.11. 1934, DJ 1935, S. 186. Das Kürzel „Kl“ in erstgenanntem Gerichtsbeschluß ist in „Kleist“ aufzulösen.

199 Ristow, Erbgesundheitsrecht, S. 105 Anm. 19 a.

200 Grunau (Richter an EOG Kiel), Erwiderung auf Lehmann, S. 1380. Ähnlich Schrader, Psychologische Einstellung, S.87.

201 Friese (Leiter der Abteilung Rassenhygiene im Reichsausschuß für Volksgesundheitsdienst der NSDAP), Erbkrankheit, S. 902; ähnlich ders., Schutz.

202 Beispielhafte Voten in dieser breit geführten Debatte vertraten: Grunau, Ein Jahr; ders. Starrer Zwang?; Schläger, Sterilisierung; Führ, Rechtsfragen; Kehrer, Kann-Vorschrift; mit Modifikationen auch: Friese, Medizinisch-gesetzliche Grundlagen; Heuß, „Kann“-Bestimmung; Koester, Grundlagen; Linden, Praktische Anwendung; Reichsärzteführer Wagner, Bemerkung zu Linden; Gütt/Rüdin/Ruttke, Gesetz ${ }^{1}$, S.104; Ristow, Erbgesundheitsrecht, S. 135. Die Gegenthese bei: 
rungsrat Linden vom Reichsinnenministerium am 11. März 1935 der Arbeitsgemeinschaft II des Sachverständigenrates für Bevölkerungspolitik und Rassenhygiene vorschlug, den Gesetzeswortlaut zu ändern und „kann“ durch „muß“ zu ersetzen. Ihm widersprach der Leiter des Rassenpolitischen Amtes der NSDAP Walter Groß: Er rate dazu, die weitere Rechtsprechung abzuwarten und nur dann das Gesetz zu ändern, wenn es sich als „unbedingt erforderlich“ erweise. Bisher habe eine Art „Schockwirkung“ bestanden, die Diskussion über das Gesetz beginne erst jetzt, und wer daran rühre, wecke schlafende Hunde ${ }^{203}$. Diese Auffassung setzte sich durch: der Gesetzeswortlaut blieb bis Kriegsende unverändert und wurde so weiterhin von OLG-Bezirk zu OLG-Bezirk unterschiedlich interpretiert ${ }^{204}$. Bonhoeffer war im Februar 1935 mit einem - von der Presse heftig angegriffenen - Gutachten für ein Gerichtsverfahren erfolgreich ${ }^{205}$.

c) Hinsichtlich der Epilepsiediagnose betonte Bonhoeffer mit Verweis auf die Lehrbücher, daß es unverändert schwierig sei, erbliche Epilepsie von nicht-erblicher zu unterscheiden ${ }^{206}$. Im Hinblick auf die „schwere Verantwortung, die der Arzt durch den Antrag auf Unfruchtbarmachung auf sich nimmt", würde man gerne "Sicherheit" haben, aber es bleibe eine "bedrückende Unsicherheit“. Namhafte Neurologen würden die Erblichkeit von Epilepsie überhaupt in Frage stellen. Seiner Vermutung nach fielen unter den Begriff „genuine Epi-

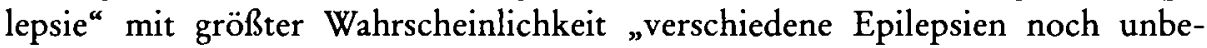
kannter Aetiologie“. Daher solle man auf den Begriff „genuine Epilepsie“ verzichten und zwischen „erbliche[r] Epilepsie“ und „Epilepsie unbekannter Aetiologie“ unterscheiden, und im Fall der letzteren auf einen Sterilisationsantrag verzichten. Mit der Definition einer „Epilepsie unbekannter Herkunft “ war Bonhoeffer in keiner Weise originell, denn er schloß sich der Diagnosetabelle des Deutschen Vereins für Psychiatrie $a^{207}$. Die heute allgemein anerkannte These, Epilepsie sei keine einheitliche Krankheit, wurde schon vor 1933 von einer einflußreichen Minderheit vertreten. Dennoch fand Bonhoeffer in jenen schwierigen Jahren nur bei seinen Mitarbeitern Schulte und Creutzfeld ${ }^{208}$ und

Lehmann, Erwiderung auf Grunau; Möller, Kann oder muß?; Wille, Unfruchtbarmachung; Kopp, Starrer Zwang?; Kopp, Schlußwort; Goetz, Sterilisierungsgesetz; Gütt/Rüdin/Ruttke, Gesetz ${ }^{2}$, S.111; Ristow, Nachtrag 1939, S.10f.

${ }^{203}$ BAK, R 22 RJuM 1933, Bl. 146.

204 "Kann" als „kann": EOG Hannover, 26.11. 1935, EA 3 (1936), S.15; die württembergischen Gerichte nach Goetz, Sterilisierungsgesetz, S. 1621. „Kann“ als "muß“: EOG Kiel, 9.2. 1935, JW 64 (1935), S.1432 ff.; EOG Dresden (mit ausdrücklicher Kritik an Bonhoeffer), 16.1. 1936, JW 66 (1937), S. 995 f.; EG Stettin, o.D. o.Az. nach Encke, Kann-Vorschrift. Ein Versuch von Prof. Dr. Kl.[eist], als Gutachter auch in Zweibrücken die Kann-Bestimmung durchzusetzen, vermochte das Gericht nicht zu überzeugen; vgl. EOG Zweibrücken, 10.5. 1935, JW 64 (1935), S. $1866 f$. unter Berufung auf eine Rede Franks vom 5.5. 1935 auf einer NS-Juristentagung.

${ }^{205}$ Bezug darauf nimmt Musikdirektor Alfred S., der Bonhoeffer darum bat, ein vergleichbares Gutachten für seine Tochter zu schreiben; vgl. HUB, NK 9, Bl. 13, S. an Bonhoeffer, 9.9. 1935.

206 Bonhoeffer, Epilepsiediagnose.

207 Vgl. S. 36.

${ }^{208}$ Vgl. Schulte, Erbliche Fallsucht; Creutzfeld, Epilepsie. 
in einem Beschluß des EOG Berlin ${ }^{209}$ Unterstützung. Unter den übrigen Kollegen galt, daß Bonhoeffer den „extremsten Standpunkt “210 einnahm. Die zeitgenössische Wissenschaft stand viel eher auf dem Standpunkt, der Geltungsbereich des Erbgesundheitsgesetzes müsse verbreitert werden. So hieß es z.B. (wieder in Anspielung auf, aber ohne namentliche Nennung von Bonhoeffer): „Wollen wir einen erbgesunden Nachwuchs, so müssen wir das Gesetz in jeder Weise fördern; es ist nicht als Förderung anzusehen, wenn heute noch Autoren das Gebiet der erblichen Fallsucht lediglich auf Fälle mit nachgewiesener Erblichkeit beschränken wollen" 211 . Man warf Bonhoeffer vor, seine Unterscheidung zwischen erblicher Epilepsie und Epilepsie unbekannter Herkunft sei zwar "theoretisch“ richtig, in der Praxis des Sterilisationsverfahrens aber "unrichtig"; sie mache die Sterilisation "weitgehend vom Zufall und vom guten Willen der Kranken" abhängig, auf deren Auskunft man, in Bezug auf etwaige erkrankte Verwandte, größtenteils angewiesen $\operatorname{se}^{212}$. „Auch wenn eine Unterteilung der genuinen Epilepsie in erbliche und in Formen unbekannter Ätiologie (Bonhoeffer) als wissenschaftliche Arbeitshypothese vertretbar ist, so kommt ihr doch praktisch, wie die Ergebnisse der Zwillingsforschung gezeigt haben, keine erhebliche Bedeutung zu. Vor allem kann nicht gefordert werden, der Nachweis der Erblichkeit sei für die Annahme eines Erbleidens in jedem Fall zu erbringen " ${ }^{213}$. Ein anderer Vorwurf lautete, daß bei derartigen Diagnosekriterien nur noch die Hälfte ${ }^{214}$ oder gar nur ein Viertel ${ }^{215}$ aller Epileptiker hätten sterilisiert werden können.

${ }^{209}$ EOG Berlin, 25.2. 1935, JW 64 (1935), S. 2147. Der Gutachter entstammte der Charité.

${ }^{210}$ So kritisch der Literaturbericht Stauder, Epilepsie Teil B, S. 192. Eine Sichtung sämtlicher Arbeiten zur Epilepsie vermittelt Baltram G.Schmidt, der auch Bonhoeffers Außenseiterposition würdigt; vgl. ders., „Epileptische Wesensveränderung“, S.116. Einen Überblick über sämtliche medizinischen Dissertationen zur Epilepsie liefert Kischkel, der vier von sechsunddreißig Dissertationen nennt, die eine "kritische bzw. ablehnende Haltung" zum Erbgesundheitsgesetz eingenommen hätten; vgl. ders., Dissertationen, S.148. Keine der dort vertretenen Thesen ging auch nur ungefähr so weit wie die Bonhoeffers.

211 Stefan, Praktische Handhabung, S. 967. Ähnlich: Demme, Stellung, S. 1568; Enge, Epilepsieforschung, S. 917-923; Kolle, Psychiatrie ${ }^{1}$, S. 249. Kolle forderte übrigens sogar noch nach Kriegsen-

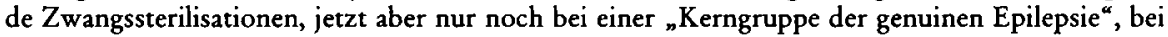
Chorea Huntington, einer "Kerngruppe des angeborenen Schwachsinns“ insbesondere bei Verbindung mit „Asozialität, Kriminalität“; vgl. ders., Psychiatrie, S. 349.

212 Vgl. Conrad, Erbanlage II, S. 276.

${ }^{213}$ Dubitscher, Psychiatrische Fragen, S.300. Ähnlich der Schweizer Manfred Bleuler, Erblichkeit, S. 260.

214 So der Göttinger Ordinarius Gottfried Ewald, der Anfang der zwanziger Jahre Hilfsarzt bei Bonhoeffer gewesen war und 1940 gegen die "Euthanasie“-Aktion protestierte: "Ich kann mir nicht vorstellen, daß fast die Hälfte unserer charakteristisch verblödeten epileptischen Kranken latent exogene Epilepsien (etwa Geburtsherde oder Narbenherde an stummer Hirnstelle), d.h. ,Epilepsien unbekannter Ätiologie‘ im Sinne Bonhoeffers sein sollen“; ders., Nochmals Epilepsie, S.1132.

${ }^{215}$ In Bethel wären es nur 443 von 1580 tatsächlich sterilisierten Epileptikern gewesen, errechnete der dortige Chefarzt, der zwar einräumte, daß „der große Rest der durch Ausschließung aller äußeren Ursachen zu sichernden Fälle zu diagnostischen Unbehaglichkeiten und Schwierigkeiten immer wieder Anlaß gibt", dies aber nicht als Grund ansah, , ihn im Bonhoeffer'schen Sinne als nicht erblich anzusehen"; Villinger, Erbliche Fallsucht, S.465f. 
Bonhoeffer blieb gegenüber all diesen Vorwürfen unbeirrt. Er reagierte allein auf die Kritik Luxenburgers, „der neuerdings gegen den Ausdruck, symptomatische Epilepsie" polemisiert", tat dessen Kritik als klinisch „unbefriedigend" $\mathrm{ab}^{216}$, suchte weiterhin die Möglichkeiten exogener Epilepsieentstehung zu unterstreichen, riet zum Verzicht auf Sterilisation bei menstruellen Epilepsien ${ }^{217}$ und bei Epilepsien, die mit „Pubertätslängenwachstum“ kombiniert waren ${ }^{218}$, und versuchte, wie Dörner zu Recht beobachtet, zahlreiche Formen der Epilepsie unter die Diagnose "Tetanie“ zu zwingen ${ }^{219}$.

d) In der Diagnose des „angeborenen Schwachsinns“ ${ }^{\text {"220 }}$ ist es nach Bonhoeffer schon eine "alte Frage“, inwiefern „Schwachsinn“ durch „Anlage“ und „Hirndefekt" bedingt sei oder wieweit "mangelhafter Schulbesuch, Entbehren geistiger Anregung, unregelmäßiges Leben, schlechte Familienverhältnisse usw." ein "ganz ähnliches Bild" hervorrufen könnten. Diese Frage sei bis heute nicht beantwortet. Unbestritten existierten "gewisse Formen angeborenen Schwachsinns leichten Grades", die aber nicht unter das Sterilisationsgesetz fielen, weil diese Menschen „brauchbare Arbeitskräfte in einfacher Berufstätigkeit“ seien. Bonhoeffer will aus dem Geltungsbereich des Gesetzes auch die „partialen Begabungsausfälle" ausnehmen, „von denen manche so sein können, daß sie die Ursache besonders schlechter Schulbeurteilung werden und an Imbezillität denken lassen, während sie für die Gesamtintelligenz tatsächlich wenig besagen. Ich denke an isolierte Defekte der Rechenfähigkeit, der Orthographie, der Lesefähigkeit, auch die Unfähigkeit der Rechts-Links-Unterscheidung, auffällige Orientierungserschwerung gehören hier hin." Von einer Diskussion nach Bonhoeffers Vortrag wird berichtet, daß Bonhoeffer eine landläufige „Dummheit“ gegenüber dem "angeborenen Schwachsinn" abzugrenzen suchte und den nichtsterilisierungspflichtigen Bereich um „erbbiologisch unbedenkliche Debilität" erweitern wollte. Er warnte vor dem „Schematismus des Intelligenzprüfungsbogens“221.

e) Zum Verfahrensrecht äußerte Bonhoeffer sich nur ein einziges Mal, und zwar gemeinsam mit Landgerichtsdirektor Schmitz zu der Frage, ob Menschen, bei denen ein Sterilisationsverfahren anhängig war, vor Abschluß des Verfahrens aus der Anstalt entlassen werden könnten, solange „Fortpflanzungsgefahr" bestehe $^{222}$. Laut Runderlaß des Reichsinnenministers vom 12. März 1935 durfte dies

\footnotetext{
${ }^{216}$ Bonhoeffer, Fehldiagnose, S. 678.

217 Vgl. Bonhoeffer/Stoeckel, Menstruelle Epilepsie, S. $836 \mathrm{f}$.

${ }^{218}$ Vgl. Bonhoeffer, Klinische Tagesfragen, S.28.

219 So Dörner, Nationalsozialismus, S.103, bezugnehmend auf Bonhoeffer, Klinische Tagesfragen, S. 28. Dörner und im Anschluß daran Müller, Bonhoeffers Kampf, S. 291 f., vermuten die Absicht Bonhoeffers, Menschen durch Fehldiagnosen vor der "Euthanasie“ zu retten. Da Bonhoeffers Vortrag schon vom Februar 1939 stammt und ihm Überlegungen zur „Euthanasie“ damals kaum bekannt gewesen sein dürften, scheint mir der Versuch einer Umgehung des Erbgesundheitsgesetzes wahrscheinlicher.

$220 \mathrm{Vgl}$. Bonhoeffer, Rückwirkungen, S. 29.

221 Vgl. Dubitscher/Kresimer, Intelligenzuntersuchung, S. 3 f.

222 Vgl. Bonhoeffer/Schmitz, Entlassung zulässig?
} 
nach Genehmigung des Amtsarztes nur „ausnahmsweise“ geschehen. Während Schmitz den Begriff „ausnahmsweise“ im Erlaß so verstand, daß „der Amtsarzt auch wirklich nur in Ausnahmefällen von diesem Recht Gebrauch machen soll“, interpretierte Bonhoeffer, daß „der Amtsarzt sich einem berechtigten, den Entlassungsvoraussetzungen entsprechenden Antrag kaum entgegenstellen wird“.

In der Gesamtübersicht zeigt sich, daß Bonhoeffer, wiewohl er das Erbgesundheitsgesetz nie frontal angegriffen hat, es doch konstant zu nivellieren versuchte und daß seine Kollegen diese Botschaft sehr wohl verstanden haben. Bonhoeffer verfolgte stets das Ziel, das Gesetz jedenfalls auf dem Weg der Durchführung zu entschärfen. Prof. Dr. H.J.Krauß, Teilnehmer an Bonhoeffers Kursen, berichtet, daß für ihn als Studenten nicht der geringste Zweifel daran bestanden habe, daß Bonhoeffer das Erbgesundheitsgesetz grundsätzlich ablehnte ${ }^{223}$. Der wissenschaftliche Diskurs, des bisher referiert wurde, spricht gleichfalls dafür, daß die Kollegen die Intention des Charité-Chefarztes begriffen hatten und auch im $\mathrm{Be}-$ reich ihrer Möglichkeiten diese Einstellung attackierten. Im Ausland konnte darüber offener gesprochen werden: Schweizer Kollegen, die sich 1938 in einem Sammelband kritisch zur deutschen Gesetzgebung äußerten, lobten Bonhoeffers „äußerst besonnene und klug abwägende Stellungnahme“, gegen die Rüdin "heftig“" polemisiert habe. Ihnen war deutlich, daß Bonhoeffer die Sterilisation nur in besonderen Fällen und nur bei Zustimmung des Betroffenen für legitim hielt $^{224}$ und daß er sich darin in unversöhnlicher Rivalität zu Rüdin befand ${ }^{225}$.

\section{Gutachtertätigkeit am Erbgesundbeitsobergericht und in der Charité}

Im folgenden soll Bonhoeffers Tätigkeit als sachverständiger Psychiater (Richter) am Erbgesundheitsobergericht und seine Gutachtertätigkeit untersucht werden. Sie hat in der Literatur schon zu sehr eigenwilligen Spekulationen geführt $^{226}$. Eine Analyse der Tätigkeit Bonhoeffers beim Erbgesundheitsobergericht steht

223 Brief an den Verfasser, 30.10. 1989.

224 Binswanger, Manisch-Depressives Irresein, S. 134. Ähnlich verstand man in auch Bonhoeffers Epilepsie-Aufsatz; vgl. Braun, Epilepsie, S.140f.

225 Ebenda. Franz Kallmann, der nacheinander unter Bonhoeffer und Rüdin gearbeitet hatte, 1935 aufgrund der Rassengesetze entlassen wurde und sich nun mit Zeugnissen beider im Ausland bewerben mußte, berichtete Bonhoeffer, „daß ich bei den Besprechungen mit den holländischen Universitätsprofessoren den Eindruck gewonnen habe, daß Ihre eigene Empfehlung, sehr geehrter Herr Geheimrat, mir überall die Türen öffnete und daß meine Berufung auf Prof. Rüdin an einigen Stellen eher das Gegenteil tat“; vgl. HUB, NK 3, Bl. 75, Kallmann an Bonhoeffer, 8.11. 1935.

226 Grell meint einen besonders verhängnisvollen Einfluß Bonhoeffers auf das Berliner Erbgesundheitsobergericht dadurch nachweisen zu können, daß die Beschlüsse des vom Obergericht abhängigen Berliner Erbgesundheitsgerichtes für die Wittenauer Heilanstalten im Durchschnitt schärfer waren als der Reichsdurchschnitt; vgl. dieselbe, Bonhoeffer, S.238. Der Zusammenhang ist wenig einsichtig, und tatsächlich hat Bonhoeffer auf die einige Jahrzehnte später nach ihm benannte Heilanstalt keinen besonderen Einfluß ausgeübt. Außerdem läßt sich aus den Wittenauer Zahlen kein für Berlin repräsentativer Eindruck gewinnen; vgl. die regional gegliederte Sterilisationsstatistik im Anhang. 
vor dem Problem, daß die Akten aufgrund von Kriegseinwirkung nur unvollständig erhalten sind ${ }^{227}$. Über Bonhoeffers Rolle Aufschluß gewinnen läßt sich nur mittels einer Sammlung von Beschlüssen des Erbgesundheitsobergerichts im Bestand des Berliner Erbgesundheitsgerichts. Nach dieser Quelle war Bonhoeffer in seiner richterlichen Funktion an 4 (von 937) Beschlüssen beteiligt: Dreimal wurde ein Sterilisationsbeschluß bestätigt, einmal ein solcher aufgehoben ${ }^{228}$. Wie Bonhoeffer in diesen vier Beschlüssen votierte, konnte wegen des Beratungsgeheimnisses nicht ermittelt werden. Faktisch war Bonhoeffers Richtertätigkeit am Berliner Erbgesundheitsobergericht jedenfalls nur eine sporadische Tätigkeit. Wenn er in seinen Erinnerungen von seinem „Einfluß auf die Begutachtung der Gerichte [...] in Berlin und auch in den Provinzen" spricht ${ }^{229}$, so ist damit nicht die richterliche, sondern die gutachterliche Funktion seines Postens angesprochen. In dieser Funktion wurde er von anderen deutschen Erbgesundheitsobergerichten häufig mit Gutachten beauftragt.

Im Charité-Archiv sind sämtliche an der Psychiatrischen und Nervenklinik der Charité geschriebenen Gutachten als Durchschrift erhalten, davon 1072 aus der Zeit, in der Karl Bonhoeffer Chefarzt war (1934 bis Juni 1938) ${ }^{230}$. Sie umfassen 15 bis 30 Seiten, ausnahmsweise bis zu 70 Seiten, und wurden selten von Bonhoeffer, meist aber „im Auftrag des Direktors der Psychiatrischen und Nervenklinik der Charité" von einem seiner Assistenz- oder Oberärzte unterzeichnet. In einem Teil dieser Gutachten sind keine Einzeldiagnosen, sondern Grundsatzfragen besprochen, z.B. ob das Down-Syndrom ("mongoloide Idiotie“) als „angeborener Schwachsinn“ im Sinne des Gesetzes bewertet werden solle ${ }^{231}$.

Diese Gutachten sollen im folgenden statistisch daraufhin ausgewertet werden, ob sie der Tendenz nach die Sterilisation befürworten (= Steri), ablehnen (=kSteri) oder eine Tendenz nicht erkennbar ist $(=w e-n o)$. Viele Gutachten geben nicht explizit Antwort auf die Frage, ob eine Sterilisation befürwortet wird

${ }^{227}$ Laut Auskunft des Präsidenten des Kammergerichtes ist der Restbestand 1987 vollständig an das Landesarchiv Berlin abgegeben worden. Verwaltungsvorgänge des Erbgesundheitsobergerichtes aus der Zeit vor Mai 1945 seien „infolge der Kriegsereignisse nicht mehr vorhanden“; vgl. Brief an den Verf., 24.7. 1988.

228 Vgl. LAB, Rep. 209 Acc. 3693 Nr. 45 535, Bl. 157, 237; Nr.45648, Bl. 1; Nr. 45651 Bl. 45. Keine Beteiligung Bonhoeffers als Erbgesundheitsoberrichter ebenda, Nr. 45646, Nr.45647. Es gab am Erbgesundheitsobergericht Berlin (Stand 1936) in zwei Senaten je sechs ärztliche Beisitzer mit jeweils einem persönlichen Vertreter, also 24 Ärzte.

${ }^{229}$ Bonhoeffer, Lebenserinnerungen, S. 102.

${ }^{230}$ Im folgenden nach HUB, NK 15, 16, 23, 33, 34, 36, 39, 49, 47, 48, 50, 51, 53, 54, 59, 60, 62, 63,64 .

${ }^{231}$ Diese Frage war vom ersten Obergutachter Prof. Dr. Weygandt bejaht worden. Bonhoeffer kam als zweiter Obergutachter zu dem Ergebnis, die Entstehung der "mongoloiden Idiotie ${ }^{*}$ sei ungeklärt, gegen Erblichkeit spräche aber, daß eineiige Zwillinge sich diskordant verhielten. Seine hochpräzise Sprache ist hier zugleich recht boshaft: „Der Herr Vorgutachter nimmt, obwohl er in seiner sehr eingehenden Beachtung des Schrifttums die gleichen Feststellungen kennen gelernt hat und aus eigenen Beobachtungen nichts mitteilt, was als Beweis für die Erblichkeit der mongoloiden Idiotie anzusehen ist, eine Erblichkeit des Leidens an. Soweit sich überhaupt eine Begründung dieser Auffassung in den Ausführungen, die er in seinem Gutachten macht, finden läßt, [ist sie] nicht stichhaltig“; HUB, NK 60, Nr.354. 
oder nicht, sondern antworten auf speziell formulierte Fragen, beispielsweise, ob es beim Patienten Hinweise auf Hirnschädigungen durch Verletzungen gebe. Antwortete der Gutachter dann, ein Hirnschaden habe "nicht nachgewiesen“ werden können, sei aber „wahrscheinlich“, wurde das als ein der Tendenz nach die Sterilisation ablehnendes Gutachten bewertet, wie umgekehrt die Auskunft, eine erworbene Schädigung sei "möglich“, habe aber "nicht nachgewiesen“ werden können, als tendenziell die Sterilisation befürwortende Stellungnahme bewertet wurde. Die nachfolgende Bilanz stellt zum einen auf die Diagnosen, zum anderen auf die Gutachter/innen ab. Die jeweils vorgetragenen Argumente können hier nicht erfaßt werden. Verzichtet wurde auch auf die (nur mit erheblichem Aufwand zu leistende) Untersuchung darüber, ob die Gerichte dem/der Gutachterin gefolgt sind.

Den folgenden Ergebnissen steht die statistische Bilanz für die Sterilisationsbeschlüsse in ganz Deutschland gegenüber: Etwa 7,4-15,2\% der Beschlüsse im Reichsdurchschnitt haben sich gegen eine Sterilisation ausgesprochen ${ }^{232}$.

Sterilisationsgutachten an der Psychiatrischen und Nervenklinik der Charité 1934 bis Juni 1938, nach Diagnosen:

\begin{tabular}{lcccc} 
Diagnose & Steri & kSteri & \multicolumn{1}{l}{ we-no } & \multicolumn{1}{l}{ zus } \\
angeb. Schwachsinn & $196(52 \%)$ & $176(47 \%)$ & $5(1 \%)$ & $377(35 \%)$ \\
Schizophrenie & $154(51 \%)$ & $135(44 \%)$ & $15(5 \%)$ & $304(28 \%)$ \\
erbl. Epilepsie & $89(32 \%)$ & $171(65 \%)$ & $5(2 \%)$ & $265(25 \%)$ \\
Manisch-Depressiv & $18(46 \%)$ & $21(43 \%)$ & & $39(4 \%)$ \\
Schw. Alkoholismus & $22(49 \%)$ & $20(44 \%)$ & $3(7 \%)$ & $45(4 \%)$ \\
erbl. Blindheit & 1 & 3 & & 4 \\
erbl. Taubheit & 10 & 2 & 10 & $22(2 \%)$ \\
schw. erbl. körp. Mißbildung & 2 & 3 & & 5 \\
Chorea Huntington & 3 & 8 & & $11(1 \%)$ \\
zus. & $495(46 \%)$ & $539(50 \%)$ & $38(4 \%)$ & $1072(100 \%)$
\end{tabular}

Sterilisationsgutachten an der Psychiatrischen und Nervenklinik der Charité 1934 bis Juni 1938, nach Gutachter/in:

$\begin{array}{lcccc}\text { Person } & \text { Steri } & \text { kSteri } & \text { we-no } & \text { zus. } \\ \text { Kurt Albrecht } & 1 & 4 & & 5 \\ \text { Herr Bahr } & 2 & 9 & & 11 \\ \text { Walter Betzendahl } & 10(26 \%) & 27(71 \%) & 1(3 \%) & 38(4 \%) \\ \text { Karl Bonhoeffer } & 33(49 \%) & 32(47 \%) & 3(4 \%) & 69(6 \%) \\ \text { Frau Bormann } & 17(39 \%) & 26(59 \%) & 1(1 \%) & 44(4 \%) \\ \text { Lucie Brosowski } & 16(35 \%) & 29(63 \%) & 1(2 \%) & 46(4 \%) \\ \text { J.G. Creutzfeld } & 104(50 \%) & 99(48 \%) & 4(2 \%) & 20719 \%) \\ \text { Martin Grotjahn } & 1 & 4 & & 5 \\ \text { Ilse Kucher } & 4 & 9 & & 14\end{array}$

${ }^{232}$ Vgl. die Statistik im Anhang. Eine genaue Statistik über die Gutachten existiert nicht. 


$\begin{array}{lrccc}\text { Person } & \text { Steri } & \text { kSteri } & \text { we-no } & \text { zus. } \\ \text { Gerhard Kujath } & 19(46 \%) & 22(54 \%) & & 31(3 \%) \\ \text { Frau Kirchhof } & 10(53 \%) & 9(47) & & 19(2 \%) \\ \text { Ernst Kluge } & 8(42 \%) & 11(58 \%) & & 19(2 \%) \\ \text { Margot Möllmann } & 39(51 \%) & 37(49 \%) & & 76(7 \%) \\ \text { D.Müller-Hegemann } & 1 & & & 1 \\ \text { Kurt Pohlisch } & 8 & 2 & & 10 \\ \text { Fredy Quadfasel } & 18(49 \%) & 17(46 \%) & 2(5 \%) & 1 \\ \text { Ernst Sternberg } & 93(55 \%) & 71(42 \%) & 6(4 \%) & 170(3 \%) \\ \text { Jürg Zutt } & 111(42 \%) & 130(50 \%) & 20(8 \%) & 262(24 \%) \\ \text { andere/unleserlich } & 495(46 \%) & 539(50 \%) & 38(4 \%) & 1072(100 \%) \\ \text { zus. } & & & \end{array}$

Im Ergebnis sprechen $50 \%$ aller Gutachten sich der Tendenz nach gegen eine Sterilisation aus, in $46 \%$ aller Fälle wurde eine Sterilisation der Tendenz nach befürwortet. Bei den Gutachtern gibt es Unterschiede zwischen $26 \%$ Befürwortung (Walter Betzendahl) und $55 \%$ (Jürg Zutt), wobei Bonhoeffer selbst mit $49 \%$ in der Mitte liegt. Dies mag ein Hinweis auf besonders starkes oder schwaches Bemühen des jeweiligen Gutachters oder der jeweiligen Gutachterin sein, Menschen vor der Zwangssterilisation zu bewahren; die Unterschiede können aber auch dadurch erklärt werden, daß die Ärzte an verschiedenen Stationen mit entsprechend unterschiedlicher Auswahl an Patientinnen oder Patienten tätig waren. $\mathrm{Zu}$ berücksichtigen ist ferner, daß die jüngeren Assistenzärzte Betzendahl, Bormann, Brosowski und Kluge überwiegend Erstgutachten für das Erbgesundheitsgericht Berlin erstellten, während die älteren - Bonhoeffer, Creutzfeld, Zutt, Sternberg, Möllmann - überwiegend an Zweit- und Drittgutachten für die Erbgesundheitsobergerichte arbeiteten, bei denen meistens das Erstgutachten, ggf. auch das Zweitgutachten, widerlegt werden mußte und die Möglichkeit, Akten zu fälschen, geringer war. Unterschiede zwischen den Assistenzärzten, etwa hinsichtlich der politischen Einstellung, sind nicht festzustellen: Dietfried Müller-Hegemann war kommunistisch eingestellt, ebenso Ernst Sternberg, für den Bonhoeffer sich nachhaltig verwandt hat. Kurt Albrecht war SS-Mitglied, Nationalsozialist auch Kurt Pohlisch, der Bonhoeffers Aufsätze zur Sterilisation als zu "milde“ kritisierte, nachdem er 1934 einen Ruf nach Bonn angenommen hatte ${ }^{233}$. Dies alles sind Hinweise darauf, daß Bonhoeffer

${ }^{233}$ Vgl. PAGJ, Interview Müller-Hegemann (1961); zu Sternberg siehe S.75; zu Albrechts SS-Mitgliedschaft vgl. HUB, NK 4, Bonhoeffer an Charité-Direktion, 6.12. 1934; zu Pohlisch vgl. ders., Epilepsie, S.5, 7 f. und in: Handbuch der Erbkrankheiten VI, S. 178. Pohlisch war später an der „Euthanasie“-Aktion beteiligt, wovon Bonhoeffer erst nach Kriegsende durch die gegen Pohlisch ermittelnde Staatsanwaltschaft erfuhr. In einem Brief an Herta Seidemann faßte Bonhoeffer seine Stellungnahme der Staatsanwaltschaft gegenüber so zusammen, daß Pohlisch 1933 überzeugter Nationalsozialist gewesen sei, sich aber an der Charité „gewissenhaft, fleißig und human“ gezeigt habe, „daß ich über die Entwicklung nach 34 nichts wußte" und Pohlisch ihm erst 1943 wieder begegnet sei, wo dieser sich "wie so viele“ inzwischen als „ziemlich geheilt“ gab; vgl. Focke, Begeg- 
die Kontrolle über die in seinem Auftrag erstellten Gutachten in der Hand behiel ${ }^{234}$. Krankenakten und Diagnosekarteien in der Charité sollen vielfach zugunsten der nicht-erblichen Krankheiten gefälscht gewesen sein, etwa so, daß man sich die Liquor-Werte für Epilepsie-Gutachten „ausdachte" ${ }^{\text {“235. }}$.

Während Bonhoeffer zu einer Begutachtung derjenigen Patientinnen und Patienten, deren Namen den Behörden bereits bekannt waren, bereit war, hat er, seinen Lebenserinnerungen zufolge, Neuanzeigen aus seiner Praxis als Verletzung des ärztlichen Berufsgeheimnisses grundsätzlich abgelehnt ${ }^{236}$. Ein lückenloser Nachweis für die Korrektheit dieser Behauptung erscheint unmöglich. Es gibt aber einige Hinweise darauf, daß er das Arztgeheimnis sehr ernst nahm:

1923 hatte Bonhoeffer auf eine ministerielle Anfrage geäußert, er zeige psychisch Kranke nicht bei der Staatsanwaltschaft oder der Polizei an, dies sei weder vorgeschrieben noch üblich, noch wünschenswert ${ }^{237}$. Unter den $937 \mathrm{Be}-$ schlüssen des Erbgesundheitsobergerichtes konnte keine einzige Anzeige Bonhoeffers entdeckt werden, nur einige wenige, die von zwei Mitarbeitern stammten ${ }^{238}$. Ein Arzt erinnert sich daran, von Bonhoeffer ermutigt worden zu sein, nicht anzuzeigen ${ }^{239}$. Bonhoeffers Tochter bezeugte: „... noch nicht einmal im Familienkreis verletzte mein Vater seine ärztliche Schweigepflicht ${ }^{\text {"240. }}$. Bonhoeffers Assistenzarzt Betzendahl wurde durch einen niedergelassenen Arzt "nach Rücksprache mit dem Vertreter der Berliner Ärztekammer, Herrn Dr. Quandt" denunziert, eine Patientin nicht angezeigt zu haben ${ }^{241}$. Vertreter des Gesundheitsamtes in Schwelm beschwerten sich, daß in der Charité bei einem sterilisations-

nung Seidemann, S. 149, Bonhoeffer an Seidemann, 15.11. 1948. Pohlisch wurde in letzter Instanz freigesprochen; vgl. Rüter/Rüter-Ehlermann (Hrsg.), Justiz III, S.465-549, und XI, S.663-731.

${ }^{234}$ Die kleine Zahl von Gutachten, die Albrecht schrieb, könnte darin begründet sein, daß Bonhoeffer ihn nur ausnahmsweise mit Gutachten beauftragte. Dagegen erklärt sich die geringe Anzahl der Gutachten Martin Grotjahns durch dessen plötzliche Flucht aus Deutschland; vgl. HUB, NK 3, Bl. 34; NK 8, Buchstabe G.Quadfasel wurde 1934 wegen Hochverrates verhaftet. Bonhoeffer hat sich erfolgreich für ihn eingesetzt; vgl. HUB, NK 3, Bl. 132, Zeugnis für Quadfasel, 13.12. 1934; ebenda, Bl. 133, Bonhoeffer an Geheimes Staatspolizeiamt, 6. 9. 1935.

${ }^{235}$ Mdl. Auskunft Prof. Dr. Hans-Heinrich Meyer, 16.9. 1990; vgl. ders., in: Pongratz, Psychiatrie, S.301.

236 Bonhoeffer, Lebenserinnerungen, S. 102.

${ }^{237}$ GeStaM, Rep. 76-Va-Sect.I Tit.X No. 85, Bl. 40, Bonhoeffer an Preußisches Ministerium für Volkswohlfahrt, 11.12. 1923.

${ }^{238} \mathrm{Vgl}$. den Bestand von S. 98 Anm. 228.

${ }^{239}$ Karl Sattler erinnert sich, er habe 1934 in Berlin Staatsexamen gemacht, sei von Karl Bonhoeffer geprüft worden und habe bei seinem "Examens-Fall“ die Diagnose "Manisch-Depressives Irre-

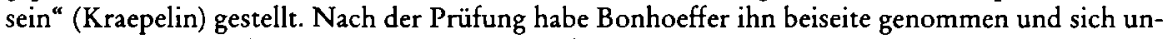
ter vier Augen mit ihm unterhalten: „Er hatte feuchte Augen, als er mich danach fragte, was bei der gestellten Diagnose seit dem 1.Januar 1934 meine, gesetzliche' Pflicht sei. Ich antwortete, daß ich die Frau melden müßte und daß sie dann sterilisiert würde. ,Und was empfinden sie dabei?", fragte er. Es tut mir in der Seele weh', antwortete ich. Seine Augen strahlten tiefe Zufriedenheit aus, als er mich mit den Worten entließ: ,Ach das ist gut." “ Ders., Leserbrief, in: Deutsches Ärzteblatt 86 (1989) B.1722f.

240 PAGJ, Interview Christine von Dohnanyi, 12.3. 1961, S.9.

${ }^{241}$ Vgl. BAP, 49.01 1355, Bl. 417-421, Emil Becker an RMdI, 12.11. 1935. 
pflichtigen Patienten kein Sterilisationsantrag gestellt worden war ${ }^{242}$. Die betroffenen Ärzte müssen wohl den Schutz des Chefarztes gehabt haben, denn zu einer Strafverfolgung wegen Nichtanzeige ist es nicht gekommen. In einem anderen Fall hat sich ein Schreiben erhalten, in dem Bonhoeffer versuchte, sich nach einer Beschwerde herauszureden ${ }^{243}$, offenbar mit Erfolg.

\section{Einsatz gegen die „Euthanasie“-Aktion}

Es gibt bis zum Jahr 1940 keine Anhaltspunkte, daß Karl Bonhoeffer sich mit der „Euthanasie“-Diskussion ausführlich befaßt hätte. Dennoch - und das ist nachdrücklich festzustellen und im folgenden zu belegen - hat er durchaus nicht positiv zur „Euthanasie“ Stellung genommen. Diese These von einer zustimmenden Stellungnahme Bonhoeffers, die inzwischen eine gewisse Publizität erreicht hat ${ }^{244}$, wird von ihren Vertretern mit einem einzigen Text belegt: einer etwas unbestimmten Aussage Bonhoeffers in seinem Sterilisationsgutachten von 1923. Hier verlangt Bonhoeffer unter Hinweis auf die von „ernsthafter Seite“ kontrovers geführte Diskussion um die Vernichtung „lebensunwerten“ Lebens, daß man dieses Problem mit der Frage der eugenischen Unfruchtbarmachung nicht

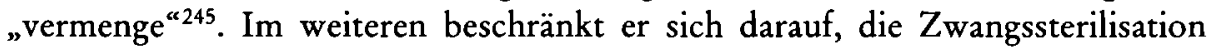
(nicht aber explizit die „Euthanasie“) abzulehnen. Daraus ist nun aber noch keine Befürwortung der nationalsozialistischen „Euthanasie“-Überlegungen abzuleiten. Da die gesamte Debatte vor 1940 durchaus nicht eindeutig und auch widersprüchlich verlief ${ }^{246}$, läßt sich Bonhoeffers Schweigen als mangelnde Sensibilität für die bedrohlichen Hintergründe der Debatte interpretieren, damit jedoch nicht als Befürwortung der „Euthanasie“.

Bonhoeffer hat zusammen mit vielen Zeitgenossen Hitlers Intentionen an dieser Stelle zunächst unterschätzt. Als er im Oktober 1933 von Hans Harmsen, dem Leiter des Referates Gesundheitsfürsorge beim Centralausschuß der Inneren Mission, zu einer Besprechung gebeten wurde, auf der im Zusammenhang

242 Vgl. BAP, 49.01 1355, RMdI an REM, 7.4. 1936.

${ }^{243}$ „Wir verlegen sehr häufig Kranke in städtische Anstalten, ohne sie zu melden, und überlassen die Meldung der dortigen Anstalt, ebenso kommt es vor, daß wir Kranke aus den Sanatorien bekommen, bei denen die Meldung erst von uns oder von der Anstalt, in die sie von uns gelangen, erstattet wird, auch wenn die Diagnose schon sichergestellt ist. Der Sinn des Gesetzes wird dadurch ja nicht irgendwie beeinträchtigt ${ }^{\star}$; HUB, NK 31, Bonhoeffer an Stoltenhoff, 14.6. 1938. Aus diesem Schreiben wurde gefolgert, daß Bonhoeffer eine Behinderung des Gesetzes fernlag; vgl. Neumärker/Seidel, Bonhoeffer, S.277. Ich interpretiere diesen Brief gegenläufig: Bonhoeffer versuchte, das Gesetz zu umgehen, und reagierte auf Beschwerden wegen Nichtanzeige mit Ausflüchten oder Notlügen.

244 Vgl. Grell, Bonhoeffer; Seidel/Neumärker, Bonhoeffer, S.199.

245 Bonhoeffer, Unfruchtbarmachung, S.799. Bonhoeffer verweist auf Binding/Hoche (diese hatten

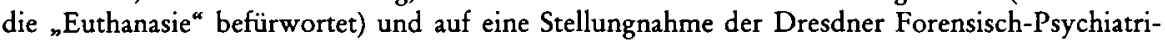
schen Gesellschaft (darin war die „Euthanasie“ verworfen worden).

246 Siehe S. 49-54. 
mit der Denkschrift Kerrls die „Frage der Tötung auf Verlangen und der Vernichtung lebensunwerten Lebens" besprochen werden sollte ${ }^{247}$, antwortete der beschäftigte Wissenschaftler bedauernd - die Dringlichkeit der Situation verkennend -, daß er wegen einer klinischen Vorlesung an der Besprechung des ihn "sehr interessierenden“ Themas verhindert sei, empfahl einen Mitarbeiter an seiner Stelle und bat um Übersendung der ihm noch unbekannten Denkschrift ${ }^{248}$. Auf die Anfrage eines anderen Kollegen antwortete er, es bestehe kein Grund zur Besorgnis, denn er habe bei einem Gespräch „mit den Herren der Strafrechtskommission im Reichsjustizministerium " erfahren, daß die Reichsregierung eine Vernichtung "unwerten“ Lebens „abgelehnt" habe ${ }^{249}$. Diese Information dürfte Bonhoeffer von seinem Schwiegersohn Hans von Dohnanyi erhalten haben, dem als Mitglied der Strafrechtskommission der Stand der Diskussion bekannt war $^{250}$.

Bonhoeffers interessierte, aber indifferente Position veränderte sich radikal, als er ab Anfang des Jahres 1940 von ersten „Euthanasie“-Maßnahmen Kenntnis erhielt ${ }^{251}$. Am 27. Februar 1940 macht eine, in ihrer Kürze gehaltvolle Andeutung im Brief des Sohnes („Von der Auflösung der pommerschen Irrenanstalten wird Papa sicherlich gehört haben " $)^{252}$ deutlich, daß das Thema in der Familie bereits diskutiert wurde. Als Karl Bonhoeffer eine Nachricht erhielt, wonach auch sein Nachfolger Maximilian de Crinis an der "Euthanasie“-Aktion beteiligt sei253, stellte Bonhoeffer diesen im Chefzimmer unter vier Augen zur Rede. De Crinis soll behauptet haben, an der "Euthanasie“-Aktion nicht persönlich beteiligt zu sein, was Bonhoeffer später dem Oberarzt Heinrich Scheller gegenüber als unglaubwürdig bezeichnete. Seine Reaktion wird folgendermaßen geschildert: „Das hat ihn so tief gekränkt, daß er sich in diesen ihm heiligen Dingen auch

${ }^{247}$ Vgl. HUB, NL KB 6, Harmsen an Bonhoeffer, 30.10. 1933, mit Bezug auf Denkschrift des Preußischen Justizministers, siehe S. 49.

${ }^{248}$ Vgl. HUB, NL KB 6, Bonhoeffer an Harmsen, 6.1. 1933. Bonhoeffer empfahl seinen Mitarbeiter Creutzfeld, der aber nicht mehr angeschrieben worden zu sein scheint.

${ }^{249}$ Vgl. HUB, NK 40, Bonhoeffer an "Hochverehrter Herr College“, 19.6. 1934.

${ }^{250}$ Dohnanyis Rolle in der Strafrechtskommission wird behandelt bei Strohm, Theologische Ethik, S. 266-277. Dohnanyi selbst hatte die Kerrlsche Denkschrift mit dem eher „technischen“ Argument kritisiert, sie führe dazu, daß eine staatlich angeordnete Vernichtung "lebensunwerten " Lebens straffrei, Beihilfe zum Selbstmord aber strafbar sei, die Bestimmungen also „sich überschneiden" würden; vgl. Quellen zur Reform 1,1, S.520.

251 Ab Januar 1940 wurden Kinder- „Euthanasie“ in besonderen „Kinderfachabteilungen“, Massenerschießungen von Anstaltsinsassen im besetzten Polen und Vergasungen mit Kohlenmonoxid in mobilen Gaswagen durchgeführt. Im Januar 1940 fanden erste Versuche mit einer stationären Gaskammer im ehemaligen Zuchthaus Brandenburg statt, die als die „effektivste" Form des Mordes ab Februar 1940 regelmäßig - zunächst in Brandenburg und Grafeneck (Württemberg) - fortgesetzt wurden; vgl. Schmuhl, Rassenhygiene, S. 196.

${ }^{252}$ Vgl. GS 2, S. 373, Dietrich an Karl Bonhoeffer, 27.2. 1940.

${ }^{253}$ Trotz Aktenvernichtung, siehe S. 18 Anm.62, ist sicher, daß de Crinis eine maßgebliche Funktion bei der ,Euthanasie"-Aktion besaß, vgl. Jasper, De Crinis, allerdings nicht an der Charité, denn Universitäts-Nervenkliniken waren prinzipiell ausgenommen, vgl. Aly, Aktion T4, S. 200. Dennoch wurde ein Fall bekannt, bei dem ein Patient der Charité auf Betreiben von de Crinis hin in eine andere Anstalt verlegt und von dort aus ermordet wurde; vgl. Jaeckel, Charité, S. 549-559. 
noch belogen fand [...] und damit, glaube ich, war der innere Bruch zwischen den beiden besiegelt ${ }^{\star 254}$.

Wohl ab März $1940^{255}$ gab es erste Kontakte zwischen Bonhoeffer und Pfarrer Braune, dem Leiter der Anstalt Lobethal über Bernau (nahe Berlin), der seinerseits in engem Kontakt zu Pfarrer Fritz von Bodelschwingh, dem Leiter der Betheler Anstalten, stand. Bonhoeffer informierte Braune, der schon so etwas vermutet hatte, daß vermeintliche Verlegungen von Anstaltsinsassen mit deren Ermordung endeten, und nannte das umgebaute Zuchthaus Brandenburg als eines der Vernichtungszentren. Wir wissen davon aus einem etwas verklausulierten Brief Braunes an von Bodelschwingh: „Heute wollte ich Dir nur mitteilen, daß ich in der Angelegenheit, die uns neulich so beschäftigt hat, noch weiterhin fortwährend tätig bin. Ich habe Fühlung genommen mit den Medizinern und bin bei Herrn Prof. Dr. Bonhoeffer gewesen. Auch über den Ort, an dem diese Dinge geschehen [Zuchthaus Brandenburg], habe ich ziemlich sichere Auskunft. Die Aussprachen haben unsere Vermutungen vollauf bestätigt. . . In der Beurteilung dieser Dinge gehen die Herren völlig mit uns einig. [. . .] Dann war gestern sehr verheißungsvoll ein Besuch beim OKW, wo ich zu einem sehr eifrigen [...] Herrn [Hans von Dohnanyi] vermittelt war, der heute schon die Sache dem minister justitiae in die Hand gibt und mich bei ihm anmeldet ${ }^{\text {"256. }}$.

Im Frühsommer 1940 bereitete Braune eine Denkschrift zur „Euthanasie“-Aktion vor, vor allem um auch diejenigen zu überzeugen, die Berichten über die „Euthanasie“ keinen Glauben schenken wollten ${ }^{257}$, in erster Linie den Reichsjustizminister. In diesem Zusammenhang fanden zwischen ihm, von Bodelschwingh und Karl Bonhoeffer eine Reihe von Treffen statt, von denen eines auf den 7. Mai 1940 datiert werden $\mathrm{kann}^{258}$. Letzterer vermittelte darüber hinaus eine Verbindung zu Heinrich Schulte, seinem früheren Assistenzarzt und nunmehrigen Anstaltsleiter des ebenfalls von der „Euthanasie“ bedrohten Waldhaus Nicolasse ${ }^{259}$. Es ist anzunehmen, daß alle Kontakte dem Erfahrungsaustausch sowie taktischen Überlegungen für die weitere Vorgehensweise gedient haben.

Es steht ferner fest, daß Bonhoeffers Schwiegersohn Hans von Dohnanyi ebenfalls mehrere Gespräche mit Braune geführt, diesen „mit großem Interesse“ bei der „Zusammenstellung von Beweismaterial“ unterstützt ${ }^{260}$ und an der Denk-

254 PAGJ, Interview Rüsken, 4.4. 1961, S.84, 111. Von diesem Gespräch wird ferner berichtet: Ebenda, Interview Christine von Dohnanyi, 12.3. 1961, S. 1; Ebenda, Interview Prof. Dr. Helmuth Selbach (1961), S. 2. Vgl. auch Jaeckel, Charité, S. 547; Jasper, De Crinis, S. 130.

255 Bethge, Bonhoeffer, S. 773.

${ }^{256}$ Kaiser/Nowak/Schwartz, Eugenik, S. 305, Braune an Bodelschwingh o. D. (ca. Mai 1940).

257 Vgl. IfZ, NO 895, Braune an Oberstaatsanwalt bei LG Frankfurt a. Main, 12.9. 1946.

${ }^{258}$ Vgl. die Zeittafel DBW 6 (Ethik), S. 457.

${ }^{259}$ Neumärker, Karl Bonhoeffer 1990, S. 170, 182. Obwohl Schulte sich im Kampf gegen die „Euthanasie"-Aktion verdient gemacht und von der Deportation bedrohte Juden in seiner Klinik versteckt hatte, trat er noch 1947 für die Zwangssterilisation "Schwachsinniger" ein; vgl. Schmacke/ Güse, Zwangssterilisiert, S. 141.

260 Vgl. IfZ, NO 895, Braune an Oberstaatsanwalt bei LG Frankfurt a. Main, 12.9. 1946. Der Terminkalender Braunes vermeldet allein fünfmal den Namen Dohnanyi; vgl. Braune an Klaus von Doh- 
schrift mitgearbeitet hat. Dafür sprechen auch die juristische Diktion der Denkschrift - bei völligem Fehlen theologischer Argumente - und Hinweise etwa auf die "Unverletzlichkeit der Person“, die man "ohne jeden Rechtsschutz“ nicht preisgeben dürfe ${ }^{261}$. Nach außen trat Braune als alleiniger Verfasser der unter dem 9.Juli datierten Denkschrift in Erscheinung, was seine Inhaftierung vom 12. August bis zum 31. Oktober 1940 zur Folge hatte. Hans von Dohnanyi und Karl Bonhoeffer mußten im Hintergrund bleiben, wenn sie ihre seit 1938 bestehenden Umsturzpläne nicht gefährden wollten ${ }^{262}$. Der Inhalt dieser schon seit 1947 bekannten Denkschrift, die wesentlich vor getarnten „Verlegungen“ von Anstaltsinsassen warnt und die angeblich "natürlichen“ Todesursachen enttarnt, braucht hier nicht noch einmal referiert werden.

Braune und von Bodelschwingh erhielten durch Dohnanyis Vermittlung Gelegenheit, Justizminister Gürtner am 12.Juli 1940 die Denkschrift zu überreichen, die Begegnung fand aus Sicherheitsgründen in Gürtners Privathaus statt. Auf Karl Bonhoeffers Vorschlag nahm sein Kollege Ferdinand Sauerbruch an der Zusammenkunft teil ${ }^{263}$, um als Mediziner die Theologen zu unterstützen. Der Reichsjustizminister, der sich in früheren Jahren verschiedentlich gegen eine „Euthanasie“" ausgesprochen hatte ${ }^{264}$, reagierte Braune zufolge entsetzt und erschrocken auf die Fakten des Berichtes: „Der erste Satz seiner Erwiderung ist mir noch deutlich im Gedächtnis: ,Es ist für einen Reichsjustizminister eine fatale Angelegenheit, wenn ihm von glaubwürdigster Seite gesagt wird: In Deinem Reich wird am laufenden Band gemordet, und Du weißt nichts davon!' Er äußerte sich dann ausführlich über die Ungesetzlichkeit solcher Maßnahmen, teilte völlig unsere Auffassung über die Rechtlosigkeit und Gottlosigkeit solchen Vorgehens. [.. .] Wir waren erstaunt, daß wir bei ihm als einem Mitglied der Reichsregierung ein so volles Verständnis für unseren Einspruch fanden. Er versprach uns zu helfen ${ }^{\star 265}$.

Am 23.Juli 1940 bat Gürtner den Chef der Reichskanzlei, Lammers, „den gesetzlosen Tötungen entweder Einhalt zu gebieten oder sie zumindest auf eine ge-

nanyi, 1.11. 1985, nach Müller, Bonhoeffers Kampf, S.292ff. Auch in dem Notizkalender, den Christine von Dohnanyi führte, heißt es am 27.5. 1940: „16 [Uhr, U.G.] Pfarrer Lobethal“; vgl. NL D.

261 Braune, Denkschrift, S.31f.

${ }^{262}$ Ein besonders auffälliges Zeichen hierfür ist auch, daß Dohnanyi in Gegenwart Roland Freislers im Reichsjustizministerium den „Führerbefehl“ zur "Euthanasie“ als verbindliches Recht anerkannte; vgl. Klee, Dokumente, S.204-207, Kreyssig an Frankfurter Staatsanwaltschaft, 1.3. 1963. Dohnanyi war bereits mehrmals mit Freisler zusammengestoßen, vgl. Strohm, Theologische Ethik, S. 266-278, von einem Mitarbeiter Freislers denunziert und daraufhin aus dem Justizministerium entfernt worden, vgl. Chowaniec, „Fall Dohnanyi“, S.14, und konnte es sich angesichts seiner Widerstandspläne nicht mehr erlauben, ein weiteres Mal denunziert zu werden.

${ }^{263}$ So Bonhoeffers Kollege von der Gynäkologie, vgl. Stoeckel, Erinnerungen, S.326f., 342. Sauerbruch hatte die Nationalsozialisten 1933 mit Einschränkungen begrüßt, war allerdings später von ihnen wieder abgerückt; vgl. Kudlien/Christian, Sauerbruch; Genschorek, Sauerbruch. Er versorgte Bonhoeffer mit "Neuigkeiten aus der Parteihierarchie“, vgl. Bethge, Bonhoeffer, S.702.

${ }^{264}$ Siehe S. $49 \mathrm{f}$.

${ }^{265}$ Vgl. Braune, Niederschrift, 12.9. 1946, zit. nach Gruchmann, Justiz, S. 507. 
setzliche Grundlage zu stellen“, was Hitler ablehnte. Daraufhin forderte er, jedenfalls „genaue Durchführungsbestimmungen“" zu erlassen ${ }^{266}$, was Hitler ebenfalls ablehnte. Gürtner muß in eine schwere innere Krise geraten sein und soll sogar seinen Rücktritt erwogen haben ${ }^{267}$. Am 29. Januar 1941 starb er; damit verloren Bonhoeffer und Dohnanyi den letzten einflußreichen Ansprechpartner im Regierungsbereich.

Noch geringer war die Wirkung der Denkschrift im kirchlichen Bereich. Zwar wurde sie von der Kirchenkanzlei der Deutschen Evangelischen Kirche (der offiziellen, nicht der Bekennenden Kirche) mit Billigung des geistlichen Vertrauensrates am 16.Juli 1940 an den Chef der Reichskanzlei mit der Bitte weitergeleitet, die Maßnahmen "wie sie in dem vorliegenden Bericht behauptet werden", nach ihrer "rechtlichen, medizinischen, sittlichen und staatspolizeilichen Seite" zu prüfen. Zu weiteren Schritten war aber der Vertrauensrat nicht bereit. Man beschränkte sich darauf, an das Reichsinnenministerium zu schreiben: „Der geistliche Vertrauensrat der DEK glaubt davon Abstand nehmen zu sollen, zu der Frage gesetzlicher Maßnahmen über die Ausmerzung lebensunwerten Lebens namens der ev. Kirche in ähnlicher Weise Stellung zu nehmen, wie das die ,In imprema sacra congregatio sancti officii' in Rom in ihrem Decretum vom 27. November 1940 getan hat. Die evangelische Kirche kennt keine Instanz, die mit autoritativer Lehrgewalt ausgestattet wäre und Entscheidungen zu treffen habe, die auch für den Staat verbindlich sein sollen. Sie ist der Meinung, daß die staatliche Gesetzgebung vom Staate selbst und seinen verantwortlichen Leitern vor Gott und dem eigenen Gewissen verantwortet werden muß. Deshalb beschränkt sich der geistliche Vertrauensrat darauf, auf den schweren Ernst der zu treffenden Entscheidung hinzuweisen" 268 .

Karl Bonhoeffer hatte inzwischen Kontakt zum Landesbischof von Württemberg, Theophil Wurm, aufgenommen (Zeitpunkt ungewiß) ${ }^{269}$. Wurm, von dem Braune zuvor Beweismaterial für eine beabsichtigte Ergänzung seiner Denkschrift erbeten hatte ${ }^{270}$, hatte inzwischen bei Innenminister Frick gegen die „Eu-

${ }^{266}$ Gruchmann, Justiz, S. 507, 513.

${ }^{267}$ So berichtet der „illegale“ Dahlemer Gemeindepfarrer Helmuth Gollwitzer von einem Gespräch mit dem Justizminister in dessen Privathaus in der Nacht vom 3. auf den 4. 9.1940. Er habe Gürtner darin bestärkt, im Amt zu bleiben: „Das ist mir eines der Exempel, wo diese Formel ,um Schlimmeres zu verhüten', die so oft eine heuchlerische Formel ist, genau zutrifft. Nämlich für jemanden, der durch Irrtum oder Schuld schon so tief sich hineinverwickelt hat, das er jetzt nur noch versuchen kann, in dem Unheil, das er mitangerichtet hat, einiges zu mildern und einige Leben zu retten [. . .] Hitler hätte ja seinen Rücktritt sofort angenommen, ohne daß ihm irgendetwas passiert wäre, und er hätte eine große Pension bekommen." Vgl. Niederschrift, 3.10. 1979, Archiv der Aktion Sühnezeichen Az. 021/5186, S. 1 f., nach Willems, Kreyssigs Protest, S. 102.

${ }^{268}$ Vgl. Klügel, Lutherische Landeskirche II, S.175, 177.

269 Vgl. Bethge, Bonhoeffer, S. 774.

${ }^{270}$ Braune erbat „Einzelmaterial“, eine „Sammlung einzelner Fälle, mit genauen Daten: woher gekommen, wann in Grafeneck eingeliefert, wann und woran gestorben", Braune an Wurm, o.D. (zwischen 19.7. und 6.8.1940), nach Schmuhl, Rassenhygiene, S.317. 
thanasie"-Maßnahmen protestiert ${ }^{271}$. In diesem Zusammenhang wurde Dietrich Bonhoeffer um eine theologische Stellungnahme zu einem Vortrag Wurms gegen die „Euthanasie"-Aktion gebeten ${ }^{272}$. Hans von Dohnanyi und Dietrich Bonhoeffer haben noch verschiedentlich mit Bodelschwingh Kontakt gehabt ${ }^{273}$.

Noch in einem weiteren Falle förderte Bonhoeffer einen Protest gegen die „Euthanasie“-Aktion. Da die Herausgeber von Fachzeitschriften üblicherweise auch für jeden in ihrer Zeitschrift erschienenen politisch mißliebigen Artikel zur Rechenschaft gezogen wurden ${ }^{274}$, trug Bonhoeffer als Herausgeber der letzten ihm verbliebenen Zeitschrift, des Centralblattes für Neurologie und Psychiatrie, auch die Verantwortung für eine von Geheimrat Ilberg verfaßte Rezension, in der folgendermaßen gegen die „Euthanasie“-Aktion Stellung genommen wurde: „Man hatte die Meinung vertreten, der Psychiater stehe auf verlorenem Posten, Geisteskranke und Nervenkranke bedürften keiner oder nur eines Minimums von Betreuung, die Psychiatrie werde immer überflüssiger, man brauche für sie keine Pfleger, die von richtiger Krankenpflege etwas verständen, am besten man löse eine Anstalt nach der anderen auf. [...] Wenn man heutzutage die Psychiatrie, d.i. die Lehre von der kranken Seele und was mit ihr zusammenhängt, keineswegs selten für minderwertig und entbehrlich ansieht, ja die Erbkranken und mit ihnen oft die Geisteskranken überhaupt herabwürdigt, ja für die Vernichtung schwerer Fälle eintritt - natürlich soweit es sich nicht um Erkrankungen in der eigenen Familie handelt! -, so ist das ein großes Unrecht ${ }^{\text {“275. }}$.

Obwohl Ilberg seine Kritik an der „Euthanasie“-Aktion noch relativ verhalten abgefaßt hatte, entbehrte sie im zeitgenössischen Kontext nicht der Deutlichkeit und Eindeutigkeit. In dem kleinen Kreis wissenschaftlich orientierter Psychiatrie mußte es Aufsehen erregen, wenn dies ausgerechnet durch einen Freund Karl Bonhoeffers geschah ${ }^{276}$, der gemeinsam mit ihm den Vorstand des Deutschen Vereins für Psychiatrie gegen die "Gleichschaltung" zu verteidigen ver-

271 Vgl. Beckmann, Kirchliches Jahrbuch 1933-1945, S. 412 ff. Von diesem Protestschreiben verschickte er auch ein Exemplar an Braune und Bodelschwingh; vgl. Schmuhl, Rassenhygiene, S.317. Im Widerspruch dazu haben mehrere württembergische Oberkirchenräte gegenüber nationalsozialistischen Behörden behauptet, es handele sich um einen "Privatbrief“ Wurms, dessen Verbreitung in kirchlichen Kreisen wider Willen des Landesbischofs von unbekannter Seite, wohl von einer undichten Stelle im Reichsinnenministerium, betrieben worden sei. Diese Version klingt extrem unglaubwürdig; es dürfte sich um eine Notlüge handeln. Anders Klee, Dokumente, S. 143; Schmuhl, Rassenhygiene, S. 316.

272 Siehe S. 126.

${ }^{273}$ Dohnanyi mit Bodelschwingh am 12.12. 1940, vgl. NL D, Eintrag Notizkalender Christine von Dohnanyi. Reise Dietrich Bonhoeffers nach Bethel zu unbekanntem Zeitpunkt, vgl. NL D, 14 I, Bl. 35, Haftnotiz Hans von Dohnanyi, 10.8. 1943.

${ }^{274}$ Siehe S. 89.

${ }^{275}$ Ilberg, Rez. Enge, Zukunft. Der rezensierte Aufsatz kann ebenfalls als ein Protest gegen die „Euthanasie“-Aktion gedeutet werden, die der von Enge geleiteten Anstalt Lübeck-Strechnitz drohte; vgl. Delius, Ende.

${ }^{276}$ So charakterisiert ihn Ilbergs nächster noch lebender Verwandter, sein Neffe Prof. Dr. Egmont Zechlin; mdl. Auskunft, 12.5. 1990. Bonhoeffer hatte die Festschrift zu Ilbergs 70. Geburtstag herausgegeben; vgl. AZP 97 (1932). 
sucht hatte und zudem bis 1922 Leiter der Anstalt Sonnenstein bei Pirna gewesen war, derjenigen Anstalt, die 1940 geschlossen und zur Aufstellung von Gaskammern genutzt worden war. Berthold Kihn, Professor für Psychiatrie in Jena und außerdem „Euthanasie“-Gutachter, denunzierte ihn bei Ministerialdirektor Linden im Reichsinnenministerium. Dieser wandte sich an Hermann Paul Nitsche, der inzwischen vom Nachfolger Ilbergs zum stellvertretender Leiter der „Euthanasie“-Zentrale aufgestiegen war: „Wer ist denn der Schriftleiter des ,Zentralblattes für die gesamte Neurologie und Psychiatrie‘? Man müßte meines Erachtens diesen Herren eine Verwarnung zukommen lassen. Es geht selbstverständlich nicht an, daß Maßnahmen, die von Staats wegen durchgeführt werden, in einer derartigen Weise in der Öffentlichkeit kritisiert werden “277. Daraufhin erteilte Nitsche der Schriftleitung des Centralblattes ${ }^{278}$ einen offiziellen Verweis: „Ich kann nicht umhin, mein Befremden darüber zum Ausdruck zu bringen, daß die Redaktion des Zentralblattes eine solche Behandlung so wichtiger Fragen zulassen konnte. [...] Damit wird in dem Referat eine Massnahme, die heute von zahlreichen verantwortungsbewussten Menschen aus ethisch hochwertigen Gründen befürwortet und auch [...] von weiten Kreisen des Volkes eindeutig gebilligt wird, diffamiert“ ${ }^{\text {"279 }}$. Es folgte eine mündlich geführte Aussprache zwischen Bonhoeffer und Nitsche, von der Bonhoeffer nach Kriegsende einer emigrierten Schülerin berichtete: „Einer der führenden psychiatr. Nazis, Nitsche, der in Heidelberg Assistent bei mir war (04) ${ }^{280}$, hat mir das Zeugnis ausgestellt, ,ich sei einer von den ewig Gestrigen', was mir in dem Zusammenhang, in dem das gesagt wurde, eine Ehre war. Er ist vor einigen Tagen zum Tode verurteilt worden, wegen Beteiligung an den Vergasungen Geisteskranker. Die Einzelheiten sind mir nicht bekannt. Früher ein harmloser Durchschnittspsychiater, für ,psychische Hygiene' interessiert, ist er zum ,Euthanasiefanatiker' geworden mit diesem düsteren Ende ${ }^{281}$.

Die eher beiläufige Schilderung läßt erkennen, daß Bonhoeffer selbst mit einem der Hauptverantwortlichen für die „Euthanasie“-Aktion verhältnismäßig

277 Vgl. BAK, R 96 I 9, Bl. 12825, Linden an Nitsche, 20.8. 1942.

${ }^{278} \mathrm{Ob}$ Nitsche sich auch bei Ilberg beschwerte, ist nicht bekannt. Ilberg starb am 11.9. 1942; vgl. Kürbitz, Ilberg.

${ }^{279}$ Vgl. BAK, R 96 I 9, Bl. 127428f., Nitsche an Zutt (Entwurf), 3. 9. 1942. Bonhoeffer war Herausgeber, Zutt hatte die Redaktion inne.

${ }^{280}$ Bonhoeffer hatte Nitsche während seiner Heidelberger Tätigkeit (Sommersemester 1904) von seinem Vorgänger Kraepelin übernommen.

281 Focke, Begegnung Seidemann, S. 138, Bonhoeffer an Seidemann, 10.7. 1947: „Der Tod scheint mir hier eine sinnlose Strafe. Ich möchte wohl versuchen, sie in irgend eine Arbeitsstrafe zu verwandeln, in der er zu Besinnung gebracht werden kann. Ich fürchte, es wird nicht gelingen. " Im nächsten Brief berichtete Bonhoeffer zunächst scheinbar zusammenhangslos von der "Sorge um die Kinder während der Verfolgungen durch die Gestapo“, um dann zu erläutern, daß „die Einschätzung des Todes - wie übrigens auch schon während des ersten Weltkrieges - eine andere Bewertung bekommen hat. Damit hängt vielleicht auch meine Meinung über die Todesstrafe, die ich bei vielen Kriegsverbrechern besser durch Arbeitszwang ersetzt wünschte, zusammen.“ Ebenda, S. 140, Bonhoeffer an Seidemann, 12.10. 1947. 
offen diskutierte. Zwar wäre Nitsche jederzeit in der Lage gewesen, Bonhoeffer und Ilberg zur Rechenschaft zu ziehen, doch scheint er den Emeriti eine gewisse Narrenfreiheit eingeräumt zu haben. So blieb die Rezension folgenlos und Bonhoeffer wurde nicht einmal von der Herausgabe des Centralblattes entbunden, das er erst nach Kriegsende einem Schüler übergab.

\section{Rückblick nach Kriegsende}

In dieser durch Trauer um die ermordeten Angehörigen gezeichneten Lebensphase fand Bonhoeffer erst allmählich ein „Maß von Lebensbejahung und Hoffnung“, welches "mir zu arbeiten ermöglichte“ ${ }^{282}$. Doch mußte er notgedrungen wieder berufstätig werden: Pensionen des als faschistisch angesehenen, preußischen Staates wurden im sowjetischen Sektor nicht ausbezahlt ${ }^{283}$. Zwei Töchter und zwei Schwiegertöchter, die Witwen der Hingerichteten, hatten z.T. ebenfalls keinen Pensionsanspruch; sie und ihre Kinder mußten unterstützt werden. So beantragte Bonhoeffer bei der Universität, „mich zu reaktivieren und mir einen Forschungsauftrag [...] zu verleihen ${ }^{\text {" } 284}$, wehrte aber die ihm angetragene Leitung der Psychiatrischen und Nervenklinik in der Charité erfolgreich $a b^{285}$. Neben der Forschungsprofessur wurde er konsultierend für die Kuranstalt Westend ${ }^{286}$ und als dirigierender Arzt für die Wittenauer Heilanstalten tätig.

Es liegt auf der Hand, daß Bonhoeffer im Alter zwischen 77 und 80 Jahren unter dieser - schon für einen jungen Menschen ungewöhnlichen - Mehrfachbelastung kaum mehr Kraft und Zeit für die aktuellen politischen Fragen gefunden hat. Zum Nürnberger Ärzteprozeß hat er keine Stellungnahme abgegeben, bedauerlich insofern, als dort etliche Berliner Fakultätsmitglieder genannt wurden und Bonhoeffers diesbezügliches Votum von Interesse gewesen wäre ${ }^{287}$. Im-

282 Ebenda, S. 133, Bonhoeffer an Seidemann, 9.11. 1947.

${ }^{283}$ Erst nach Sonderantrag der Fakultät erkannte der Ministerrat der DDR seiner Witwe 1950 „in Würdigung der Verdienste Ihres verstorbenen Gatten“ eine Personalpension zu; vgl. HUB, 378, Personalakte Bonhoeffer, Roggenbau an Brugsch, 22.11. 1949.

$284 \mathrm{Vgl}$. HUB, 378, Personalakte Bonhoeffer, Bonhoeffer an Rektor, 30.11. 1945.

285 Vgl. HUB, Med. Fak. 2335, Fakultätsratsprotokoll, 29.10. 1947.

286 Zutt, Karl Bonhoeffer, S.7.

${ }^{287}$ Bei Mitscherlich/Mielke, Diktat und Platen-Hallermund, Ärzteprozess, fanden Erwähnung: De Crinis wegen Beteiligung an der „Euthanasie“-Aktion, von Hallervorden wegen hirnpathologischer Forschungen an „Euthanasie“-Opfern, Sauerbruch und Heubner wegen Nichtprotestes gegen Menschenversuche. Bonhoeffer war an den meisten diesbezüglichen Fakultätsratssitzungen krankheitshalber verhindert; vgl. HUB, Med. Fak. 2335, Fakultätsratsprotokolle von 1947. Einem Schreiben Heubners kann man entnehmen, daß dessen Polemik gegen Mitscherlich/Mielke „einigen prominenten Fakultätsmitgliedern [...] Bauchschmerzen“ bereitete und daß die „älteren“ Wert legten auf die Feststellung, „daß die am Ärzteprozess beteiligten Berliner gegen den Willen der Fakultät berufen worden waren"; vgl. HUB, Med. Fak. 13, Bl. 45, Heubner an Hoepke, 4.9. 1947. Sauerbruch/Heubner einerseits und Mitscherlich andererseits haben ihre Kontroverse öffentlich ausgetragen, vgl. den Anhang von Mitscherlich/Mielke, Wissenschaft, S. 279-298; vgl. auch ihren Briefwechsel HUB, Med. Fak. 13, Bl. $40 \mathrm{ff.}$ 
merhin kam es noch (teilweise posthum) zu weiteren Veröffentlichungen, die alle auf die Zeit des Nationalsozialismus bezogen sind. Eine sehr knappe Stellungnahme behandelt die psychischen Schäden, die Folter und KZ-Haft verursachen konnten ${ }^{288}$. Diese kurze Erwähnung ist für ein Jahrzehnt die einzige diesbezügliche Stellungnahme aus dem Bereich der deutschen Psychiatrie. Ein Hinweis findet sich bei Bonhoeffer auch auf die gezielte Unterernährung der Patientinnen und Patienten in der Heilanstalt Wittenau ${ }^{289}$.

Im posthum erschienenen Vorwort für eine neugegründete psychiatrische Zeitschrift nahm Bonhoeffer grundsätzlich dazu Stellung, was er von der Psychiatrie der Zukunft erwartete: „Wir hoffen mit dieser Neugründung nicht nur für die Nervenkliniken, Anstalten und die wissenschaftlich arbeitenden Fachgenossen der sowjetischen Besatzungszone ein Publikationsorgan zu schaffen [...], sondern über die Zonengrenzen hinweg die wissenschaftlichen Beziehungen zu pflegen und durch die Mitarbeit der Kollegen aus allen deutschen Gauen und dem Ausland den alten Zusammenschluß zu gewinnen, der früher selbstverständlich war und den wir auf den regelmäßigen Jahresversammlungen der deutschen Psychiater und Neurologen seinen äußeren Ausdruck finden sahen. Man denkt an diese Zeit wissenschaftlicher und kollegialer Zusammenarbeit mit Sehnsucht zurück, nachdem man den Abstieg durch die nationalsozialistische Politisierung und Terrorisierung auch in unserem Fach durchlebt hat. [...] Eine Erweiterung des Stoffgebietes in der Richtung der [...] Nachbargebiete erscheint uns zunächst um dieser selbst willen geboten und dann, um dem Nervenarzt diese heute besonders wichtige soziale Seite der Grenzgebiete zur Anschauung zu bringen. [...] Das gilt heute im besonderen Maße, nachdem von der nationalsozialistischen Ideologie die Betätigung in der Psychiatrie, insofern sie sich mit voraussichtlich Unheilbaren und dauernd Arbeitsunfähigen beschäftigt hat, als ,sinnwidrige Humanitätsduselei ${ }^{i}$ und ,Ausdruck einer überholten Weltanschauung bezeichnet worden ist, eine Auffassung, die schließlich während des Krieges ihre letzte Auswirkung in der systematischen Tötung von Tausenden von Geisteskranken gefunden hat. Die deutsche Psychiatrie hat begreiflicherweise durch diese Vorgänge einen schweren Schaden an Vertrauen im In- und Ausland genommen. Wenn wir selbst auch wissen, daß es eine unzutreffende Verallgemeinerung ist, eine solche Entartung des ärztlichen Denkens einzelner fanatisierter nationalsozialistischer Ärzte dem deutschen Psychiater generell zu unterstellen, so wird es Zeit und Anstrengung erfordern, das Vertrauen der Bevölkerung und das Ansehen, das der deutsche Nervenarzt in wissenschaftlicher und humanitärer Hinsicht vor 1933 gehabt hat, wiederherzustellen. Daran mitzuarbeiten wird die nächste Aufgabe der neuen Zeitschrift sein“290.

\footnotetext{
${ }^{288}$ Bonhoeffer, Psychopathologische Erfahrungen, S.4. Eine Auseinandersetzung mit Aly/Pross, Offener Brief, kann an dieser Stelle nicht geführt werden.

289 Bonhoeffer, Psychopathologische Erfahrungen, S.4.

290 Bonhoeffer, Vorwort, in: Psychiatrie 1 (1949).
} 
Dieses Vorwort hat dazu gedient, Bonhoeffer für die Verdrängung des Nationalsozialismus beim Wiederaufbau der Psychiatrie in der Bundesrepublik Deutschland verantwortlich zu machen. Um diese These vertreten zu können muß dazu allerdings nicht nur aus dem Zusammenhang gerissen zitiert ${ }^{291}$, sondern berücksichtigt werden, daß das Buch in der Sowjetischen Besatzungszone erschienen war. Tatsächlich handelt es sich hierbei um das einzige Vorwort zur ersten Nachkriegsnummer einer deutschen psychiatrische Zeitschrift, in dem die Morde der Vergangenheit überhaupt thematisiert wurden.

Inhaltlich ist bemerkenswert, daß Bonhoeffer die nationalsozialistische „Politisierung und Terrorisierung " durch einen Abfall von Wissenschaftlichkeit und von Humanität beschrieben hat, also die nationalsozialistische Rassenpolitik als unwissenschaftlich und inhuman ansah. Abhilfe versprach er sich von einer Rückkehr zu beiden Prinzipien, von einer Öffnung der Psychiatrie gegenüber der von den Nachbardiszplinen stärker betonten sozialen Seite. Seine starke Warnung vor einer "Politisierung" der Psychiatrie entsprach seinem immer schon geäußerten Wunsch, frei von Behinderungen durch die Politik wissenschaftlich tätig sein zu können, mag jedoch angesichts kommunistischer „Politisierung“ in der sowjetischen Zone auch eine aktuelle Spitze enthalten haben ${ }^{292}$ : Der Wunsch, „über die Zonengrenzen hinweg“ psychiatrische Wissenschaft treiben zu dürfen, richtete sich auf dem Höhepunkt der Berlin-Blockade unverkennbar an die Adresse der Sowjets.

Im (gleichfalls posthum erschienenen) „Rückblick auf das nationalsozialistische Sterilisationsgesetz "293 vergleicht Bonhoeffer das radikale deutsche Vorgehen mit der Praxis im Ausland und stellt fest, „daß dem nationalsozialistischen Gesetz in seiner rigorosen Zwangsformulierung kein anderer Staat gefolgt ist“".

291 Vgl. Grell, Bonhoeffer, S. $214 \mathrm{f}$.: Als „Erklärungsmuster bot er auch seinen medizinischen Kollegen an: ,Die deutsche Psychiatrie hat [...] durch die systematische Tötung von Geisteskranken [...] während des Krieges [...] begreiflicherweise einen schweren Schaden an Vertrauen im In- und Ausland genommen'. Dennoch dürfe, eine solche Entartung des ärztlichen Denkens einzelner fanatisierter nationalsozialistischer Ärzte dem deutschen Psychiater generell ${ }^{c}$ nicht unterstellt werden. Damit legte Bonhoeffer die Linie von Selbstmitleid, Abschieben der Verantwortung und von der Wahnhaftigkeit des Nationalsozialismus mit fest und leistete damit in seinen letzten Lebensjahren einen wichtigen Beitrag für das Selbstverständnis und den, Wiederaufbau' der Bundesrepublik Deutschland."

292 Bonhoeffer war bis zu seinem Tod im Ostsektor der Stadt Berlin, nämlich an der Humboldt-Universität, tätig, und ließ die Pressemeldung, er sei am Aufruf zur Gründung der FU Berlin beteiligt gewesen, ausdrücklich dementieren; vgl. Bonhoeffer gegen Westuniversität, in: ND 25.6. 1948; HUB, Personalakte Bonhoeffer, 378. Vgl. dazu auch folgende private Stellungnahme: „Ich denke, wir werden schon hier absterben müssen und ich bin so optimistisch zu glauben, daß die jetzige Krise mit einem Rückzug der Russen, d.h. mit einer Rücknahme der Blockade enden wird.“ Focke, Begegnung Seidemann, S. 157, Bonhoeffer an Seidemann, 11.10. 1948.

${ }^{293}$ Bonhoeffer, Rückblick Sterilisationsgesetz. Dem Manuskript liegt ein Vortrag zugrunde, den Bonhoeffer auf einer 'Tagung der Deutschen Zentralverwaltung für das Gesundheitswesen (sowjetische Zone) vom 22./23.11. 1946 gehalten hat und auf der die Rolle der Medizin im Nationalsozialismus behandelt wurde, vgl. den Bericht in: Das deutsche Gesundheitswesen 1947, S. 32. Die „Euthanasie"-Aktion wird deshalb kaum thematisiert, weil auf sie in einem Vortrag von Bonhoeffers Mitarbeiter Lindenberg eingegangen wurde. 
Bonhoeffer bringt hier ausführliches statistisches Material bei, identisch mit einer vom Reichsjustizministerium geführten, heute im Bundesarchiv gelagerten Statistik (vgl. Anhang dieser Arbeit), die allerdings 1935 endet, und konstatiert eine im Verlauf der dreißiger Jahre abnehmende Sterilisationswelle ${ }^{294}$. Diese These, der zwischenzeitlich wenig qualifiziert widersprochen wurde ${ }^{295}$, ist in den letzten Jahren durch die Veröffentlichung regionaler Statistiken gestützt wor$\operatorname{den}^{296}$.

Mit einer Fülle von Einzelbelegen wird weiterhin gezeigt, daß das Erbgesundheitsgesetz im Ausland bei fast allen namhaften Psychiatern auf Widerspruch gestoßen ist: „Die Gründe der Ablehnung liegen im wesentlichen in der Unvereinbarkeit mit der Idee der persönlichen Freiheit und in religiösen Bedenken; auch sei die Kenntnis der tatsächlichen Vererbungsverhältnisse noch nicht soweit gesichert, um gesetzlich formuliert zu werden." Daß dies auch sein eigener Standpunkt war, im Gutachten von 1923 dokumentiert, streift Bonhoeffer nur beiläufig in einer Fußnote - ein understatement, das zwar für ihn charakteristisch ist, aber zu Mißverständnissen geführt hat. Die „völkische“ Intention des Gesetzes gibt er unkommentiert wieder: „Im GüTr-RüDIN-RUTTKEschen Kommentar heißt es im Vorwort: ,Nicht wirtschaftliche Gesichtspunkte stehen im Vordergrund, sondern der entschlossene Wille der Regierung, den Volkskörper zu reinigen [...] eine Bresche in das Geröll und die Kleinmütigkeit einer überholten

${ }^{294}$ Bonhoeffer nannte fünf Gründe: 1. „weil die in den Anstalten angesammelten, an sich entlassungsfähigen Erbkranken [... s sterilisiert waren“, 2. "weil ein zu Anfang bestehender Übereifer mancher fachlich unzulänglich vorgebildeter und nach politischen Gesichtspunkten ausgewählter Ärzte und Amtsärzte, die glaubten, es gehöre zur Bekundung guter nationalsozialistischer Gesinnung, möglichst viele Kranke dem Erbgesundheitsverfahren zu stellen, mit der Zeit sich abgekühlt hatte“, 3. weil sich „in der Bevölkerung unter dem Einfluß des Gesetzes eine Abneigung entwickelte, ihre psychisch Kranken den Ärzten und Anstalten zuzuführen, wenn es irgend zu umgehen war, eine Abneigung, die während des Krieges noch sehr anwuchs, als die Gerüchte sich verbreiteten, daß die Anstaltskranken nach Lazaretten verlegt wurden, aus denen meist nach kurzer Zeit die Todesnachricht ihrer Angehörigen käme“, 4. habe sich der "mäßigende Einfluß der Obergerichte und die allmählich sorgfältigere Besetzung der Gerichte mit Sachverständigen, die eine Gewähr für kritische und dem Stand des Wissens angemessene Beurteilung gaben ", bemerkbar gemacht, 5. im Krieg als „Folge der Einziehung vieler Ärzte und Amtsärzte zum Heer“, was "nicht in der Absicht einer grundsätzlichen Milderung des Gesetzes" geschah.

295 Bock, Zwangssterilisation, S. 240, bespricht nur die vierte Begründung Bonhoeffers, die sie mit der nicht weiter belegten Behauptung kritisiert, daß die Obergerichte höchstens $2 \%$ aller Sterilisationsbeschlüsse korrigiert hätten. Diese Zahl gibt sie an anderer Stelle auch mit $7 \%$ an, vgl. ebenda, S. 271. Aufgrund von Bocks Hypothese gilt Bonhoeffer als besonders hartnäckiger Apologetiker; vgl. Weingart/Kroll/Bayertz, Rasse, S. 470. Eine Überprüfung anhand des Berliner Erbgesundheitsobergerichtes ergab, daß dieses in $18,25 \%$ (1935) bzw. 24,05\% (1939) aller Beschlüsse einen Sterilisationsbeschluß des Berliner Erbgesundheitsgerichts in einen "Freispruch" umwandelte und in 0\% (1935) und 3,8\% (1939) aller Beschlüsse einen „Freispruch" in einen Sterilisationsbeschluß. Durchzählung des Bestandes von S. 98 Anm. 228.

296 So verteilt sich die Zahl der gesamten Sterilisationsbeschlüsse des EG Frankfurt/ EG Hamburg folgendermaßen auf die einzelnen Jahre. 1934: 9,37\%/ 10,44\%; 1935: 24,56\%/ 21,63\%; 1936: $22,36 \% / 19,73 \%$; 1937: 17,86\%/ 14,80\%; 1938: $10,69 \% / 12,90 \% ; 1939: 5,04 \% / 8,73 \% ; 1940$ : $1,29 \% / 5,69 \% ; 1941: 1,15 \% / 3,98 \% ; 1942: 0,95 \% / 3,98 \% ; 1943: 0,64 \% / 0,38 \% ; 1944: 0,30 \% /$ 0,00\%; zusammen: 100\%/ 100\%. Zahlen in Prozentsätze umgerechnet nach Daum/Deppe, Zwangssterilisation, S.172, und Rothmaler, Sterilisationen, S.213. 
Weltanschauung und einer übertriebenen selbstmörderischen Nächstenliebe $z u$ legen, ,das Primat und die Autorität des Staates auf den Gebieten des Lebens, der Ehe und der Familie zu sichern" ".

Bonhoeffer schließt mit der Unterscheidung zwischen der Eugenik und ihrer Diskreditierung durch das NS-Regime. Auch in der Zukunft will er der erbbiologischen Forschung ein Aufgabengebiet zuweisen: „Wenn man heute zu überlegen hat, ob etwas von dem ursprünglichen Ideengehalt der Eugenik, die ja, wie schon gesagt, nicht nationalsozialistischen Ursprunges ist, aber vom Nationalsozialismus durch die Vermengung mit den menschenunwürdigsten Menschenvernichtungsversuchen aufs schwerste diskreditiert worden ist, wert ist erhalten zu werden, so würde ich glauben, daß in dem heutigen Deutschland, in dem die Lebenshaltung auf das primitive Niveau der Sorge um die Erhaltung der einfachen körperlichen Existenz der Individuen abgesunken ist, in dem Hunger, Wohnungsnot, Kindersterblichkeit, Tuberkulosegefahr im Vordergrund der Gesundheitsfürsorge stehen müssen, die Frage der genetischen Aufbesserung späterer Generationen zurücktreten und vorerst auf erziehliche Belehrung im biologischen Unterricht, auf Eheberatung u. ä. sich zu beschränken hat. Dagegen sollte die erbbiologische Forschung auf klinischem und theoretischem Gebiete besonders in den angedeuteten Richtungen, die weiterer Klärung bedürfen, unterstützt werden. Man wird sich z. B. auch der Frage zuwenden müssen, wie sich die nichtkranken Kinder von Erbkranken sozial entwickeln. Die Angabe, daß unter den Kindern von Schizophrenen und Manisch-Depressiven große Zahlen von Psychopathen sich finden, bedarf durchaus noch der Ergänzung, denn mit der Diagnose Psychopathie ist noch nichts über die soziale Brauchbarkeit gesagt. Die Untersuchung dieses Problems ist nicht unwichtig, weil von ihrem Ergebnis die Beurteilung abhängig ist, inwieweit es bevölkerungspolitisch sinnvoll ist, durch Unfruchtbarmachung eines Erbkranken einen Stamm auszulöschen."

Der achtzigjährige Bonhoeffer argumentierte hier deutlich, in Kontinuität zu seinen früheren Äußerungen, innerhalb eugenischer Denklogik. Gleichwohl votierte er nicht minder deutlich für eine Klassifizierung des Erbgesundheirsgesetzes als nationalsozialistisches - und damit zu verfemendes - Gesetz. Er widersprach damit dem Juristen Eduard Kohlrausch, der die Berliner medizinische Fakultät um ein Gutachten darüber gebeten hatte, daß das Erbgesundheitsgesetz "kein nationalsozialistisches Gesetz" gewesen $\operatorname{se}^{-297}$. Es hat lange gedauert, bis diese Einsicht Anerkennung erfuhr, denn erst 1988 hat der Bundestag der BRD, 1989 die Volkskammer der DDR eine Erklärung verabschiedet, wonach das Erbgesundheitsgesetz nationalsozialistischen Ursprunges $\operatorname{se}^{298}$. Seinerzeit fand Bon-

\footnotetext{
297 Vgl. HUB, Med. Fak. 187, S.29, Kohlrausch an Condekan, 23.6. 1946. Eine diesbezügliche Stellungnahme der Fakultät konnte nicht ermittelt werden, weil die Protokolle des Fakultätsrates zwischen dem 2.9. 1945 und dem 16.4. 1947 fehlen.

${ }^{298}$ Vgl. Dörner, Tödliches Mitleid, S. 92.
} 
hoeffers Stimme, auch durch die Dissonanzen des Kalten Krieges, nicht mehr viel Gehör. Zwar plädierte im Osten Bonhoeffers ehemaliger Schüler Hanns Schwarz unter Benutzung von Bonhoeffers Aufsatzmanuskript für die Strafverfolgung von Psychiatern, die wiederholt, diagnostisch leichtfertig und unbegründet Zwangssterilisationen beantragt oder begutachtet hatten, und verwies zum Maßstab dessen, was zwischen 1933 und 1945 möglich und jedem Arzt zuzumuten war, auf die „warnende und nicht zu überhörende Stimme Bonhoeffers und seiner Mitarbeiter" in Bonhoeffers erstem erbbiologischen Kurs von 1934, die „jede Leichtfertigkeit bei der Begutachtung Sterilisationsgefährdeter verbot" ${ }^{299}$. Doch wurden Schwarz" Überlegungen im Westen als „überflüssig“ bezeichnet ${ }^{300}$ oder mit Hinweis auf den „Bolschewismus“ des Verfassers abqualifiziert ${ }^{301}$. Im Zuge der erneuten Protegierung eines eugenischen Sterilisationsgesetzes behauptete der Eugeniker Hans Nachtsheim sogar, daß Bonhoeffer noch 1947 für ein Sterilisationsgesetz eingetreten sei ${ }^{302}$. Dadurch ist Bonhoeffers Ruf in Mißkredit geraten $^{303}$. Dieser mündlichen Überlieferung steht freilich der höhere Quellenwert der anderslautenden zahlreichen schriftlichen Dokumente gegenüber, denenzufolge Bonhoeffer gesetzliche Regelungen der Sterilisation und besonders Zwangsmaßnahmen durchweg abgelehnt hat.

\section{Medizinisches Ethos bei Karl Bonhoeffer}

Bonhoeffer war, durch seinen Lehrer Wernicke geprägt, in seinem psychiatrischen Ansatz naturwissenschaftlich und an der Hirnpathologie orientiert; seine Forschung hat in diesem „exogenen“ Bereich erstaunliche Erfolge verzeichnet.

299 Schwarz, Gutachten, S.7.

${ }^{300}$ Vgl. Gruhle, Rez. Schwarz, Gutachten.

301 Nachtsheim, Für und Wider, S. 8.

302 „Am 3.Januar 1947 lud die Zentralverwaltung für das Gesundheitswesen der Ostzone [. . . ] zu einer Besprechung der Frage der Sterilisierung und anderer eugenischer Maßnahmen. An der Besprechung nahmen teil der inzwischen verstorbene Professor Bonhoeffer, Professor Roggenbau, Professor Muckermann und ich, sowie einige Herren der Zentralverwaltung. [.. . ] Wir waren uns darüber einig, daß der Mißbrauch, der in den 12 Jahren des ,Dritten Reiches' mit dem Gesetz zur Verhütung erbkranken Nachwuchses getrieben wurde, nicht Grund sein könne und Grund sein dürfe, in $\mathrm{Zu}$ kunft auf bevölkerungspolitische und eugenische Maßnahmen zu verzichten, daß aber der Abstand, den wir damals - nicht einmal zwei Jahre nach Kriegsende - von den Greueln des Nationalsozialismus hatten, doch noch zu gering war, um aufs neue mit gesetzgeberischen Vorschlägen an die Öffentlichkeit zu treten"; Nachtsheim, Für und Wider, S.7. Nachtsheim hat im Ausschuß des Deutschen Bundestages für Wiedergutmachung sogar für ein neues $Z$ wangsgesetz plädiert, zit. nach Weingart/Kroll/Bayertz, Rasse, S. 599.

${ }^{303}$ So kommt der Nachtsheim-Schüler Vogel, Bonhoeffer nach Nachtsheim zitierend, zu dem Schluß, beide hätten nach Kriegsende die Meinung vertreten, das Erbgesundheitsgesetz habe dem Stand der Vererbungsforschung entsprochen; vgl. Vogel, ,Gesetz", S. 43. Im Anschluß an Vogel, der das Projekt ${ }_{n}$ von Anfang an auf vielfältige Weise gefördert und es sodann bis zum endgültigen Manuskript mit offener und konstruktiver Kritik begleitet ${ }^{*}$ hat, heißt es dann auch in der wichtigsten Publikation zur Geschichte der Eugenik, Bonhoeffers Einschätzung sei „ebenso fragwürdig wie etwa die Nachtsheims"; vgl. Weingart/Kroll/Bayertz, Rasse, S.11, 470. 
Gegenüber psychiatrischer Theoriebildung blieb er vorsichtig. „Durch seine Arbeiten geht ein Hauch von Bescheidung vor den ungeheuren Rätseln“, urteilt Karl Jaspers ${ }^{304}$. Daß seine differenzierte Ausdrucksweise mitunter $z u$ vorsichtig geklungen hat, zeigen die Mißverständnisse, denen seine Position bis heute ausgesetzt ist: Der entschiedene Gegner der nationalsozialistischen Doktrin und ihrer Auswüchse im Erbgesundheitsgesetz wird im nachhinein für dieses Gesetz und bedingt sogar für die nationalsozialistische Ideologie haftbar gemacht. Wohl hat Bonhoeffer der eugenischen Forschung als solcher nicht negativ gegenübergestanden, was heute zu Recht kritisiert werden darf, soweit die Kritik ein differenziertes Bild zu bewahren vermag. Doch argumentierte er in keiner Hinsicht stärker eugenisch, als das im Ausland, etwa in der Schweiz, den USA oder bei der Exil-SPD üblich war ${ }^{305}$. Tatsächlich blieb er, von der Warte einer „neutralen" Wissenschaftlichkeit aus, in außerordentlicher Weise souverän. Jaspers bescheinigt ihm den „sicheren Blick“, die „empirische Nähe zum Kleinen und den Sinn für wesentliche Grundzüge“, man wird ergänzend hinzufügen können, daß Bonhoeffer in der Herausforderung des Nationalsozialismus als Wissenschaftler und Arzt beharrlich und unbestechlich blieb. Das oben benannte wissenschaftliche Ethos, das sich um die Anerkennung der Grenzen eigener Erkenntnis mühte, stand der Tendenz entgegen, Kenntnislücken durch Vermutungen oder ideologische Prinzipien aufzufüllen.

Bonhoeffers medizinisches Ethos war von der Vorstellung des Persönlichkeitsrechts des einzelnen Menschen getragen. Dieser Ansatz kommt implizit in seinem Eintreten für freie Arzt- und Therapiewahl für psychisch Kranke zum Ausdruck $^{306}$, explizit im Gutachten von 1923 zur Zwangssterilisation ${ }^{307}$. Bonhoeffer hat diese Prämisse nicht erläutert oder begründet, sondern ihre Anerkennung wohl im Anschluß an die Weimarer Verfassung - vorausgesetzt. Er sah das Persönlichkeitsrecht für die Medizin nur im außerordentlichen Ausnahmefall eingeschränkt, wenn die Allgemeinheit akut und nachgewiesenermaßen gefährdet war und andere zum Schutz der Allgemeinheit führende Möglichkeiten nicht zur Verfügung standen ${ }^{308}$. $\mathrm{Da}$ er die These einer nachhaltigen Schädigung der Gesamtbevölkerung, die das Erbgesundheitsgesetz zu vermitteln versuchte, schon statistisch als nicht erwiesen ansah ${ }^{309}$, war nach seinem Urteil der Beweis für die Notwendigkeit dieses Gesetzes nicht zu führen. Auch in jedem Einzelfall verwahrte Bonhoeffer sich gegen die raschen Diagnosen seiner Kollegen. Die ideologischen Voraussetzungen dieser Art von „Diagnostik“ hatte er sofort erkannt.

${ }^{304}$ Jaspers, Allgemeine Psychopathologie', S.713.

${ }^{305}$ Zur Schweizer Rezeption seiner Aufsätze vgl. S. 97, zur Kritik im Ausland an der deutschen Sterilisationsgesetzgebung siehe $S .47 \mathrm{f}$.

${ }^{306}$ Siehe S. 64-66.

${ }^{307}$ Siehe S.81.

${ }^{308}$ Siehe S.81.

${ }^{309}$ Siehe S. 81; vgl. dagegen die absurde amtliche Begründung des Erbgesundheitsgesetzes, wonach die Bevölkerung in nur drei Generationen überwiegend aus Erbkranken bestünde; siehe S. 26. 
In summa kann man sagen, daß er weder der pseudoreligiösen Legitimation des Gesetzes $^{310}$ Glauben schenkte - sie stand seiner streng naturwissenschaftlichen Einstellung entgegen - noch der juristischen, welche die Gültigkeit der Menschenrechte bestritt, noch der im Gesetz vorgelegten naturwissenschaftlichen Begründung, denn nach seiner Sicht war eine „einschneidende Wirkung auf die Beseitigung der in Betracht kommenden Krankheiten" ${ }^{\text {311 }}$ nicht zu erwarten.

Bonhoeffer hat nie die nationalsozialistische Gesetzgebung frontal angegriffen - hierfür hätte sich am ehesten die Tagung des Deutschen Vereins für Psychiatrie vom Mai 1934 angeboten -, sondern immer nur indirekt kritisiert. Hatte er in den Jahren zuvor seine Einwände gegen verschiedene Gesetzesentwürfe deutlich artikuliert, kam er nun zu der Meinung, daß „bei der Mentalität des Nationalsozialismus“ an eine „Rücknahme des Zwangsgesetzes“ nicht zu denken gewesen sei $^{312}$, und übte Kritik innerhalb des durch das Gesetz abgesteckten Rahmens. Dies geschah freilich in einer Form, die viele seiner Zeitgenossen, z. B. seine Schweizer Kollegen, als grundsätzliche Kritik an den Zwangsmaßnahmen verstanden. Bonhoeffers Dilemma bestand darin, daß die Arbeit an der Entschärfung des Gesetzes ihm nur unter der Voraussetzung möglich war, daß es implizit nicht nur als der Legalität nach existierend, sondern als legitim anerkannt wurde.

In nüchterner Erkenntnis dessen, was ihm - auch altersbedingt, aber auch mit den Mitteln seiner Autorität - möglich war, fand Karl Bonhoeffer zu seiner Methode, sich zu widersetzen. Es ist wichtig festzuhalten, daß es ihm gut möglich gewesen wäre, sich um des persönlichen Gewissens willen nicht an der Durchführung des Gesetzes zu beteiligen: Der ursprünglich geplante Antrag auf Emeritierung mit Erreichen des 65. Lebensjahres (1933) wäre ein verhältnismäßig konfliktfreier Weg gewesen ${ }^{313}$. Eine weitere "gesinnungsethische" Alternative wäre jene Verfahrensweise gewesen, die den katholischen Ärzten durch den katholischen Episkopat geraten wurde: allein der gesetzlich gebotenen Anzeigepflicht $\mathrm{zu}$ genügen und jede weitergehende Beteiligung an der Durchführung des Erbgesundheitsgesetzes zu unterlassen ${ }^{314}$. Bonhoeffer verhielt sich anders (gegenüber der katholisch protegierten Position praktisch gegenläufig), indem er die als Erfassungsvoraussetzung entscheidende Anzeige verweigerte und auf seiner Schweigepflicht beharrte, und bei denjenigen, die einmal angezeigt waren, mit seinen Gutachten möglichst oft eine Sterilisation $\mathrm{zu}$ vermeiden versuchte. Das ärztliche Ethos artikuliert sich hier so, daß auf der Schweigepflicht und einer de-

\footnotetext{
${ }^{310} \mathrm{Zu}$ den drei Legitimationsweisen des Gesetzes siehe S. 42-49.

${ }^{311}$ Leitsätze zum Gutachten von 1923; siehe S. 83.

312 Bonhoeffer, Lebenserinnerungen, S. 102; siehe S. 87.

${ }^{313}$ Siehe S.68.

${ }^{314}$ Auf diesen Weg verwies die Kanzelabkündigung der Bischöfe die katholischen Ärzte. Zur Begründung bemühte man die alte Unterscheidung, was die "Beteiligung“ an einem sündhaften Vorgehen ausmache. Eine Antragstellung galt als "cooperatio formalis" und damit als sündhaft, die Anzeige aber als "cooperatio materialis" und zog keine Schuld nach sich; vgl. Nowak, "Euthanasie", S.117. Im Ergebnis blieben damit die Sterilisationszahlen pro Kopf der Bevölkerung in protestantischen und katholischen Gebieten in etwa gleich; vgl. die Sterilisationsstatistik im Anhang.
} 
taillierten Diagnose beharrt wird, zudem die Differenzierung der Diagnose dann bewußt gesteigert, damit die Betroffenen dem Weg in die Sterilisation entkommen. Diese Weise des Umgangs mit dem Terror des Sterilisationsgesetzes könnte man insofern als verantwortliche Folgenabschätzung bezeichnen, als hier nicht das Ausmaß der Beteiligung, sondern die Folgen des Handelns für die jeweils davon Betroffenen ein zentrales Beurteilungskriterium bilden.

In seinen zwischen 1933 und 1945 veröffentlichten Aufsätzen hat Bonhoeffer diesen Ansatz konsequent verfolgt, indem er zu jeder psychiatrisch relevanten "Erbkrankheit" die Möglichkeiten einer Alternativdiagnose aufzeigte. Die Tendenz seiner Methode wurde schnell begriffen, und Bonhoeffer mußte nicht nur "wissenschaftliche" Kritik, sondern schließlich das Verbot seiner Kurse und die Warnung vor seinen Aufsätzen hinnehmen. Dennoch schützte ihn die Autorität als „international anerkannte Kapazität“ vor „noch schärferen Angriffen“315. Entscheidend dabei war Bonhoeffers Fähigkeit, fachliche Kompetenz und allgemeine politische Verantwortung so zu verbinden, daß unter den Bedingungen der NS-Herrschaft die intendierte Obstruktion der NS-Politik als nur fachliche Teilkritik erscheinen konnte. $\mathrm{Da}$ er über weite Strecken an wissenschaftliche Veröffentlichungen der eigenen Klinik aus der Zeit vor 1933 anknüpfte, freilich zugunsten potentieller Sterilisationsopfer die Alternativdiagnosen ungleich stärker akzentuierte, war sein Verhalten wissenschaftlich schwer angreifbar.

Bonhoeffer stand mit diesem Bestreben, das Erbgesundheitsgesetz auf dem Weg der Diagnose zu entschärfen, nicht völlig allein da. So soll der Münchner Psychiater Kurt Schneider seinen "weiten“ Psychopathie-Begriff dafür genutzt haben, eine Sterilisation aufgrund von Schizophrenie zu vermeiden ${ }^{316}$, der Leipziger Ordinarius Hans Berger seine Assistenzärzte dazu aufgefordert haben, bei Sterilisationsgutachten jedes „noch so fadenscheinige organ-neurologische Symptom “ und jeden "vagen psycho-reaktiven Zusammenhang " ${ }^{1317}$ detailliert herauszuarbeiten. Bemerkenswert ist auch der Versuch Karl Kleists und seiner Mitarbeiter (vor allem Karl Leonhards) - gerade im Hinblick auf die gemeinsame Herkunft Kleists und Bonhoeffers aus der Wernicke-Schule -, in Publikationen den Schizophrenie-Begriff anders zu fassen und damit die Sterilisationen einzuschränken ${ }^{318}$. Dennoch läßt sich kein zweiter deutscher Psychiater auffinden,

315 Schmidt, „Epileptische Wesensveränderung“, S.116; vgl. auch die große Zahl von Kritikern Bonhoeffers, die seine Aufsätze wörtlich, aber ohne Namensnennung zitierten.

316 Vgl. Weber, „Ein Forschungsinstitut“.

317 So Bergers damaliger Assistenzarzt Schulte, „Euthanasie“, S.78.

318 Vgl. Kleist/Driest, Katatonie I, mit der disqualifizierenden "Anmerkung c der Redaktion (Rüdin), man habe die Spalten der Zeitschrift nur zur Verfügung gestellt, „um jeder Meinungsäußerung die Möglichkeit zu geben, gehört zu werden“, man glaube aber nicht, daß den Verfassern der „Beweis dessen gelang, was sie bewiesen zu haben glauben“. Vgl. ferner Schwab, Katatonie II; Kleist/Leonhard/Schwab, Katatonie III; Leonhard, Defektschizophrene Krankheitsbilder; Schulz/Leonhard, Erbbiologisch-klinische Untersuchungen. Von seiten Kleists lag dem die Auffassung zugrunde, daß die Vererbung von Krankheiten wie der Schizophrenie, dem Manisch-Depressiven und der Epilepsie nicht bewiesen sei, wobei Kleist aber gleichzeitig dafür plädierte, die "schweren selbständigen Psychopathien, aus denen die Mehrzahl der Gewohnheitsverbrecher, 
der mit einer ähnlichen Konsequenz wie Karl Bonhoeffer versucht hätte, das Gesetz auf dem Weg der Durchführung zu entschärfen, indem er konsequent für sämtliche relevanten Diagnosen Alternativdiagnosen herausarbeitete.

Der Prozentsatz derjenigen Sterilisationsgutachten, in denen Bonhoeffer oder seine Mitarbeiterinnen und Mitarbeiter die Sterilisation befürwortet haben, ist zwar deutlich geringer als im Reichsdurchschnitt, aber immer noch hoch. Inwiefern Bonhoeffer hier das Bestmögliche getan hat, muß offen bleiben, solange es an Vergleichsstudien aus anderen Kliniken fehlt. Es kann aber davon ausgegangen werden, daß kein Chefarzt einer größeren deutschen psychiatrischen Klinik Zwangssterilisationen völlig hat verhindern können, auch wenn einige Autobiographien dies zu suggerieren scheinen ${ }^{319}$.

Bonhoeffer ging in seinen Prinzipien ärztlichen Handelns vom Persönlichkeitsrecht des Einzelnen aus und stieß damit im Nationalsozialismus auf Widerstand. Die beharrlich-sachliche Methode der Diagnostik, mit der er auf diese Herausforderung reagierte, macht den zweiten Aspekt von Bonhoeffers Berufsethos deutlich: die Methode verantwortlicher Folgenabschätzung, welche den eigenen Beruf als Forum versteht, um konkret, in den Grenzen des Berufes, aber mit dem ganzen Einfluß der persönlichen Gestaltungsmöglichkeit, das Beste zu versuchen. Bonhoeffer hat sein hergebrachtes Berufsethos nicht verlassen müssen, um der Herausforderung zu begegnen, im Gegenteil: Die Verpflichtung seines Berufes drängte ihn zu resistentem und darin politischem Handeln. Das Ethos des Naturwissenschaftlers setzte für ihn das Maß seines Widerstands gegen das Regime fest - in bestimmten Grenzen, wie oben aufgezeigt wurde.

Diese - im Handeln impliziten - Grundbegriffe des medizinischen Ethos bei Karl Bonhoeffer werden, wie später zu zeigen sein wird, in der Ethik des Sohnes Dietrich Bonhoeffer theoretisch formuliert und theologisch bestimmt. Das von Karl Bonhoeffer grundgelegte Persönlichkeitsrecht wird von Dietrich Bonhoeffer theologisch in den Rahmen der Menschenrechte gestellt, das Ethos verantwortlicher Folgenabschätzung als Verantwortungsethik bestimmt.

\section{Zur Rolle naturwissenschaftlicher Medizin im Nationalsozialismus}

Die These eines naturwissenschaftlichen Wissenschaftsethos, welches wir für Karl Bonhoeffer festmachen konnten, bedarf noch genauerer Klärung. Denn: Einerseits kann und konnte die Psychiatrie nie im streng positivistischen Sinne

Landstreicher, Süchtigen und Dirnen hervorgeht" auch „zwangsweise“ ${ }^{\text {z }}$ zu sterilisieren; vgl. ders., Vortrag vom 6.2. 1933. An der von Kleist geleiteten Frankfurter Universitätsnervenklinik sollen auch Aktenfälschungen vorgekommen sein; vgl. Kranz, in: Pongratz, Psychiatrie, S. 203.

319 Vgl. z. B. Bürger-Prinz, Psychiater, S. 106; dazu Roth, Verhungern; vgl. mehrere Autobiographien in: Pongratz, Psychiatrie. 
"naturwissenschaftlich“ sein, da sie im Unterschied zu anderen medizinischen Disziplinen über „harte“ meßbare Daten nur ausnahmsweise verfügt. Auf der anderen Seite waren fast alle Ärzte der Generation Karl Bonhoeffers ihrem Selbstverständnis nach naturwissenschaftlich orientiert. Das gilt auch für viele, denen heute von Vertretern streng positivistischer Doktrin die Naturwissenschaftlichkeit abgesprochen wird, wie beispielsweise Sigmund Freud. Die wenigen Ärzte, die keine reinen Naturwissenschaftler sein wollten, waren meist eine Generation jünger; das Spektrum reicht von Reichsärzteführer Wagner, einem Vertreter der "Neuen Deutschen Heilkunde“ ${ }^{320}$ bis zu Victor von Weizsäcker und anderen Vertretern einer anthropologischen oder daseinsanalytischen Psychiatrie, unter denen auch eine Reihe Schüler Karl Bonhoeffers zu finden waren (z.B. Erwin Strauß, Kurt Goldstein, Jürg Zutt, Victor von Gebsattel, Ludwig Binswanger). Doch gab es keinen maßgeblichen, an einer Universität tätigen Rassenhygieniker, der von sich selbst behauptet hätte, nicht naturwissenschaftlich zu arbeiten. Und noch die Programmschrift einer ebenso verschrobenen wie blutrünstigen rassenhygienischen Sekte („Neutemplerorden“) mit dem Titel „Theozoologie oder die Kunde von den Sodoms-Äfflingen und dem Götter-Elektron - Eine Einführung in die älteste und neueste Weltanschauung und eine Rechtfertigung des Fürstentums und des Adels" beanspruchte, nach streng wissenschaftlicher Methode vorzugehen ${ }^{321}$. Dies beweist freilich nur, daß in der Neuzeit jede auch noch so absonderliche Geistesströmung einer Legitimation durch Wissenschaft nicht völlig entbehren kann. Daher kann das bloße Selbstverständnis kein Maßstab dafür sein, welche Medizin tatsächlich als naturwissenschaftlich zu gelten hat.

Sinnvollerweise kann nur diejenige Psychiatrie naturwissenschaftlich genannt werden, die zwar "weiche" Daten und beobachtende Beschreibungen von Krankheitsbildern zur Grundlage ihrer Theoriebildung macht, sich aber in bezug auf alle weitergehenden Überlegungen über die menschliche Seele äußerste Zurückhaltung auferlegt. Eugeniker wie Fritz Lenz oder Hans Luxenburger können in diesem Sinne ungeachtet ihrer diesbezüglichen internationalen Anerkennung nicht als Naturwissenschaftler angesehen werden, soweit und sofern sie so etwas wie den „Glauben“ an die „Reinheit der Rasse“ als Voraussetzung eugenischer Wissenschaft anerkannten ${ }^{322}$. Sigmund Freud mag als Grenzfall charakterisiert werden. Geradezu als Idealtypus eines Naturwissenschaftlers erscheint hingegen der Mediziner und Philosoph Karl Jaspers, der Vertreter eines reflektierten naturwissenschaftlichen Positivismus.

Jaspers ging in der Frage der Zwangssterilisation, ähnlich wie Karl Bonhoeffer, davon aus, daß die naturwissenschaftliche Kenntnis zur Rechtfertigung von Zwangssterilisationen nicht ausreiche. Darüber hinaus konstatiert er grundsätzlich, daß ein Naturwissenschaftler auch „bei viel besseren Kenntnissen“ sich in

${ }^{320} \mathrm{Zu}$ Wagner siehe S. 44 f.; zur „Neuen Deutschen Heilkunde“ siehe S. 14 Anm. 36.

${ }^{321}$ Liebenfels, Theozoologie, S.2.

322 Siehe S. 44f. 
seiner Eigenschaft als Wissenschaftler davor hüten müsse, „aus seiner Naturwissenschaft ethische Konsequenzen zu ziehen“, die der "sich selbst bestimmenden Persönlichkeit“ als „flach, grob und sinnlos“ erscheinen müßten. Jaspers hat die Denkvoraussetzungen eines naturwissenschaftlichen Positivismus scharf herausgearbeitet: „Die Naturwissenschaft hat nicht Forderungen aufzustellen, sondern Fakten zu konstatieren. Sie hat nichts weiter zu tun, als diese Fakta mitzuteilen.“ Dem kongruiert die individuelle Entscheidung: „Auf Grund derselben [der Fakten] und mit Bewußtsein der Konsequenzen hat die Entscheidung für das Handeln allein die einzelne Persönlichkeit "323. Ein zweites Kriterium neben der bewußt zurückgenommenen Wissenschaftlichkeit ist das der Humani$t_{a ̈}{ }^{324}$. Dementsprechend verwies Jaspers in einer programmatischen Rede zur Wiedereröffnung des Heidelberger medizinischen Kurses im Jahr 1947 darauf, daß nationalsozialistische „Rassentheorie“ und „Vererbungslehre“ gleichermaßen unwissenschaftlich und inhuman gewesen seien, daß Ärzte „aus unzureichendem Wissen“ vom Vererbungsgeschehen das „Material für eine Gesetzgebung“ beigebracht hätten, die andere Ärzte durch Gutachten nur noch hätten „unterstützen“ oder „in ihren unmenschlichen Wirkungen einschränken“ können $^{325}$.

Im Vergleich mit Jaspers erscheint Bonhoeffers naturwissenschaftliches Wissenschafts-Ethos insofern weniger festgelegt, als letzterer verschiedene alternative Ansätze von der Psychoanalyse bis hin zur anthropologischen Medizin zumindest als wissenschaftlich tolerierte, wenn er ihnen auch selbst nicht folgte. In einer Hinsicht allerdings war Bonhoeffer durch die spezifisch hirnorganische Ausrichtung der Wernicke-Schule noch stärker naturwissenschaftlich geprägt als Jaspers (und diese strenge Ausrichtung verhalf ihm abermals zu gewisser Unabhängigkeit gegenüber der NS-Medizin): Aus dem in der Wernicke-Schule gelehrten, von Jaspers aber als „Hirnmythologie “326 verspotteten, Grundsatz Wilhelm Griesingers, „alle Geisteskrankheiten sind Hirnkrankheiten“, ergab sich mit logischer Stringenz, daß diejenigen Geisteskrankheiten, für die man eine hirnorganische Ursache nicht gefunden hatte (und das waren fast alle), ungeklärter Natur sein mußten. Diese Auffassung mußte mit der amtlichen Begründung des Erbgesundheitsgesetzes kollidieren, derzufolge die im Gesetz genannten Krankheiten "wissenschaftlich hinreichend erforscht" seien ${ }^{327}$. Unabhängig davon, ob man die durch Griesinger geprägte, aber bis heute umstrittene hirnorganische Ausrichtung der Psychiatrie begrüßt oder ablehnt, kann man ihr die hu-

\footnotetext{
${ }^{323}$ Japsers, Psychopathologie, $1913^{1}$, S. 218 f.; $1920^{2}$, S. 268; $1923^{3}$, S. 302; $1946^{4}$, S. 693.

${ }^{324}$ Vgl. ebenso zu Karl Bonhoeffer S. 111.

${ }^{325}$ Vgl. Jaspers, Erneuerung.

${ }^{326}$ So Wernicke charakterisierend Jaspers, Allgemeine Pathologie ${ }^{5}$, S.16. Auch Bonhoeffer räumte ein, daß einige hirnorganische Thesen Wernickes sehr kühn formuliert und schon nach wenigen Jahren überholt waren, suchte seinen Lehrer jedoch damit zu verteidigen, daß er, wäre er nicht unerwartet viel zu jung gestorben, in einer geplanten Neuauflage seines Lehrbuches manches verbessert hätte; vgl. ders., Stellung Wernickes.

327 Siehe S.31.
} 
manitäre Funktion, die sie im Kontext der dreißiger Jahre besaß, nicht absprechen $^{328}$.

Wir sind der Auffassung, daß die von Jaspers geforderte reinliche Scheidung zwischen Wissen und Werten philosophisch nicht haltbar ist. Die Geschichte der Eugenik/Rassenhygiene im Nationalsozialismus hat ja gerade gezeigt, daß die Wissenschaft durch eine immanente Verschränkung von Wissen und Werten gekennzeichnet war. Immer wurden aus dem Wissen wie aus dem NichtWissen auch Folgerungen gezogen; es tendierte implizit oder explizit dahin, „angewandt" zu werden. Gleichwohl kann die nationalsozialistische Rassenhygiene nicht auf den reinen Technizismus reduziert werden, als ob es nur noch um die Anwendung bereits vorher vorhandenen Wissens gegangen wäre. Entscheidend war vielmehr die Kombination von technokratisch-modernisierenden mit romantisch-irrationalistischen, also zukunfts- mit rückwärtsorientierten Elementen. Der modernistischen Hybris, Krankheit abschaffen zu wollen und zu können, stand die "rückwärtsorientierte“, freilich historischen Untersuchungen Hohn sprechende Vorstellung entgegen, bei den alten Germanen, den "Ariern" oder den Spartanern hätte es eine von Krankheiten freie und daher besonders „reine Rasse“ gegeben. Wer dennoch meint, die nationalsozialistische Medizin mit Begriffen wie "Modernisierung“ und „Innovation" belegen zu können ${ }^{329}$, steht unter dem Verdacht, den in unserer Gegenwart durchaus berechtigten Hinweis auf die Ambivalenzen medizinischen Fortschritts auf dem Wege der Geschichtsschreibung in den Nationalsozialismus zu projizieren $^{330}$.

Wie wenig der Nationalsozialismus tatsächlich geeignet war, eine naturwissenschaftliche Medizin zu fördern, kann auch der Tatsache entnommen werden, daß die deutsche Medizin in diesen Jahren kaum herausragende Neuentdeckungen zu verzeichnen hatte und, nicht nur an Bonhoeffers Klinik, innerhalb weniger Jahre ihre international führende Rolle verlor. Exemplarisch ist das belegbar am Wechsel der Wissenschaftssprache vom Deutschen ins Englische oder an den zwischen 1930 und 1960 an Deutsche verliehenen Nobelpreisen der Medizin, von denen vier an Emigranten ${ }^{331}$ und nur $\mathrm{drei}^{332}$ an in Deutschland gebliebene

${ }^{328}$ Dagegen Dörner, Tödliches Mitleid, der im Unterschied zu früheren, differenzierteren Überlegungen, vgl. ders., Bürger, S.303, und ders., Nationalsozialismus, S.85f., einen großen Bogen von Griesinger zu den Nationalsozialisten schlägt. Dörners Standpunkt scheint nicht ganz unberührt davon zu sein, daß er selbst für die Gegenwart einer naturwissenschaftlich orientierten Psychiatrie eine deutliche Absage erteilt hat; vgl. Dörner/Plog, Irren. Doch ist vor einer vorschnellen Parallelisierung zu warnen: Die Fronten verlaufen in der Gegenwart anders als in den dreißiger und vierziger Jahren.

${ }^{329}$ So im Anschluß an eine auch außerhalb der Medizingeschichte geführte Modernisierungsdebatte Schmuhl, Rassenhygiene.

${ }^{330}$ Vgl. dagegen die scharfe Kritik Reichsärzteführer Wagners an der Gruppe der „Objektiven, der Gelehrten und Wissenschaftler"; siehe S. $44 \mathrm{f}$.

${ }^{331}$ Vgl. Warburg (Nobelpreis 1931); Loewi (Nobelpreis 1936); Lipmann (Nobelpreis 1953); Krebs (Nobelpreis 1953).

332 Vgl. Spemann (Nobelpreis 1935), Domagk (Nobelpreis 1939); Forssmann (Nobelpreis 1956). 
Forscher gingen. Selbst die skrupellose Quälereien einschließende medizinische Forschung an „Euthanasie“-Opfern oder KZ-Insassen hat bedeutende medizinische Innovationen nicht hervorbringen können.

Es konnte gezeigt werden, daß die nationalsozialistische Rassenpolitik demjenigen widersprach, was die Mehrheit deutscher Psychiater noch Anfang 1933 für den Stand naturwissenschaftlicher medizinischer Vererbungsforschung hielt ${ }^{333}$. Daher darf (ungeachtet aller philosophischen Argumente, die gegen die Ideologie des Positivismus vorgetragen werden können) das Resistenzpotential eines naturwissenschaftlichen Positivismus im Nationalsozialismus nicht unterschätzt werden ${ }^{334}$. Immer dann, wenn staatliche Wissenschaftslenkung bestimmte Forschungsergebnisse fordert, die eine empirisch eingestellte Forschung nicht belegen kann, stehen positivistisch eingestellte Wissenschaftler vor der Alternative, in Opposition zu den staatlich geforderten Ergebnissen zu geraten oder sich anzupassen und ihre positivistische Auffassung preiszugeben. Beispiel für einen Wissenschaftler, den - in gewissen Grenzen - naturwissenschaftliche Argumente selbst dann überzeugen konnten, wenn sie der ansonsten vehement vertretenen Eugenik widersprachen, ist Luxenburger, Beispiel für das Gegenteil Ernst Rü$\mathrm{din}^{335}$. Die insgesamt hohe Bereitschaft zur Preisgabe des eigenen Wissenschaftsethos im Nationalsozialismus mag damit zusammenhängen, daß ein rein empirisches, von ethischen oder religiösen Überlegungen losgelöstes Wahrheitsverständnis selten geeignet ist, einen Wissenschaftler so zu fesseln, daß er für diese formale Wahrheit auch unter Inkaufnahme eventueller Nachteile einzutreten bereit wäre. Insofern mag Victor von Weizsäckers These, derzufolge der Geist naturwissenschaftlicher Medizin die Bereitschaft zur Anpassung an die nationalsozialistische Ideologie gefördert habe ${ }^{336}$, eine gewisse Berechtigung haben, denn unter nationalsozialistischen Bedingungen vermochten pseudoreligiöse Verheißungen, Opfer-Gedanke und "Glaube" an die "Reinheit der Rasse“, aber auch Karrierestreben und politischer Opportunismus eine wesentlich stärkere emotionale Bindekraft entfalten als nüchterne naturwissenschaftliche Verer-

${ }^{333}$ Vgl. die Diagnosentabelle des Deutschen Vereins für Psychiatrie; siehe S. 31 Anm. 65.

334 Dies gilt analog für den Rechtspositivismus, der kurz nach Kriegsende ähnlich leichtfertig für den Nationalsozialismus verantwortlich gemacht wurde wie die naturwissenschaftliche Medizin. Ein berühmter, freilich oft einseitig zitierter Aufsatz Gustaf Radbruchs, Gesetzliches Unrecht, schien allen denjenigen, welche 1933 die nationalsozialistische "Rechtserneuerung" als Ende des Rechtspositivismus gefeiert hatten, die Möglichkeit zu bieten, unter Berufung auf einen Sozialdemokraten und Nazi-Gegner an ihrem bisherigen Rechtsverständnis festzuhalten. Inzwischen ist freilich überzeugend nachgewiesen, daß nicht allein die nationalsozialistische Gesetzgebung, sondern viel entscheidender die nationalsozialistische Uminterpretation der vorhandenen Gesetze, die intensive ${ }_{n}$ rechtsschöpferische" Auslegung sowie die Interpretation von Generalklauseln durch das NSDAP-Parteiprogamm, einen wesentlichen Teil nationalsozialistischer Rechtsanwendung ausmachte; vgl. Rüthers, Unbegrenzte Auslegung; Müller, Furchtbare Juristen, S.221-227. Hier ergibt sich die exakte Parallele zur Anwendung des Erbgesundheitsgesetzes, welches rigider angewandt wurde, als bei wörtlicher Befolgung unter Berücksichtigung des naturwissenschaftlichen Standes der Forschung erforderlich gewesen wäre.

${ }^{335} \mathrm{Zu}$ Luxenburger siehe S. 43; zu Rüdin vgl. Weber, Rüdin, bes. S. 220-223.

${ }^{336} \mathrm{Vgl}$. Weizsäcker, „Euthanasie“. 
bungsforschung ${ }^{337}$. Dennoch war die zeitgenössische Vererbungsforschung (ungeachtet gegenteiliger Behauptungen nach 1933) besser geeignet, die ideologisch gefärbten eugenischen Maßnahmen zu delegitimieren als zu legitimieren. Dort, wo ein naturwissenschaftliches Wissenschaftsethos zusammen mit humanitärem Ethos auftrat, konnte exakte Naturwissenschaft schon deshalb ein erhebliches Kritikpotential freisetzen, weil sie hinsichtlich des „Erfolges“ der Sterilisationspolitik über die naturwissenschaftlich besseren Argumente verfügte ${ }^{338}$. Und in der Tat ergab sich im Nationalsozialismus hinsichtlich der „Erb- und Rassenpflege" eine Koalition von exakter naturwissenschaftlicher Medizin und Humanität, denn die Durchführung von Zwangssterilisation und „Euthanasie“ machte weitgehend eine Preisgabe des naturwissenschaftlichen und diagnostischen Niveaus erforderlich. Die Charakterisierung der Gaskammern von Hadamar als „Hiroshima der Psychiatrie“ (Dörner) scheint uns daher nur teilweise den richtigen Punkt zu treffen. Zwar ist Hiroshima für die Problematik des Verhältnisses der Physik zur Ethik eine ähnlich zentrale Bedeutung zuzumessen wie Hadamar für diese Problemstellung bei der Psychiatrie. Doch bildete der Bau der Atombombe die Spitze naturwissenschaftlich-technischen "Fortschritts“ und konnte nur gelingen, indem man die besten Physiker der USA in Los Alamos versammelte. Zwangssterilisation und "Euthanasie" dagegen „funktionierten" auch, wenn sie naturwissenschaftlich schlecht begründet wurden, ja sie „funktionierten“ sogar um so besser, je schlechter sie begründet wurden. Die medizinischen Diagnosen, die zur Sterilisation oder zur Ermordung führten, konnten falsch sein, und sie waren es vielfach auch. Zwar gab es umgekehrt, offenbar auch an Bonhoeffers Klinik, Fehldiagnosen zur Bewahrung von Patientinnen und Patienten vor der Sterilisation, also naturwissenschaftlich inkorrektes Handeln aus humanitären Gründen. Aber in nicht wenigen Fällen reichte es aus, an dasjenige anzuknüpfen, was vor 1933 anerkannter Stand der Vererbungsforschung gewesen war. Unter dieser Voraussetzung konnte die Maxime, „unpolitisch“ nichts als die „reine Wissenschaft" treiben zu wollen, von größerem politischen Bewußtsein zeugen als das bewußte Eintreten für eine politische Medizin.

${ }^{337}$ In demselben, freilich sehr indirekten Sinn kann man dem politischen Liberalismus vorwerfen, daß ein rein formales Verständnis von Demokratie (etwa in dem Sinne: „Was eine parlamentarische Mehrheit verfassungsgemäß legal beschließt, ist per se legitim“") nicht geeignet war, eine hinreichende emotionale Bindekraft zu entfalten. Diese Feststellung ändert freilich nichts an dem von Bracher, Deutsche Diktatur, S.209-218, überaus überzeugend geführten Nachweis, daß bei der nationalsozialistischen Machtergreifung eine große Zahl formaler verfassungsrechtlicher Bestimmungen verletzt wurden, also eine sorgfältigere Achtung formaler demokratischer Regeln anstelle bloßer Polemik gegen die formale Legalität der Demokratie (so unter Herausarbeitung des Reichspräsidenten als "Hüter" der Legitimität, Schmitt, Legalität) angezeigt gewesen wäre.

338 Siehe S.42f. Auch Weizsäcker hat dies gesehen: "Die Ausrottung der Geisteskrankheiten durch Sterilisation war wissenschaftlich so schlecht begründet und die biologische Verbesserung der Volksgesundheit durch sie und die Steigerung der Kriegsleistung durch die "Euthanasie" ist gar nicht erreicht worden, weil sie auf diesem Wege nicht erreichbar war." Vgl. ders., „Euthanasie“, S. 129 f. Doch betont Weizsäcker diesen Punkt sehr wenig. 
